\title{
The Wooden Artefacts
}

\author{
Maisie Taylor, Michael Bamforth, Harry K. Robson, Chloe Watson, \\ Aimée Little, Diederik Pomstra, Nicky Milner, Julian C. Carty, \\ André C. Colonese, Alexandre Lucquin and Steve Allen
}

\section{Introduction}

Clark $(1954,178)$ stated that although wood must have been used for a variety of implements in the Mesolithic, including handles, shafts and bows, 'disappointingly little was found in the way of finished objects'. The two artefacts that were found were part of a wooden paddle which lay horizontally in the mud, identified by Donald Walker as birch (Clark 1954, figure 77, plate xxi), and the carbonised head of a handle found in the hole of an antler mattock (Clark 1954, 158, figure 69, plate xv). In addition, the trimmed end of a birch branch is illustrated (Clark 1954, plate xx g).

During the 1980s excavations, further wooden remains were encountered in the form of a platform (Chapter 2), but no artefacts were identified (Mellars and Dark 1998). The lack of wooden artefacts is perhaps not surprising because although they are known from other Early Mesolithic sites, particularly in Southern Scandinavia (Chapter 12), they are rare when compared to artefacts made of stone, bone and antler.

There are many difficulties when studying wooden artefacts. Larger artefacts are more likely to survive and be recognised than smaller or broken items. However, artefacts with direct modern parallels and those with distinctive shapes, such as an axe haft, are bound to be over-represented, although there is so little data about different kinds of hafts and handles that they may not be recognized, even when complete. Context may make the function of some artefacts clear or there may be recent parallels which make identification more straightforward. However, there is also the danger that although an artefact may have modern parallels which look similar, such as the paddle, these are objects which may have had many functions. To say that an artefact is a 'paddle, therefore, prioritises its form rather than identifying its function. Finally, any work on Mesolithic artefacts is further complicated because the wood, even where it is relatively well preserved, can still be extremely degraded, fragile and difficult to handle. As a result, virtually nothing is known about which tools were used for specific tasks, methods of hafting and techniques of working and shaping wood.

The study of ancient wood working, a reductive industry, has many of the same problems as the study of flint. For example, it is only recently that excavators have realised that the debris and detritus from the working of wood is as important, if not more important than the finished artefacts. This leads on to the difficulty of differentiating artefacts from waste material and specifically artefacts formed from utilised waste. As a response

How to cite this book chapter:

Taylor, M., Bamforth, M., Robson, H. K., Watson, C., Little, A., Pomstra, D., Milner, N., Carty, J. C., Colonese, A. C., Lucquin, A. and Allen, S. 2018. The Wooden Artefacts. In: Milner, N., Conneller, C. and Taylor, B. (eds.) Star Carr Volume 2: Studies in Technology, Subsistence and Environment, pp. 367-418. York: White Rose University Press. DOI: https://doi. org/10.22599/book2.o. Licence: CC BY-NC 4.0 


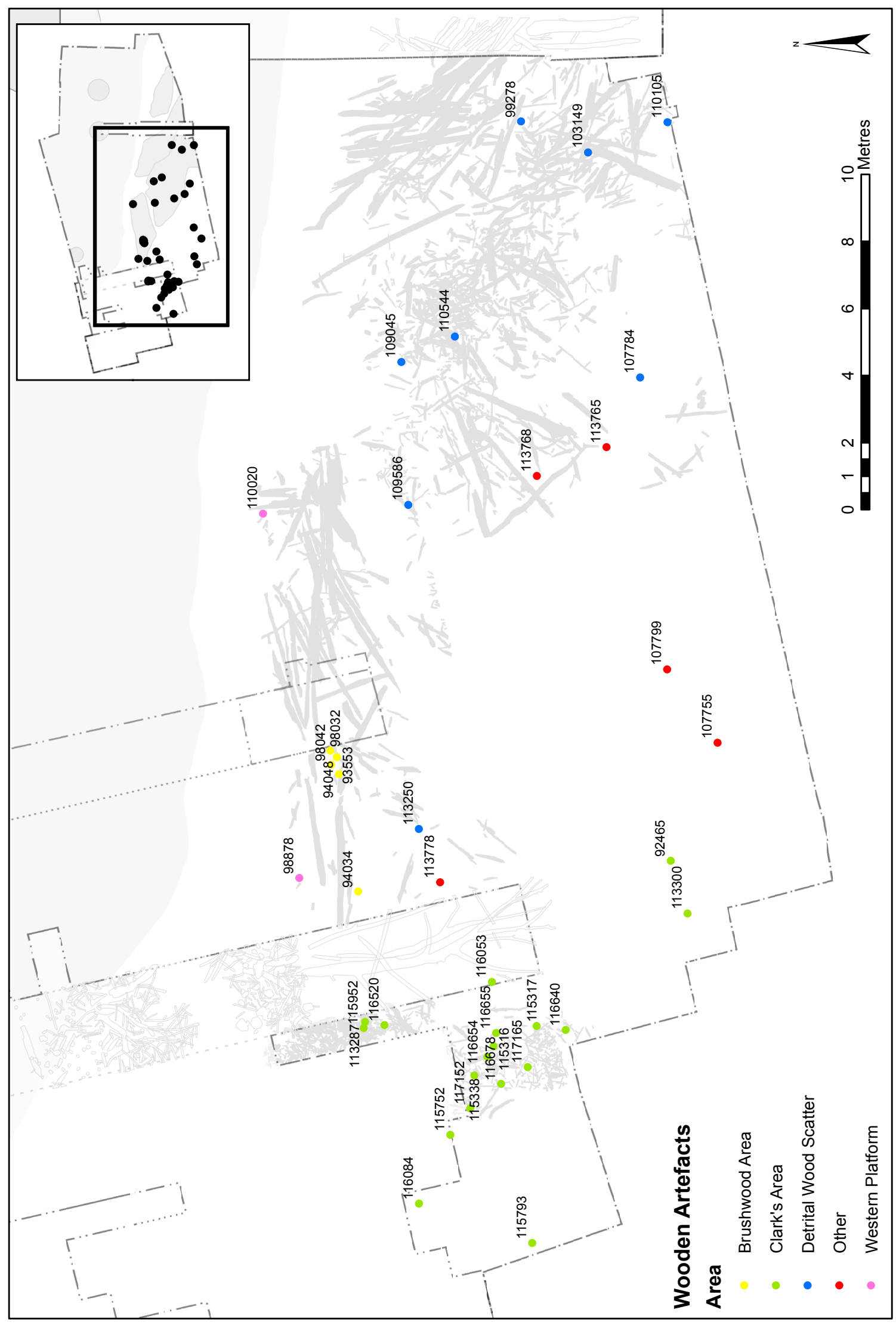

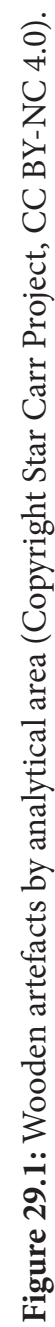


to this, for the material from the recent excavations, we have taken the approach of examining all wood, rather than hunting for artefacts, and all worked wood was recorded in detail. This revealed that the woodworking technology was simple but effective and that the bulk of the worked material from the site was produced by splitting wood and trimming. However, these two simple techniques can be used in sophisticated ways that can produce, for example, dowels.

When wood is trimmed using a stone tool, the detritus produced tends to be small because the tool does not slice through the wood as cleanly as a metal blade. This also means that there is very little detritus from the site which might be derived from hewing, although there are a number of pieces from Star Carr which were probably finished by hewing. However, splitting wood produces by-products which come in shapes and sizes that can be modified to form useful objects.

The detailed recording during excavation allowed the identification of items which were 'different' from the general woodworking assemblage, pieces which did not fit neatly into the categories defined during the general analysis. Some of these items were identified as artefacts on site, whilst others were set aside for further study due to the possibility that they could represent artefactual material. Items were identified as possible artefacts if they were heavily worked and finished, or due to the presence of unexplained features, such as the appearance of polish at an end. Finally, some items were included due to their setting or context, including the few vertically set items and items of interest due to their close association with other artefacts. Gradually it emerged that there were certain technological categories of material that the artefacts and possible artefacts could be divided into.

This analysis has resulted in a total of 38 pieces which have been classified as wooden artefacts, recovered from five spatial analytical areas (Figure 29.1). The chapter sets out the analysis, considered first by technology and then the artefacts as they have been categorised. This incorporates microwear analysis and experimental work. The results are discussed in terms of spatial patterning and taphonomy and then in the context of the European evidence.

\section{Analysis}

Once identified as artefactual or potentially artefactual material, the 38 items were initially categorised by technology as opposed to form. This produced four distinct categories: 15 utilised roundwood, 14 dowels, six utilised debris, and three other. These can be seen to be spread across the site with no clear patterning (Figure 29.2).

Once these categories had been established it was possible in many cases, although not all, to suggest an interpretation regarding the original use of the artefact, based on its appearance, form and context (Table 29.1). As all the material was classified by technology first, it could be assigned or removed from interpretive categories as work progressed and could even appear under more than one label: for example, there are possible digging stick fragments which are roundwood and some which are dowels.

A programme of identifications were carried out by Steve Allen with six different taxa of wood identified (see Chapter 15 for methods):

- Alnus spp.-alders (exact species not determinable)

- Betula spp.-birch (exact species not determinable)

- Frangula alnus Mill.-alder buckthorn

- Populus spp.-aspen, white or black poplar (exact species not determinable)

- Salix spp.-willows (exact species not determinable)

- Sambucus nigra L.-elder

Note that Populus spp. are interpreted as aspen (Populus tremula) based on the presence of its distinctive catkin scales at the site (Chapter 15).

A programme of microscopic microwear analysis was carried out by Aimée Little on artefacts that were identified as having potential for displaying wear and/or manufacture traces based on their morphology as well as macroscopically visible traces of working (see Chapter 15 for methods). Where possible, items identified in the field thought to have potential for microwear analysis were subsequently not cleaned or handled unnecessarily. 


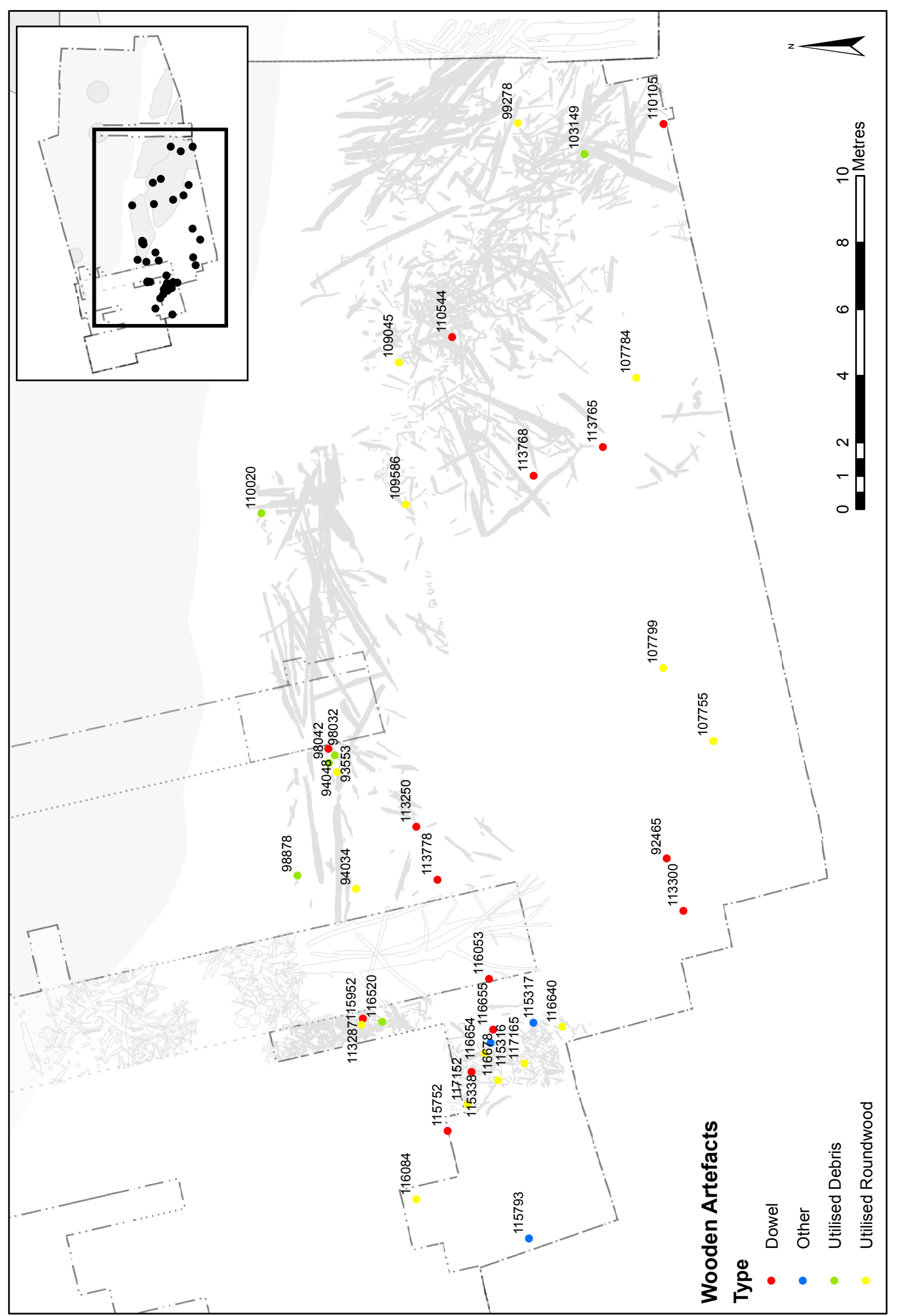

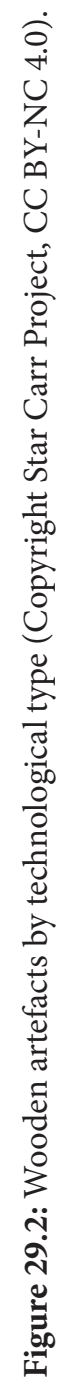




\begin{tabular}{|c|c|c|c|c|c|}
\hline & Utilised Roundwood & Dowels & Utilised Debris & Other & Total \\
\hline Ad-hoc tool & 5 & & 1 & & 6 \\
\hline Board & & & & 1 & 1 \\
\hline Bow & & 1 & & & 1 \\
\hline Decorated item & & & 1 & & 1 \\
\hline Digging stick & 4 & 3 & & & 7 \\
\hline Digging stick / haft or handle & & 1 & & & 1 \\
\hline Haft or handle & & 3 & & & 3 \\
\hline Other dowels & & 6 & & & 6 \\
\hline Peg & & & 1 & & 1 \\
\hline Roundwood with holes & 2 & & & & 2 \\
\hline Stake & 3 & & 2 & & 5 \\
\hline Vessel or container & & & & 2 & 2 \\
\hline Wedge & & & 1 & & 1 \\
\hline Withy & 1 & & & & 1 \\
\hline Total & 15 & 14 & 6 & 3 & 38 \\
\hline
\end{tabular}

Table 29.1: Technological groupings by possible function.

Ten items were selected for analysis, including six dowels and four pieces of utilised roundwood with a range of different suggested original functions. The results of this analysis are set out in the section on the artefacts.

Molecular analyses were performed on extracted lipids by André Colonese and Alexandre Lucquin from two of the wooden artefacts from Star Carr, bow $\langle 113300\rangle$ and radial dowel $\langle 113778\rangle$, in the hope of identifying residual traces of plant resins and tar that may have been used as an adhesive. Samples were collected from the extremities and the middle of these artefacts and lipids were extracted using established protocols in archaeology (Craig et al. 2013; Little et al. 2016; Regert et al. 2003). Lipids were also extracted from soil samples recovered from the artefacts for comparison. Analyses by Gas Chromatography (GC) and Gas Chromatography Mass Spectrometry (GC-MS) demonstrated the presence of lipids; however, those that were present were consistent with the local soil chemistry (e.g. alkanes, long-chain fatty acids). No evidence for plant resins or other adhesives, for example birch bark tar, were identified.

\section{Technology}

\section{Introduction}

The simplest form of a wooden tool is the unmodified stick and it can be argued that items like this were the earliest tools, probably pre-dating the emergence of humans (Sanz et. al. 2004). The next stage would be to find a piece of wood which naturally had a good shape for the task to be performed: a stick with a side branch which could be used as a hook, for example. A short step from this would be to modify the natural shape to be even more efficient, with the use of hafted flint axes and adzes for felling, trimming and shaping and wooden or antler wedges for splitting (Chapter 28). This third stage is more or less where woodworking remained until the invention of efficient saws enabled the wood worker to cut wood, to any shape, ignoring its natural shape and grain (Taylor 2010).

It would gradually become apparent that finding the best raw materials is important. Relying on chance to find an appropriate piece of wood was not always satisfactory and experience would show that the properties of wood as a raw material vary. Wood which is freshly cut is easier to work than older material which had seasoned and become harder (and more brittle). Other differences would also emerge. Living wood has different 
qualities to dead but there are also differences between the species: differences of flexibility, durability, ease of working, growth patterns and exudates. There are differences in the properties of wood taken from the different parts of the tree: between trunk, branch and root as well as at different seasons of the year. Living wood is easier to work than dead but at certain times of the year, particularly in the spring, some species (including willow, birch and poplar) 'bleed' copious amounts of sap when cut. This may lead to fungal attack of standing trees but the more immediate problem for the wood worker comes because the wood is wet and sticky and therefore harder to work. The activities of beavers illustrate the fact that some trees regenerate when felled and some die. Regenerating trees, such as willow, produces stems of a predictable shape and size. It is a short step from observing beavers and exploiting the raw materials produced by them, to controlling quality and supply by coppicing (Chapter 28 ).

\section{Roundwood}

The simplest tool is the utilised or modified stick (Sanz et al. 2004). A roundwood stick is flexible as the high level of cellulose in the young wood (sapwood) makes it more likely to bend than break. One disadvantage of this is that with many species once the stick is cut, the sapwood begins to dry, shrink, crack, break down and rapidly (this normally happens within a year) become brittle. However, as it is a stick, it is quick and easy to replace.

Not surprisingly, the 15 modified and/or utilised pieces of roundwood found at Star Carr are the most frequent type of material recognized as possible artefacts. Fourteen pieces (all the items in this category with the exception of the withy $<94048>$ ) were formed from small or medium diameter roundwood and were identified as having one or both ends worked and/or utilised (Table 29.2). A broad range of possible functions has been suggested for the utilised roundwood assemblage consisting of: five ad-hoc tools, four possible partial or complete digging sticks, two pieces of roundwood with holes including $<115952>$ that may have been part of a frame-built object, three stakes and one withy (Table 29.2). These were recovered from four of the analytical areas: two from the brushwood, four from the detrital wood scatter, seven from Clark's area and two from 'other' (parts of the site outside the key areas).

Four of these were simple pieces of roundwood where one end had broken either in antiquity or during excavation and the other end had been trimmed or utilised: $\langle 107755>;<107799\rangle ;<109045\rangle ;\langle 116084\rangle ;<116654\rangle$. Three were simple roundwood with both ends worked: $\langle 107784>;<109586>;<116678>$. Others showed evidence

\begin{tabular}{|r|r|l|l|l|l|}
\hline Number & Context & Area & Conversion & Identification & Interpretation \\
\hline 094034 & 312 & brushwood & none & willow & digging stick \\
\hline 094048 & 312 & brushwood & none & willow & withy \\
\hline 099278 & 312 & detrital wood scatter & rad $1 / 2$ & not identified & ad-hoc tool, ?antler working \\
\hline 107755 & 310 & other & none & willow? Very decayed & ad-hoc tool, ?spindle / toggle \\
\hline 107784 & 317 & detrital wood scatter & none & willow & stake \\
\hline 107799 & 312 & other & none & elder & ad-hoc tool \\
\hline 109045 & 319 & detrital wood scatter & none & willow & ad-hoc tool \\
\hline 109586 & 317 & detrital wood scatter & none & aspen & roundwood with holes \\
\hline 115952 & 312 & Clark's area & none & willow & roundwood with holes \\
\hline 116084 & 312 & Clark's area & none & willow & ad-hoc tool \\
\hline 116640 & 312 & Clark's area & none & alder buckthorn & digging stick \\
\hline 116654 & 312 & Clark's area & none & aspen & stake \\
\hline 116678 & 312 & Clark's area & none & willow & stake \\
\hline 117152 & 312 & Clark's area & none & alder buckthorn & digging stick \\
\hline 117165 & 312 & Clark's area & none & willow & digging stick \\
\hline
\end{tabular}

Table 29.2: Items categorised as utilised roundwood ( $\mathrm{rad}=$ radial). 
for coppicing and more complex modification: $\langle 94034>$; $\langle 115952\rangle$; $\langle 116640\rangle ;<117152\rangle ;<117165\rangle$. A single item, $<99278>$, had been half split and charred. It is difficult to discern whether the material from Star Carr was modified or utilised, or both, as utilisation may have removed manufacture marks and shaping might be due to wear alone. The poor preservation of the ends of many pieces of roundwood made it difficult to detect polish or gloss from use on the points or clear tool facets from shaping.

\section{Dowels}

Radically altering larger timbers or roundwood poles to produce dowels appears to have been a woodworking technique that was very important by this time. Dowels are larger items that have been reduced down and shaped longitudinally by splitting, trimming and hewing whilst generally avoiding the pith, until close to the dimensions required for the finished dowel. More surplus wood was then removed to finish the dowel probably by hewing, whittling, charring, abrasion or a combination of these techniques.

Dowels can be any shape in section, including round, square or oval. Roundwood and dowels have different properties: roundwood is very flexible, dowels less so; roundwood can be very perishable, dowels less so and in some contexts these were obviously properties which were valued. The dowels at Star Carr are usually well finished and it is difficult to be precise about methods of manufacture: digging stick $<92465>$ is a good example of this.

There is very little evidence that charring was used to shape the wood from Star Carr, although there is clear evidence dating from the Neolithic for this technique (Taylor 1998a, 154). Shaping with light charring is not to be confused with 'fire hardening' which is a persistent myth in discussions of prehistoric wooden artefacts. Charring may harden wood, but at the expense of flexibility. If charring is used as an aid to shaping, it must be very light to avoid heat penetrating the wood. Charred material can be cleanly scraped off, leaving little or no trace.

Fifteen dowels were identified for detailed analysis (Table 29.3). A broad range of functions have been suggested for the dowels including: one bow, three digging sticks or parts of digging sticks, one possible digging stick or haft/handle, three hafts or handles and six dowels of unknown function, including two items which are very tentatively identified as possible piercers. These were recovered from four of the analytical areas: one from the brushwood, three from the detrital wood scatter, seven from Clark's area and three from other.

Most of these were generally well finished but one, $<110544>$, is quite rough and others, such as $<113250\rangle$ and $<115752>$, were not particularly well finished or had been damaged during finishing. With the exception of the bow $<113300>$, all the dowels were either radially aligned or had a sub-square cross section with radially

\begin{tabular}{|r|r|l|l|l|l|}
\hline Number & Context & Area & Conversion & Identification & Interpretation \\
\hline 092465 & 312 & Clark's area & rad & willow & digging stick \\
\hline 098032 & 317 & brushwood & $\mathrm{rad}$ & aspen & digging stick \\
\hline 110105 & 317 & detrital wood scatter & $\mathrm{rad}$ & aspen & haft or handle \\
\hline 110544 & 320 & detrital wood scatter & $\mathrm{rad} / \mathrm{tan}$ & aspen & other dowel \\
\hline 113250 & 317 & detrital wood scatter & $\mathrm{rad} 1 / 4$ & willow & other dowel \\
\hline 113287 & 312 & Clark's area & $\mathrm{rad} 1 / 4$ & willow & other dowel, ?piercer \\
\hline 113300 & 312 & Clark's area & tan & willow & bow \\
\hline 113765 & 312 & other & $\mathrm{rad}$ & willow & digging stick / haft or handle \\
\hline 113768 & 317 & other & $\mathrm{rad}$ & willow & other dowel, ?piercer \\
\hline 113778 & 312 & other & $\mathrm{rad}$ & alder & other dowel \\
\hline 115338 & 312 & Clark's area & $\mathrm{rad}$ & alder & haft or handle \\
\hline 115752 & 312 & Clark's area & $\mathrm{rad}$ & willow & haft or handle \\
\hline 116053 & 312 & Clark's area & $\mathrm{rad} / \mathrm{tan}$ & alder & digging stick \\
\hline 116655 & 312 & Clark's area & $\mathrm{rad}$ & aspen & other dowel \\
\hline
\end{tabular}

Table 29.3: Items categorised as dowels ( $\mathrm{rad}=$ radial, $\tan =$ tangential $)$. 
and tangentially aligned faces. It would seem that radially aligned dowels were strongly preferred, suggesting superior performance of this conversion for many tasks. In terms of the tangentially aligned stave for the bow, this alignment is a prerequisite to take advantage of increased performance of this form under the flexing stress of a bow in use (Bamforth et al. forthcoming).

It is apparent that the techniques and skills existed to produce dowels in a wide variety of shapes and sizes. A clue to how they were used could have lain in the modification and wear on the ends but here there were similar problems to those encountered with the roundwood. Ten pieces, $\langle 92465\rangle,\langle 098032\rangle,\langle 113287\rangle,\langle 113300\rangle$, $<113765\rangle,<113768>,<113778>,<115338>,<116053>$ and $<116655\rangle$ have ends with indications of tooling or wear. Of these, several different end shapes were observed, including those shaped to a point $(<113287>$, $<113300\rangle$ (at both ends), $<113765>$, $<113768>,<113778>,<115338>$ and $<116053\rangle$ ) or wedge $<116655\rangle$ or in the case of $<92465>$ and $<098032>$, shaped like a digging stick tip with a rounded, somewhat flattened end. Three of the dowels had broken at one end in antiquity: $<115338>,<115752>$ and $<116053>$.

\section{Utilised debris}

Six items are classed as utilised debris (Table 29.4). These items are all formed from woodworking debris that has been modified or utilised at one or both ends. A single item was interpreted as an ad-hoc tool, one item is possibly decorated, one is a possible peg and one is a wedge. These were recovered from four analytical areas: two from the brushwood, one from the detrital wood scatter, two from the western platform and one from Clark's area.

The utilised debris items are generally relatively small and there are radial, tangential and cross-grain aligned items. They are relatively intact and ancient damage is limited to that from possible use: the top of stake $<98878>$ seems to have been damaged by hammering during insertion, possible peg or wedge $<103149>$ has buckled at the tip, perhaps during use, and possible splitting wedge $<116520>$ has possible 'bruising' from hammering at the thick end of the wedge.

\section{Other}

Three items were assigned to the category 'other' (Table 29.5). Two of the pieces are highly likely to form part of the same artefact, a vessel or container in the shape of a platter $\langle 115316-7\rangle$. An item interpreted as a board $<115793>$ is also included in this category. All these items were recovered from Clark's area.

\begin{tabular}{|r|r|l|l|l|l|}
\hline Number & Context & Area & Conversion & Identification & Interpretation \\
\hline 093553 & 312 & brushwood & $\tan$ & aspen & ad-hoc tool, ?burnishing \\
\hline 098042 & 312 & brushwood & rad? & willow & decorated item \\
\hline 098878 & 317 & western platform & rad 1/4/ tan outer & willow & stake \\
\hline 103149 & 312 & detrital wood scatter & cross grain & willow & peg or wedge \\
\hline 110020 & 312 & western platform & rad & aspen & stake \\
\hline 116520 & 312 & Clark's area & tan & willow & wedge \\
\hline
\end{tabular}

Table 29.4: Items categorised as utilised debris ( $\mathrm{rad}=$ radial, $\tan =$ tangential).

\begin{tabular}{|c|r|l|l|l|l|}
\hline Number & \multicolumn{1}{|l|}{ Context } & Area & Conversion & Identification & Interpretation \\
\hline 115316 & 312 & Clark's area & tan & willow & vessel or container \\
\hline 115317 & 312 & Clark's area & rad $1 / 4$ and tan & willow & vessel or container \\
\hline 115793 & 312 & Clark's area & tan? & willow? Very decayed & board \\
\hline
\end{tabular}

Table 29.5: Items categorised as other $(\mathrm{rad}=$ radial, $\tan =$ tangential $)$. 


\section{Artefact interpretation}

\section{Ad-hoc tools}

Six items have been identified as possible 'ad-hoc tools': five pieces of utilised roundwood and a single piece of utilised debris (Table 29.6; Figure 29.3). These items all display evidence of possible use or utilisation whilst not having the level of finish or design seen with other more formalised artefacts considered in this chapter. They are pieces of woodworking debris or roundwood that appear to have been 'to hand' and pressed into action as an ad-hoc tool. Several of these items have suggested functions whilst others do not. They were found across the site: brushwood, detrital wood scatter, Clark's area and other.

$<$ 93553 > (Figure 29.3b): This may have been used for polishing or burnishing. It is a piece of tangentially aligned debris measuring $256 \times 20 \times 8 \mathrm{~mm}$. One end is rounded and appears smooth and polished, leading to the suggestion that it may have been used for some kind of polishing or burnishing. The wood is more dense than other material in this deposit. It is very hard and fibrous although it has been identified as aspen.

$<99278>$ (Figure 29.3e): This was recovered from the detrital wood scatter in close association with two removed splinters of antler: $<099270>$ and $<099271>$. The splinters had both been detached from the beam but not worked any further and are unusual items within the wider antler assemblage. $<99278>$ is a half split piece of roundwood that measures $116 \times 24 \times 14 \mathrm{~mm}$ with an original diameter of $24 \mathrm{~mm}$. One end has modern damage and the other is lightly charred to a depth of approximately $2 \mathrm{~mm}$. Due to its association with the small cache of blank antler splinters, $<99278>$ was identified on site as a possible antler working tool, perhaps a wedge used for splitting. However, the evidence for this is slight and although these items may have been intentionally placed together as an antlerworking toolkit, it seems equally likely to be the product of other material connections, or pure chance.

$<\mathbf{1 0 7 7 5 5}>$ (Figure 29.3c): This is a short length of willow roundwood with one end missing. The other end is trimmed down to a blunt point of approximately $2 \mathrm{~mm}$ diameter and appears to be worn. The surviving length is $121 \mathrm{~mm}$ and the diameter is $17 / 22 \mathrm{~mm}$.

Microwear analysis showed that the worked surface (L3) contrasts with non-worked surface (L1). At times it was possible to see a clear difference in the surface of the object between unworked and worked. Transverse polish located towards the tip in addition to a very rounded/smoothed surface at the very tip of

\begin{tabular}{|c|c|c|c|c|c|c|c|}
\hline Number & Context & Area & Type & Conversion & Description & Identification & Function \\
\hline 093553 & 312 & brushwood & $\begin{array}{l}\text { utilised } \\
\text { debris }\end{array}$ & $\tan$ & $\begin{array}{l}\text { One end appears } \\
\text { rounded and } \\
\text { utilised }\end{array}$ & aspen & ?burnishing \\
\hline 099278 & 312 & $\begin{array}{l}\text { detrital wood } \\
\text { scatter }\end{array}$ & $\begin{array}{l}\text { utilised } \\
\text { roundwood }\end{array}$ & $\operatorname{rad} 1 / 2$ & $\begin{array}{l}\text { One end lightly } \\
\text { charred }\end{array}$ & not identified & $\begin{array}{l}\text { ?antler } \\
\text { working }\end{array}$ \\
\hline 107755 & 310 & other & $\begin{array}{l}\text { utilised } \\
\text { roundwood }\end{array}$ & none & Worn tip of object & $\begin{array}{l}\text { willow? Very } \\
\text { decayed }\end{array}$ & $\begin{array}{l}\text { ?spindle / } \\
\text { toggle }\end{array}$ \\
\hline 107799 & 312 & other & $\begin{array}{l}\text { utilised } \\
\text { roundwood }\end{array}$ & none & $\begin{array}{l}\text { Proximal end } \\
\text { worked, possibly } \\
\text { charred and } \\
\text { utilised } \\
\end{array}$ & elder & \\
\hline 109045 & 319 & $\begin{array}{l}\text { detrital wood } \\
\text { scatter }\end{array}$ & $\begin{array}{l}\text { utilised } \\
\text { roundwood }\end{array}$ & none & $\begin{array}{l}\text { Pointed, utilised } \\
\text { end }\end{array}$ & willow & \\
\hline 116084 & 312 & Clark's area & $\begin{array}{l}\text { utilised } \\
\text { roundwood }\end{array}$ & none & $\begin{array}{l}\text { Several small } \\
\text { notches near tip }\end{array}$ & willow & \\
\hline
\end{tabular}

Table 29.6: Material interpreted as ad-hoc tools $(\mathrm{rad}=$ radial, $\tan =$ tangential $)$. 

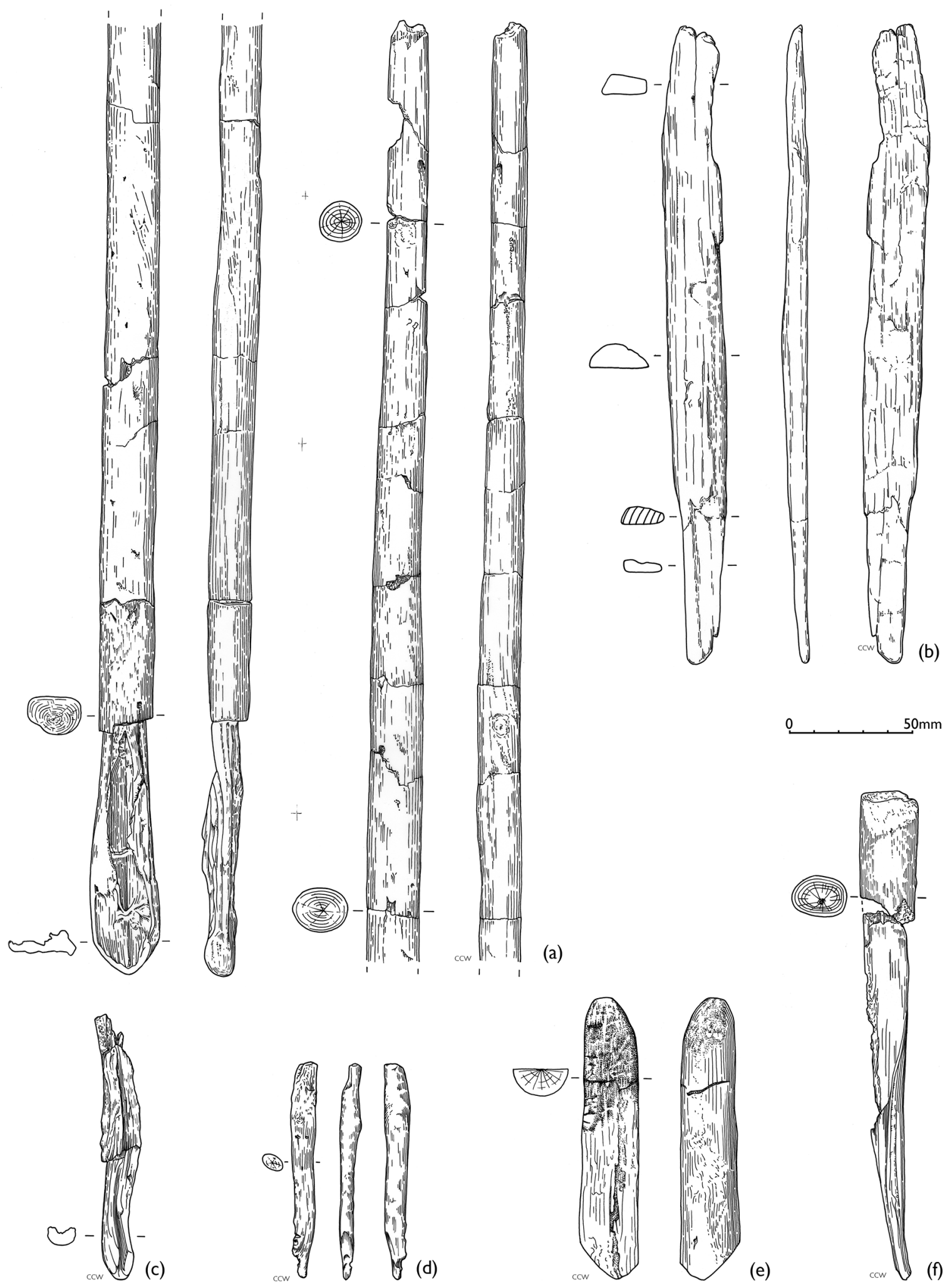

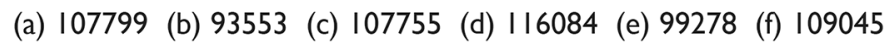

Ad hoc tools 
the object suggests it was repetitively used to penetrate and possibly rotate within an unidentified material. Polish that is perpendicular (transverse) to the long axis may be related to manufacture. Possible use-related traces, consisting of a series of parallel shallow grooves, may have been caused by something being wound tightly around the wood, perhaps rather than being pulled. Interestingly, what could be a residue of plant origin was also identified in situ using indirect light microscopy (Figure 29.4). The weave itself is very fine but within the width range ( $10 \mu$ and sometimes below; Figure 29.4) of a number of elements present in different types of plant tissue (e.g. plant hair, plant vessels). Unfortunately, as the wood began to dry, we were unable to remove the plant fibre for analysis under transmitted light, which may have enabled a more accurate identification of the plant species. Nonetheless, the consistency in the morphology and size of such plant material suggests deliberate selection and the overlapping/geometric pattern may be the result of fibre being repetitively wound around the wooden object. However, we cannot completely rule out that it is of wood origin, rather than plant fibres. When combined with the microwear evidence for parallel grooves, it is possible that this small wooden object may have functioned as a spindle, bobbin or toggle. Considering the evidence for plant craftwork that has emerged from microwear analysis of numerous flint tools and a bone bodkin (Chapters 8, 24 and 35), such an artefact fits within the broader body of evidence for plant-working now known from the site.

$<\mathbf{1 0 7 7 9 9}>$ (Figure 29.3a): This is a length of elder roundwood with one end broken. It is $765 \mathrm{~mm}$ long and slightly tapered: $22 / 27 \mathrm{~mm}$ at the proximal end and $16 / 19 \mathrm{~mm}$ at the distal end. It is straight with no side branches and is probably derived from coppice. The surviving end is worked, possibly slightly charred and appears to have

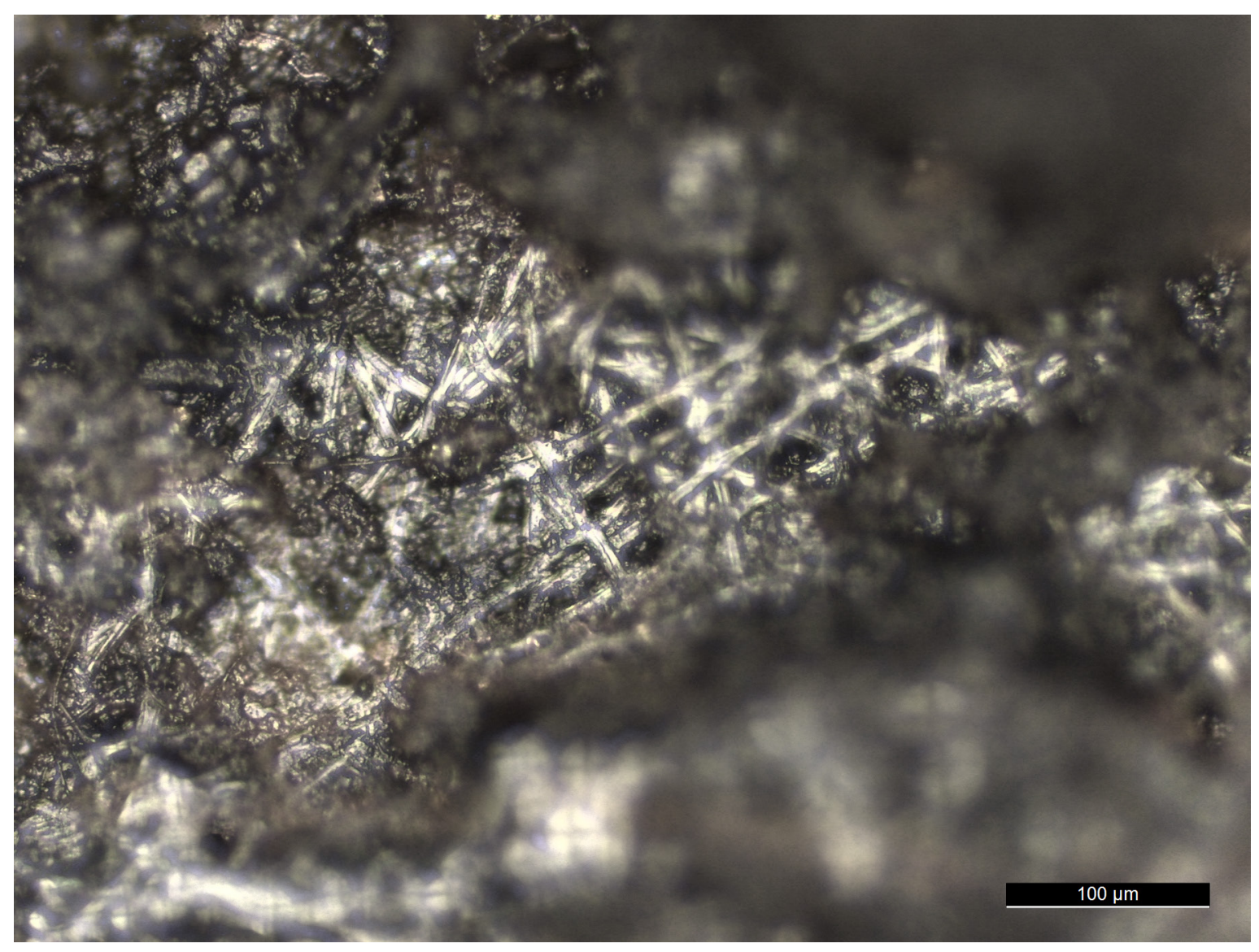

Figure 29.4: Transmitted light micrographs, $\times 20$ magnification, showing possible plant weave identified during microwear analysis of the wooden ad hoc tool <107555> (Copyright Aimée Little, CC BY-NC 4.0).

Figure 29.3 (page 376): Ad-hoc tools (Copyright Chloe Watson, CC BY-NC 4.0). 
been utilised. Towards the tip one side has been trimmed by splitting off some of the wood tangentially. No function is suggested for this item. In terms of microwear analysis, no wear or manufacture traces were identified, but the cell structure was intact.

$<\mathbf{1 0 9 0 4 5}>$ (Figure 29.3f): This is a piece of willow roundwood with a slender pointed end which appears to have been utilised. It measures $198 \mathrm{~mm}$ long with a compressed diameter of 15/22 $\mathrm{mm}$. No original function is suggested for this item. In terms of microwear analysis, no wear or manufacture traces were identified, but the cell structure was intact.

$<\mathbf{1 1 6 0 8 4}>$ (Figure 29.3d): This is willow roundwood, with several small notches near the tip. These may represent deliberate working but may also have been caused by root action. One end is broken but $83 \mathrm{~mm}$ survives and the compressed diameter measures $7 \times 9 \mathrm{~mm}$. No original function is suggested for this item.

\section{Boards}

A single item, $<115793>$, has been identified as a board (Figure 29.5). It does not fall into any of the primary interpretative categories and is therefore listed as 'other'. This item was recovered from context (312) in Clark's area. It is a thin board $338 \times 215 \mathrm{~mm}$ with a maximum thickness of $10 \mathrm{~mm}$. The board appears to have been tangentially split from a relatively large tree (probably willow) and then has probably been significantly thinned down, likely by hewing. The flat surfaces are smooth and well finished. There is a diagonal cut across one surface, probably a remnant of the thinning-down process. The board has broken on one edge in antiquity, with three smashed fragments pushed into the vertical plane.
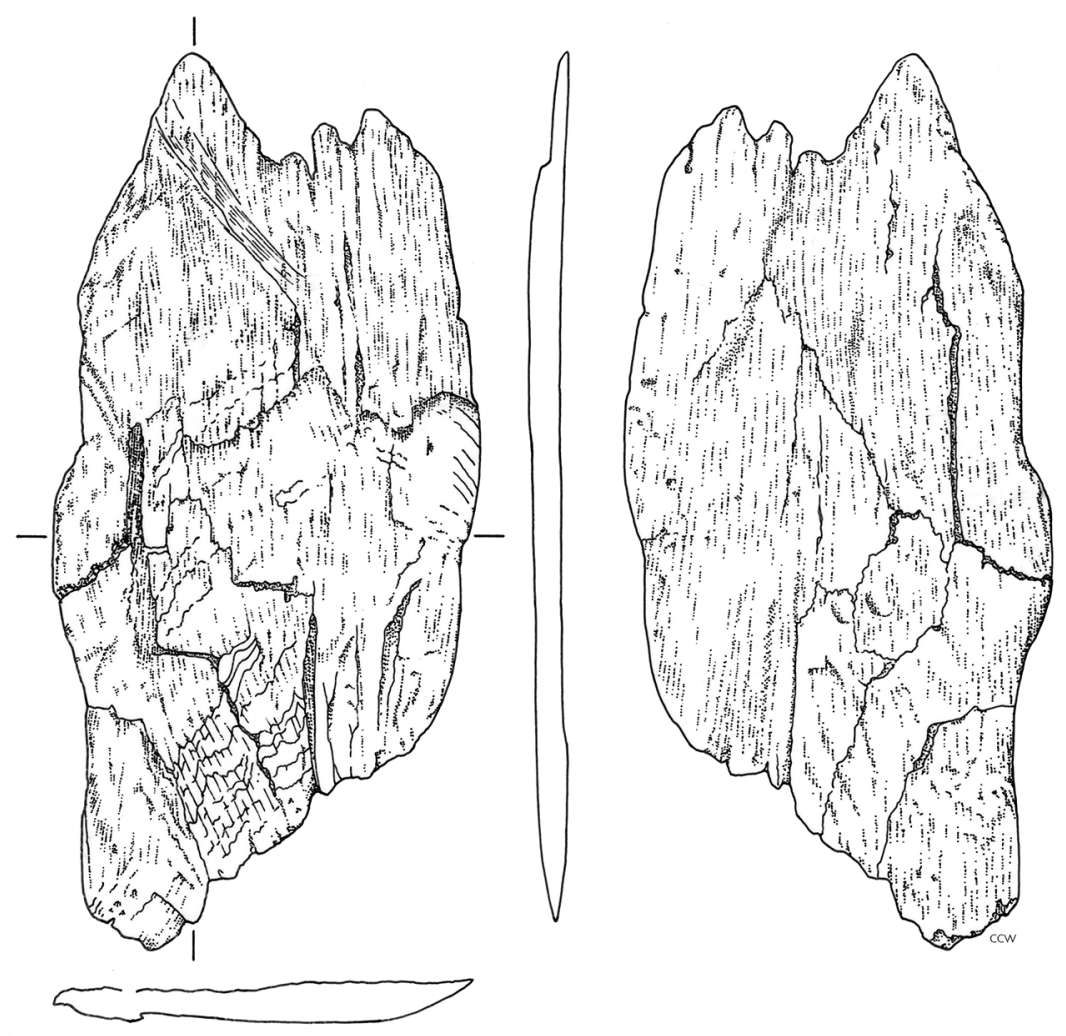
Dowel $<113300>$ has been identified as a bow (Figure 29.6 and 29.7). This artefact was recovered from Clark's area within the reed peat context (312). This artefact lay point to point with digging stick $\langle 92465>$ in shallow water, some $15 \mathrm{~m}$ from the edge of the lake suggesting perhaps a deliberate placement. Initially, only one end of this artefact was excavated within a narrow trench in 2010, when it was thought to represent the end of a digging stick. However, full excavation of the remainder of the item in 2015 showed it to be pointed at both ends and to be of appropriate size, form and conversion to be a bow (Bamforth et al. forthcoming).

Measuring $1411 \mathrm{~mm}$ in length with a maximum width of $22 \mathrm{~mm}$ and thickness of $19 \mathrm{~mm}$, this tangentially aligned sub-oval dowel (Figure 29.7) was worked to a slender point at both ends with no discernible nock or notch. It was worked down from a willow pole with a diameter of $70 \mathrm{~mm}$ or greater (Figure 29.7). The wood is knot free and straight grained with a slight twist along the length. Where the growth rings are visible they display even growth of c. $2.5-3.0 \mathrm{~mm}$. The artefact is well finished with only slight, faint faceting, suggesting it was finished by burnishing, perhaps with a stone tool. The two limbs of the bow are slightly asymmetrical.

A series of experiments were carried out to test the possible function and performance of bow $<113300>$ and three slightly different bows were produced (Figure 29.8). Initially, an 'idealised' version was produced to test the use of willow for bow making. This replica had symmetrical limbs (unlike the original) and the outer growth ring was not truncated on the back of the bow (again, unlike the original). Once the 'idealised' bow had been shown to be effective, two replica bows were produced. One was designed to be as close as possible to the dimensions of the artefact as excavated (Replica A), whilst the second was allowed to be up to $30 \%$ thicker in the belly to back plane (up and down as found in the ground) to compensate for vertical compression in the burial environment (Replica B). It is important to note that in all cases it was necessary to some extent to follow the grain and form of the wood that the replicas were created from, leading to some difference between intended dimensions and those achieved (Table 29.7). Indeed, only Replica B had a width and thickness comparable to $<113300>$ as excavated. The bows were strung with twisted linden bast fibre cord.

Replica B took 1.5 hours for an experienced woodworker (DP) to produce from a split willow stave, using stone tools. This replica was able to shoot an arrow to a horizontal distance of $25 \mathrm{~m}$ and a vertical height of around $15 \mathrm{~m}$. Despite this relative success, it was felt that the replica bow was too 'light' to have been effective for hunting big game. It was with this in mind that Replica B was used to shoot a small dead fish, held some $0.3 \mathrm{~m}$ below the surface of a lake (in a swimming position) with a barbed point tipped arrow (Figure 29.9). This was a success with the barbed point penetrating the fish by some $120 \mathrm{~mm}$ and securely holding the fish on the barbs.

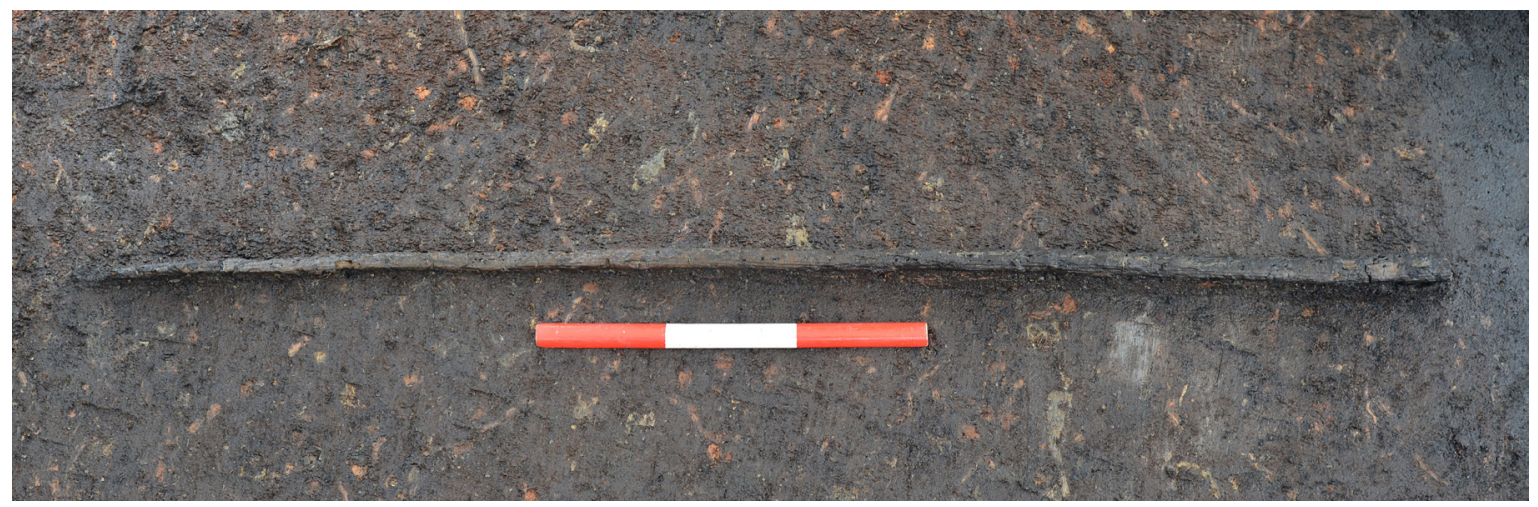

Figure 29.6: Photograph of western portion of bow $<113300>$ in situ (Copyright Star Carr Project, CC BY-NC 4.0).

Figure 29.5 (page 378): Board <115793> (Copyright Chloe Watson, CC BY-NC 4.0). 


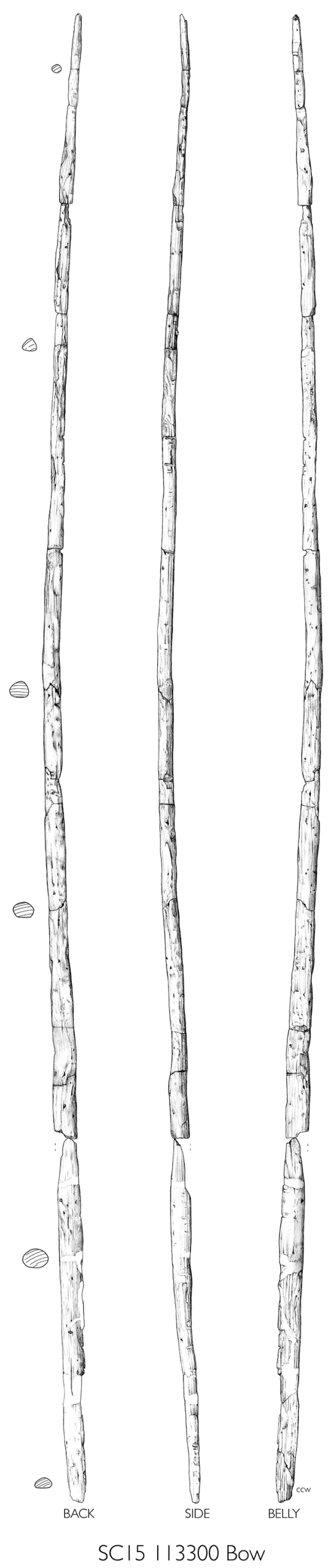

I. BACK

2.

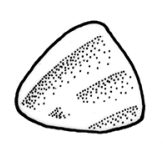

3.

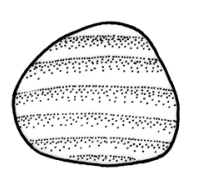

4.

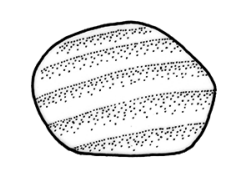

5.

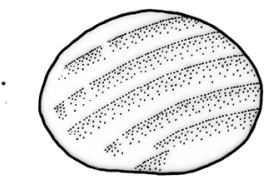

6.
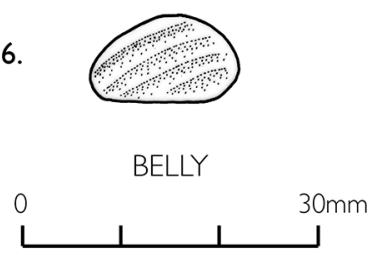

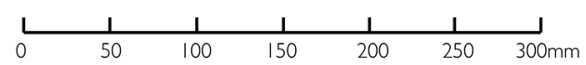

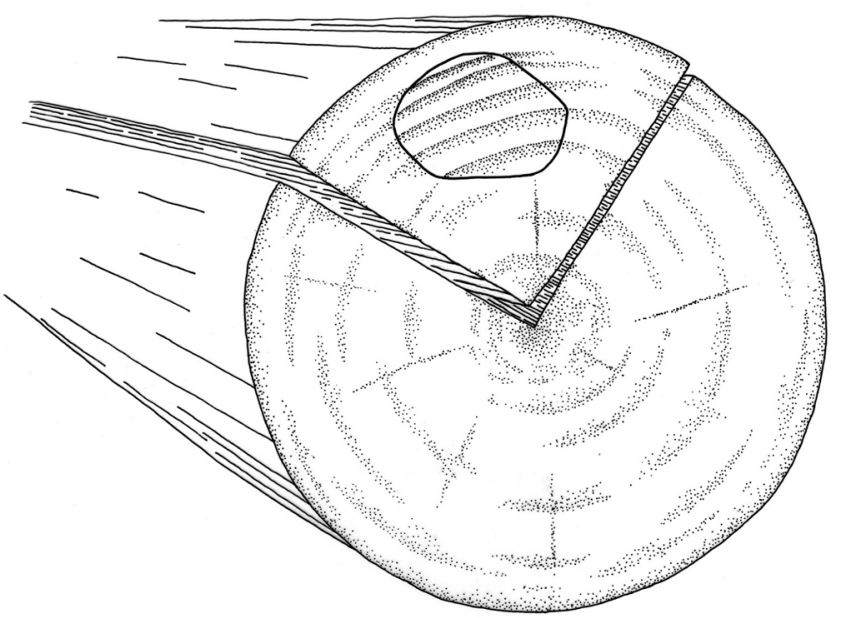




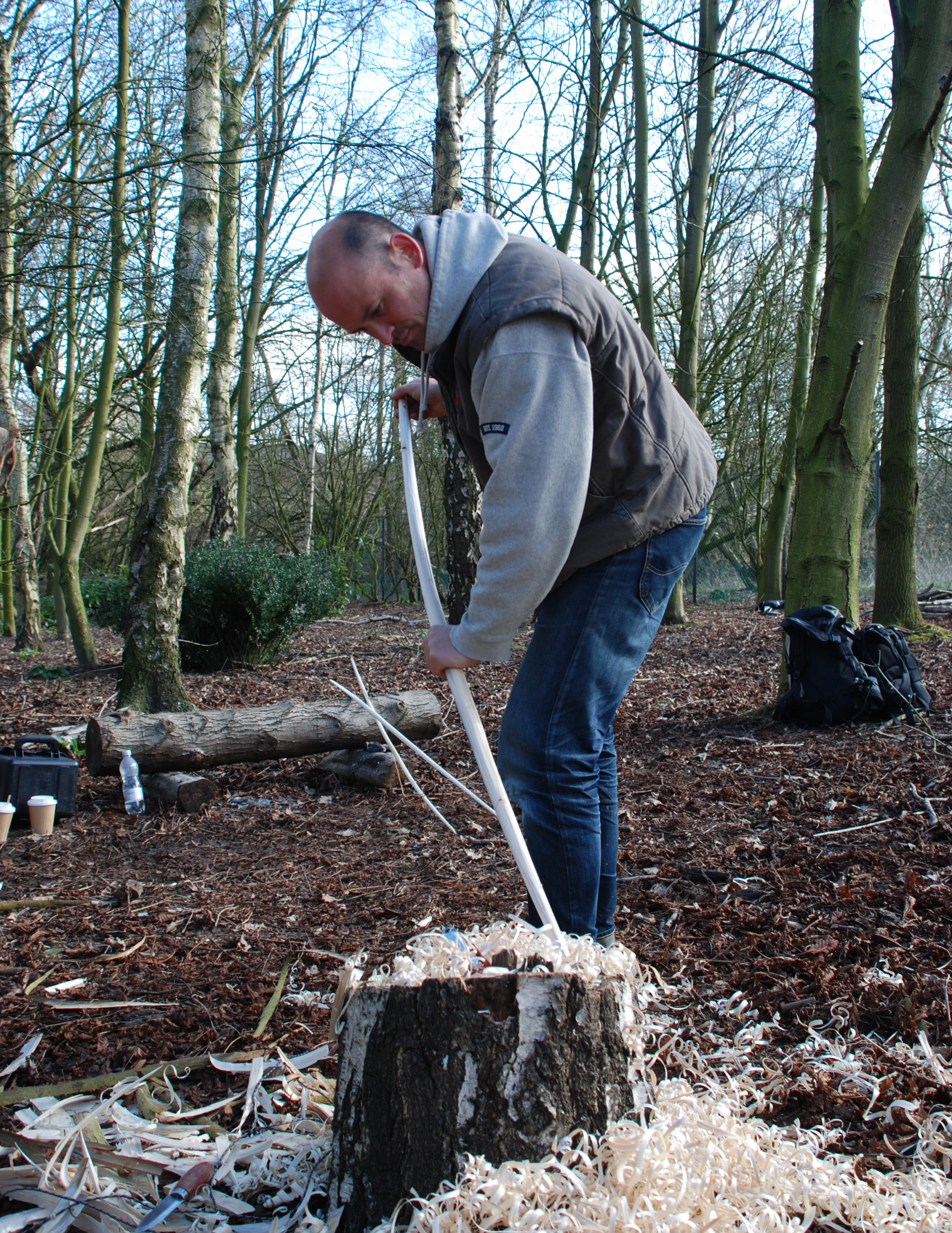




\begin{tabular}{|c|c|c|c|c|c|c|}
\hline Bow & $\begin{array}{l}\text { Length } \\
(\mathrm{mm})\end{array}$ & $\begin{array}{l}\text { Width } \\
(\mathrm{mm})\end{array}$ & $\begin{array}{l}\text { Thickness }(\mathrm{mm}) \\
\text { belly to back }\end{array}$ & $\begin{array}{l}\text { Draw weight @ } \\
0.25 \mathrm{~m}\end{array}$ & $\begin{array}{l}\text { Draw weight @ } \\
0.45 \mathrm{~m}\end{array}$ & $\begin{array}{l}\text { Maximum } \\
\text { draw weight }\end{array}$ \\
\hline 113300 & 1411 & 22 & 19 & $\mathrm{~N} / \mathrm{A}$ & N/A & N/A \\
\hline Idealised & 1370 & 15 & 15 & $7 \mathrm{lb}$ & N/A & N/A \\
\hline Replica A & 1370 & 16 & 16 & $4 \mathrm{lb}$ & N/A & N/A \\
\hline Replica B & 1450 & 21 & 20.5 & $7 \mathrm{lb}$ & $9 \mathrm{lb}$ & $10 \mathrm{lb}$ \\
\hline
\end{tabular}

Table 29.7: Dimensions and draw weights of bow and replicas.

Figure 29.7 (page 380): Bow $<113300>$ alongside cross sections through bow and cross section of bow within pole (Copyright Chloe Watson, CC BY-NC 4.0).

Figure 29.8 (page 381): Flexing the bow during its production to test its strength. Note the quantity of woodworking debris produced (Copyright Aimée Little, CC BY-NC 4.0).

Figure 29.9 (below): Bowfishing using a replica bow and hafted antler barbed point (Copyright Aimée Little, CC BY-NC 4.0).

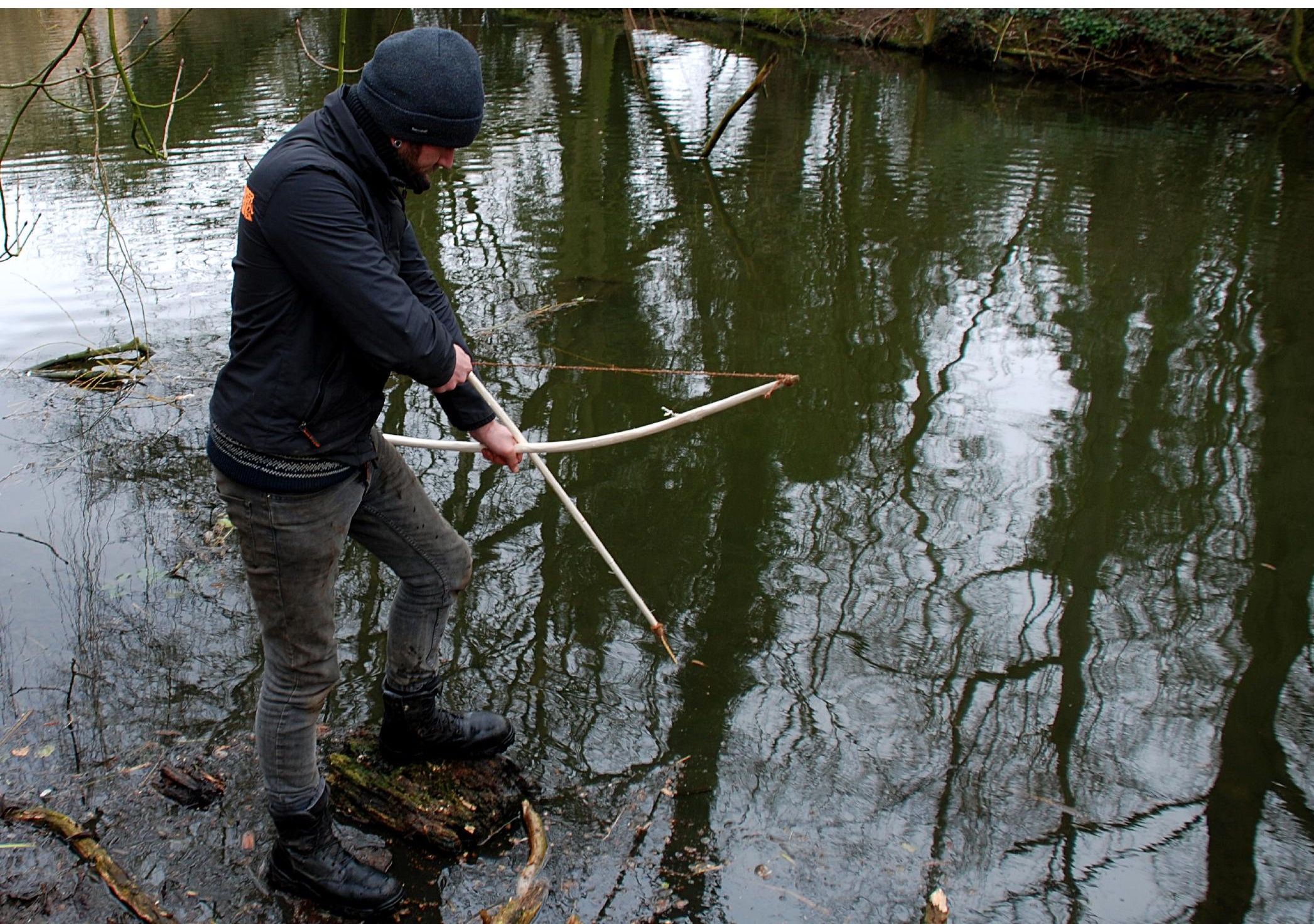


Although relatively small for a bow, $<113300>$ lies within the size range of published Mesolithic and Neolithic Bows (Bamforth et. al. forthcoming). Other finds from the site provide further evidence for archery, including flint and a stone tool that may have been an arrow burnisher (Chapters 34 and 35). No arrows or possible arrow shafts were identified from the wood assemblage. The absence of arrow shafts in the archaeological record at Gwisho was also noted (Fagan and van Noten 1966, 151) and here Fagan suggests that reeds from the adjacent reed beds may have been used as arrow shafts given that the arrowheads are light and made of wood.

\section{Decorated item}

Only one wooden item from the excavations shows traces of possible decoration. Woodchip <98042> was recovered from context (312) in the brushwood. It is a parallel-sided willow woodchip, measuring $85 \times 25 \times$ $7 \mathrm{~mm}$ (Figure 29.10 and 29.11). It is probably radially aligned but the wood is very fine grained making it hard to assess. It is heavily charred on one face and one edge, which again obscures the grain. The charring has dried out the wood so that it has distorted and is concave in two planes. There are several straight grooves criss-crossing the uncharred face. The profile of the grooves is not symmetrical. One side is cut straight with quite a sharp edge but the wood is slightly 'feathered' on the other side. Where the lines begin (or end) there is a slightly bulbous depression. It has not been possible to ascertain how these marks were made and whether they represent deliberate working.

\section{Digging sticks}

The first digging stick encountered was a complete dowel example excavated in $2010<92465>$ (Figure 29.12). At first it was clear that it was an artefact but its function was less clear. The definitive identification of this item as a digging stick was made by Brian Fagan who saw it whilst it was being recorded and drawn. He also supplied a reference for closely similar objects which he had excavated in Africa (Fagan and van Noten 1966).

Using the complete digging stick <92465> for comparison, seven other pieces were identified as parts of possible digging sticks (Table 29.8; Figures 29.13 and 29.14). Four of the items are radial dowels and four are roundwood, generally with a natural, spherical 'handle' section.

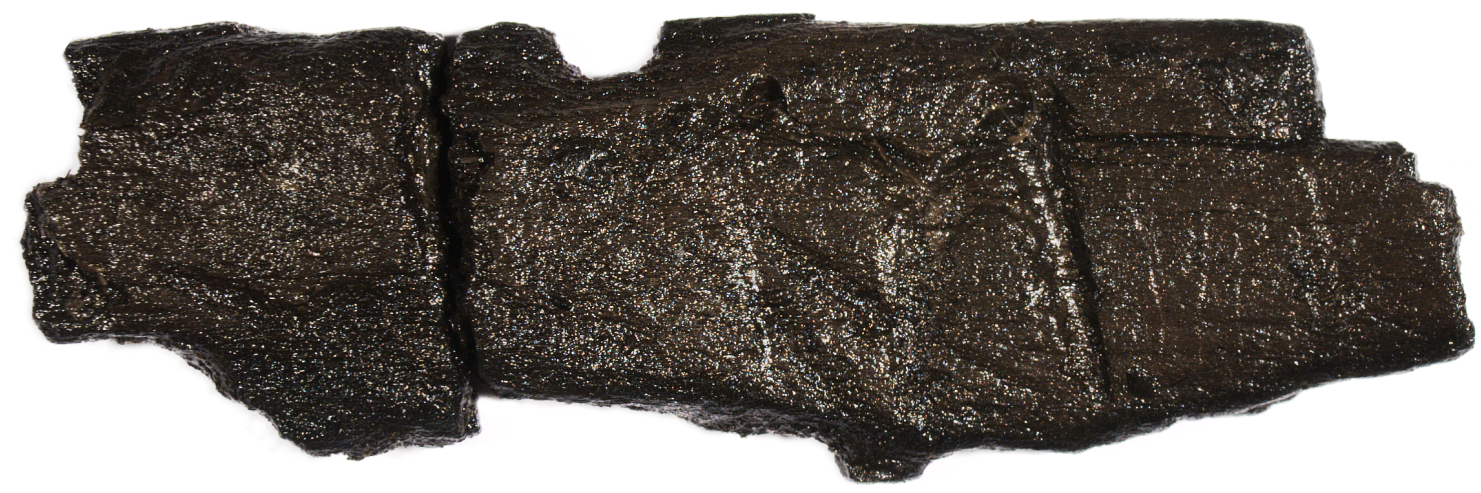

$0 \quad 50 \mathrm{~mm}$

Figure 29.10: Photograph of decorated woodchip <98042> (Copyright Michael Bamforth, CC BY-NC 4.0). 

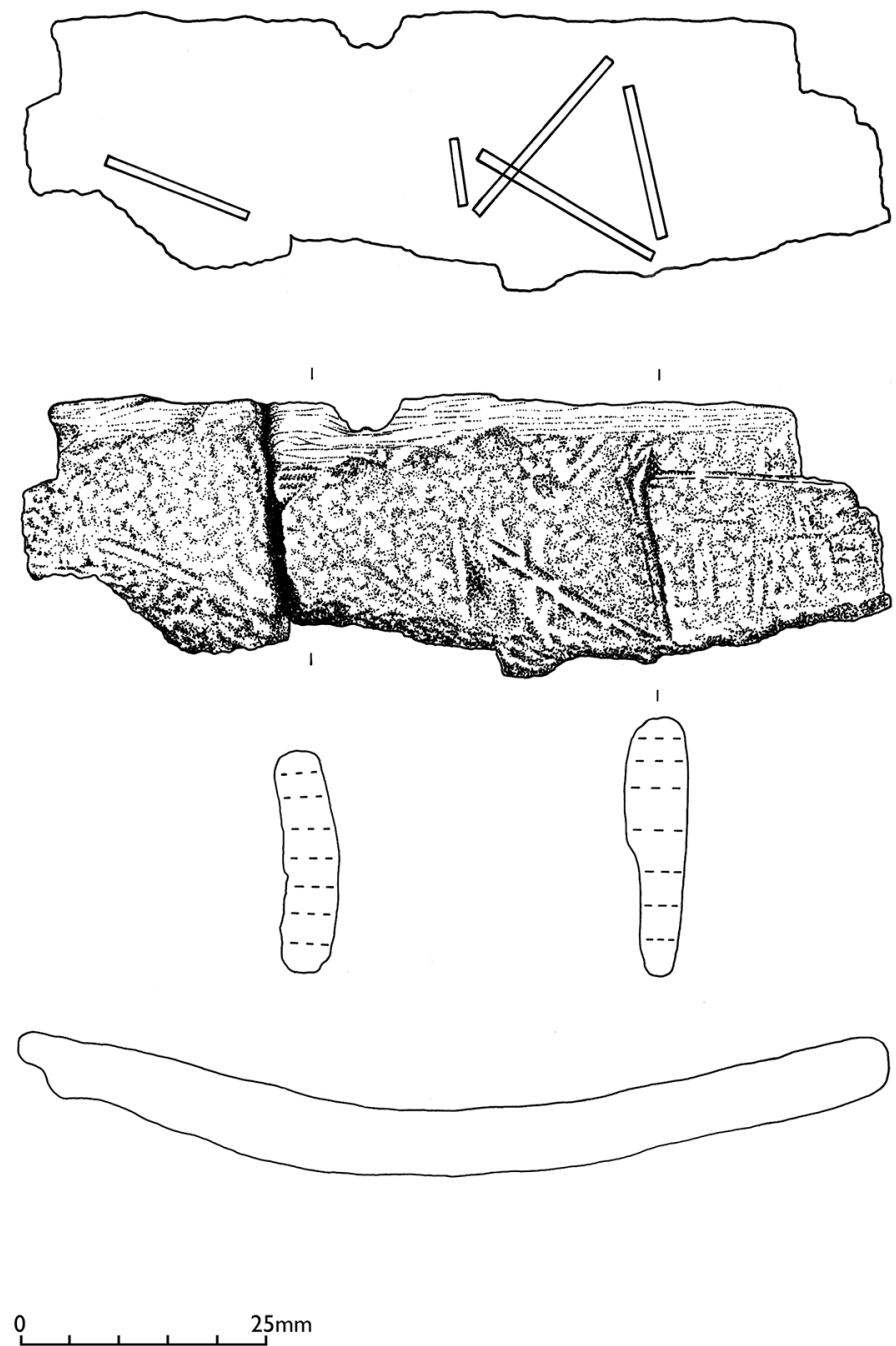

Figure 29.11: Illustration of decorated woodchip <98042> (Copyright Chloe Watson, CC BY-NC 4.0).

Two digging sticks were recovered from the brushwood, five from Clark's area and one from other areas. It is interesting to note that none were recovered from any of the three lake edge platforms or from the detrital wood scatter.

$<$ 92465> (Figure 29.13): This is a complete digging stick, $1100 \mathrm{~mm}$ long and made from a well-carved dowel measuring 15/28 mm, worked down from a quarter split log of willow. One end gradually flattens from one side, and this flattened end is rounded. The other end has been carved into a roughly spherical knob. The grain of the knob or handle is slightly gnarled suggesting that it comes either from near the base of a tree trunk or from the bottom end of a coppiced stem. It is so well made that it was only after a cross-section was examined that it became apparent that it is a dowel and not roundwood.

This artefact was replicated using experimental archaeology in order to test whether it functioned as a digging stick. It was fashioned from a $1 \mathrm{~m}$ section of 'green' birch tree trunk with a diameter of $130 \mathrm{~mm}$ (this round of experimental work was carried out prior to the taxonomic identification of the wooden artefacts: the

Figure 29.12 (page 385): Digging stick $<92465>$ (foreground) tip to tip with bow $<92684>\mid<113300>$ (extending into baulk) (Copyright Star Carr Project, CC BY-NC 4.0). 


\begin{tabular}{|c|c|c|c|c|c|c|}
\hline Number & Context & Area & Type & Conversion & Description & Identification \\
\hline 92465 & 312 & Clark's area & dowel & $\mathrm{rad}$ & $\begin{array}{l}\text { Complete, used end is flattened and } \\
\text { rounded, gnarled spherical handle }\end{array}$ & willow \\
\hline 94034 & 312 & brushwood & $\begin{array}{l}\text { utilised } \\
\text { roundwood }\end{array}$ & none & $\begin{array}{l}\text { Possible unfinished digging stick } \\
\text { formed from coppice stem with } \\
\text { gnarled heel }\end{array}$ & willow \\
\hline 98032 & 317 & brushwood & dowel & $\mathrm{rad}$ & $\begin{array}{l}\text { Flattened tip of possible digging } \\
\text { stick, with notches }\end{array}$ & aspen \\
\hline 113765 & 312 & other & dowel & $\mathrm{rad}$ & $\begin{array}{l}\text { Pointed, sub oval dowel. Possible } \\
\text { digging stick or haft / handle }\end{array}$ & willow \\
\hline 116053 & 312 & Clark's area & dowel & $\mathrm{rad} / \tan$ & $\begin{array}{l}\text { Broken dowel. Pointed at one end. } \\
\text { Possible tip of digging stick }\end{array}$ & alder \\
\hline 116640 & 312 & Clark's area & $\begin{array}{l}\text { utilised } \\
\text { roundwood }\end{array}$ & none & $\begin{array}{l}\text { Gnarled spherical end. Broken } \\
\text { in antiquity. Possible handle of } \\
\text { digging stick }\end{array}$ & $\begin{array}{l}\text { alder } \\
\text { buckthorn }\end{array}$ \\
\hline 117152 & 312 & Clark's area & $\begin{array}{l}\text { utilised } \\
\text { roundwood }\end{array}$ & none & $\begin{array}{l}\text { Spherical end. Broken in antiquity. } \\
\text { Possible handle of digging stick }\end{array}$ & $\begin{array}{l}\text { alder } \\
\text { buckthorn }\end{array}$ \\
\hline 117165 & 312 & Clark's area & $\begin{array}{l}\text { utilised } \\
\text { roundwood }\end{array}$ & none & $\begin{array}{l}\text { Roundwood with spherical end. } \\
\text { Possible rough-out for digging stick }\end{array}$ & willow \\
\hline
\end{tabular}

Table 29.8: Material interpreted as digging sticks $(\mathrm{rad}=$ radial, $\tan =$ tangential $)$.

digging stick was subsequently identified as willow). The log was split with unseasoned wooden wedges and a wooden mallet into two radial half splits, one of which was further reduced into two radial quarter splits. A radial quarter split was used to produce the digging stick. The artefacts were trimmed and hewn into shape using flint tranchet axes hafted as adzes in willow, dowel hafts.

A replica digging stick was produced by a non-skilled wood worker (MB) and took two hours with a flint adze to produce. The item was partially finished using a flint flake for 30 minutes. The item was not brought to a high level of finish due to time constraints. In total, about 2.5 hours of work were taken to convert a radial quarter split into a functional, but poorly finished, digging stick. The completed digging stick was successfully used to a dig a hole some $0.5 \mathrm{~m}$ in diameter by $0.4 \mathrm{~m}$ deep, which took one hour (Figure 29.15). It was noted that whilst the digging stick was efficient when used for the primary task of digging, it broke easily when used to 'lever' an intrusive root in the hole.

$<$ 094034> (Figure 29.14): This is a possible unfinished digging stick. It is a coppiced willow stem with a gnarled, bulbous end which is part of the coppice stool. It is $621 \mathrm{~mm}$ long with a diameter of $19 / 36 \mathrm{~mm}$. The tip is missing. The bulbous end strongly resembles the handle of the known digging sticks before completion of carving. Although several of the other pieces identified as whole or partial digging sticks are dowels, it should not be assumed that all digging sticks are dowels. Digging sticks made of roundwood would have been more flexible and could have been used differently. It may be significant in this context that the roundwood is a little more heavyweight than the dowels.

$<098032>$ (Figure 29.14): This is a dowel, made from a radially split piece of aspen which has been further modified. The section is rounded but flattened with a rounded end. It measures $102 \times 20 \times 15 \mathrm{~mm}$. Although only a short length survives, this piece is closely similar to the flattened end of the complete digging stick $<92465\rangle$. Only the $102 \mathrm{~mm}$ nearest the tips can be used for comparison, but at this point the dimensions are closely similar. Along one edge are a series of parallel notches. There may have been one $40 \mathrm{~mm}$ from the tip but the piece is broken at this point, the grain is crumpled and therefore it is impossible to be sure. The two definite notches are 65 and

Figure 29.13 (page 387): Digging sticks (Copyright Chloe Watson, CC BY-NC 4.0). 

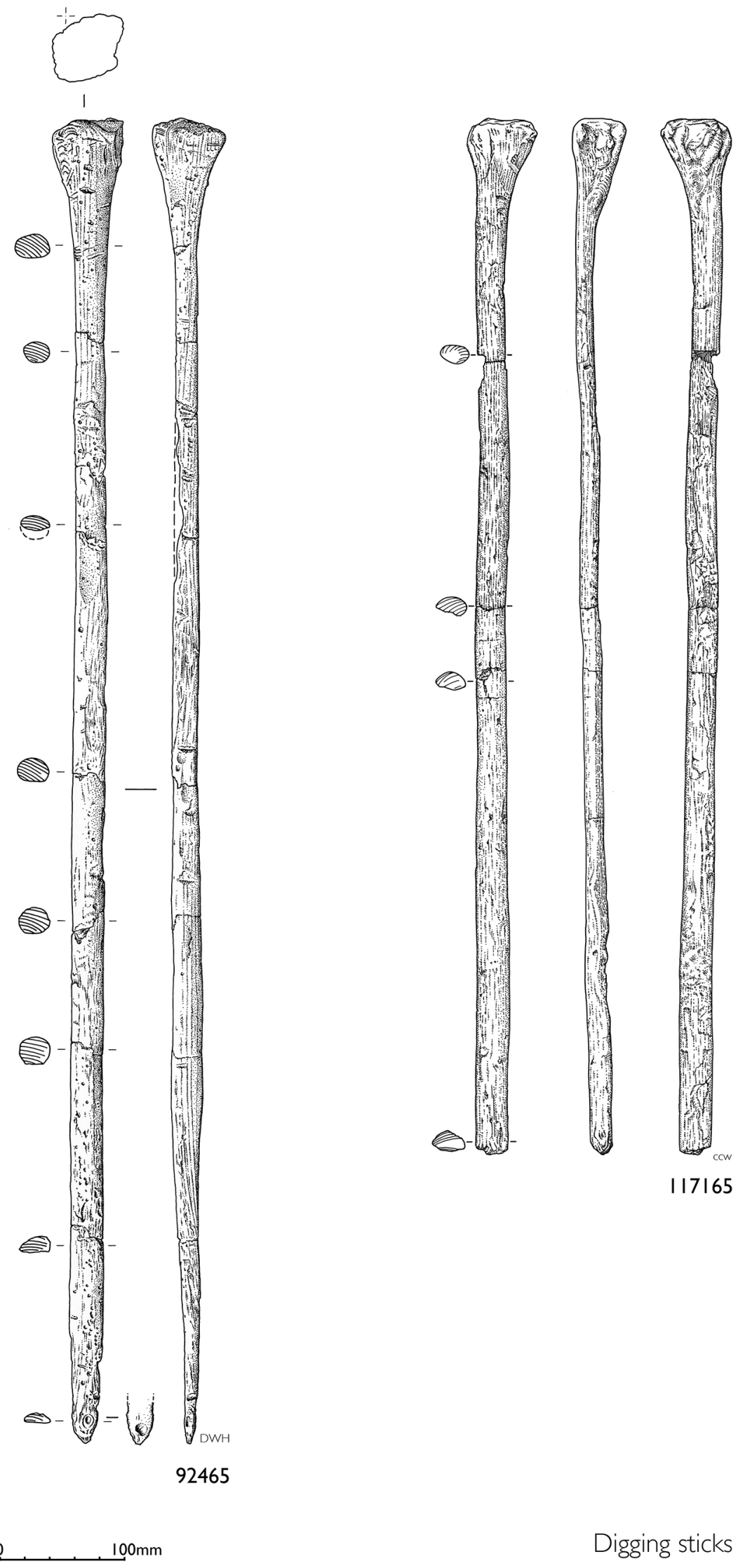

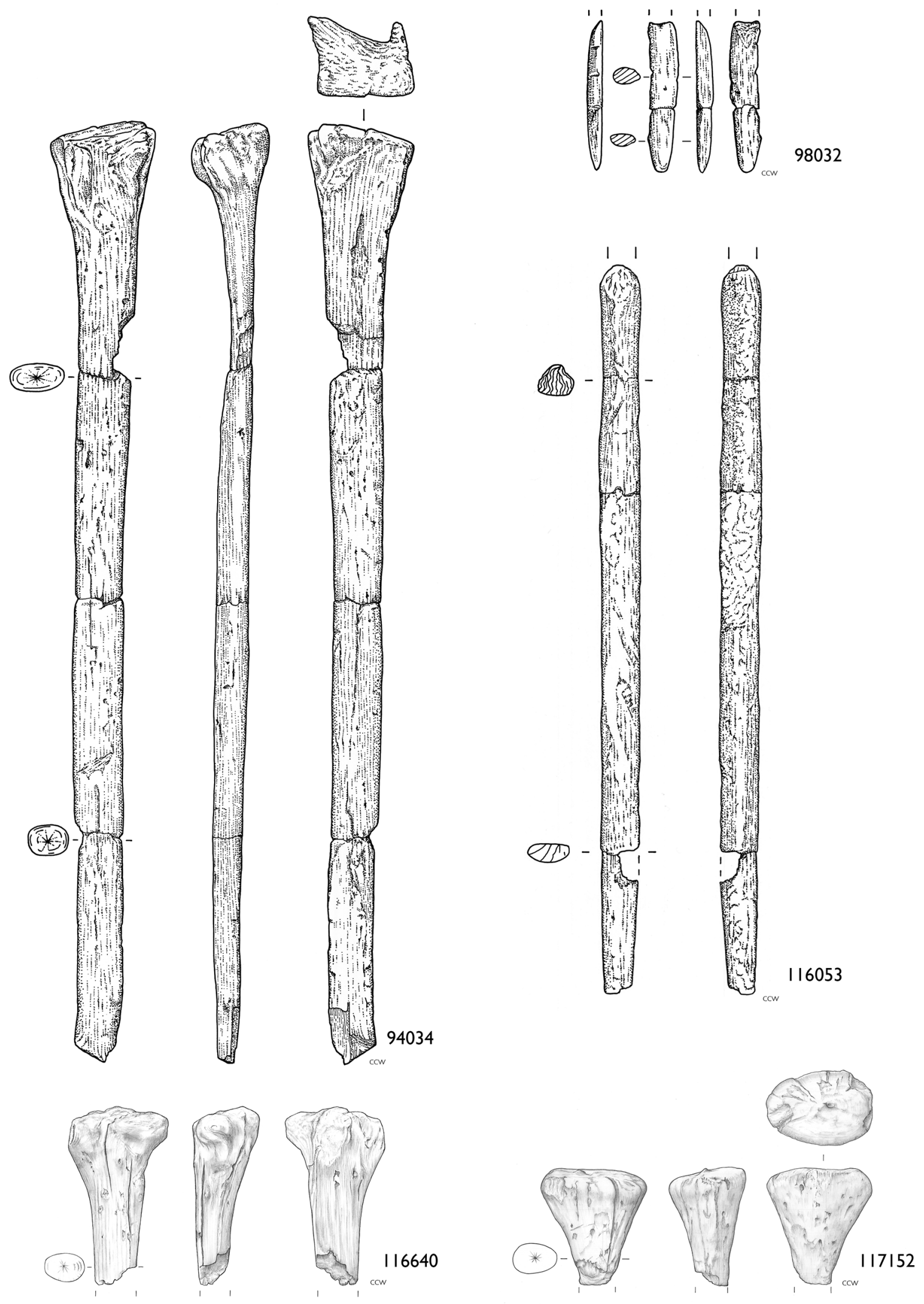

Digging sticks 


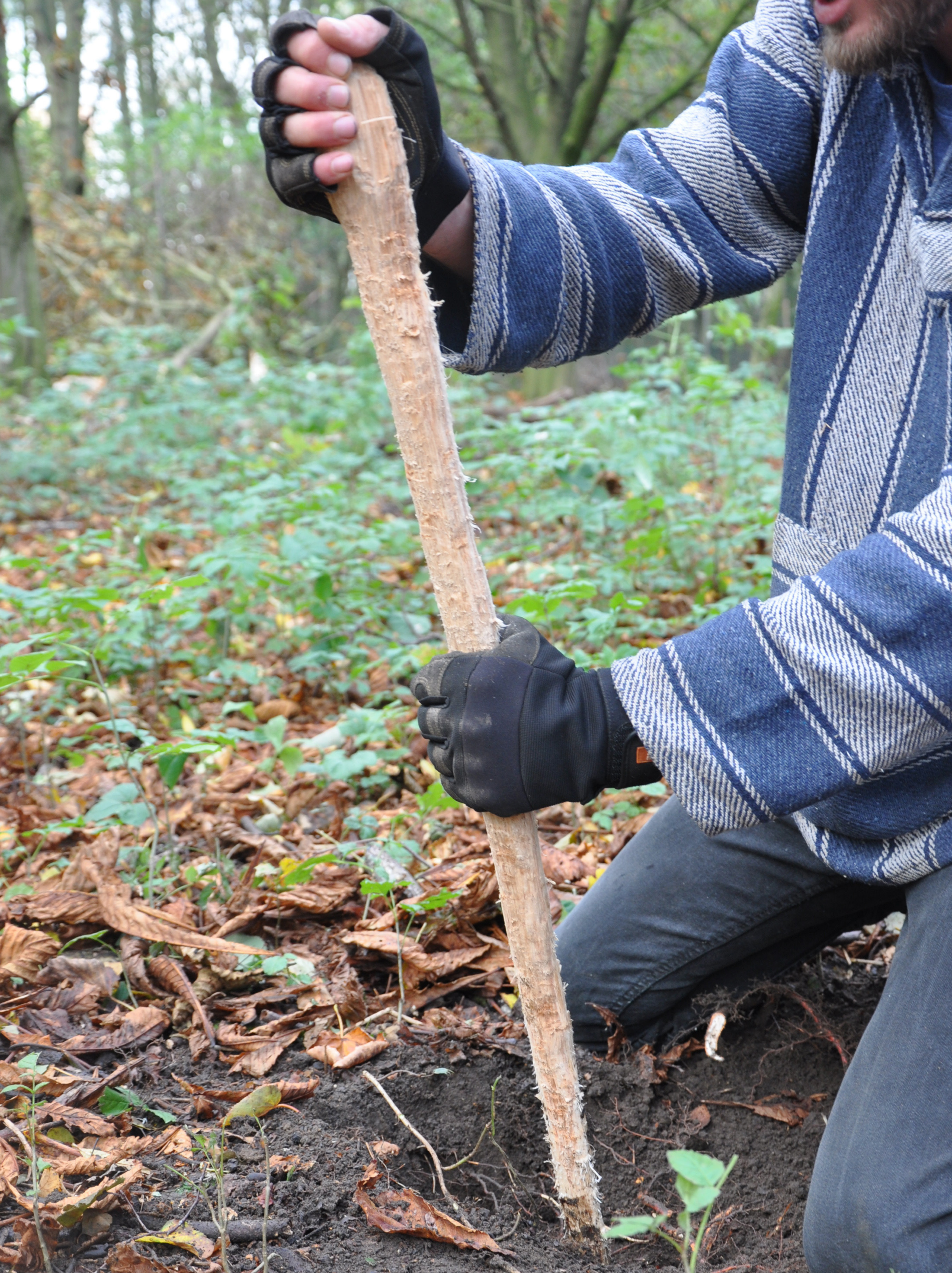




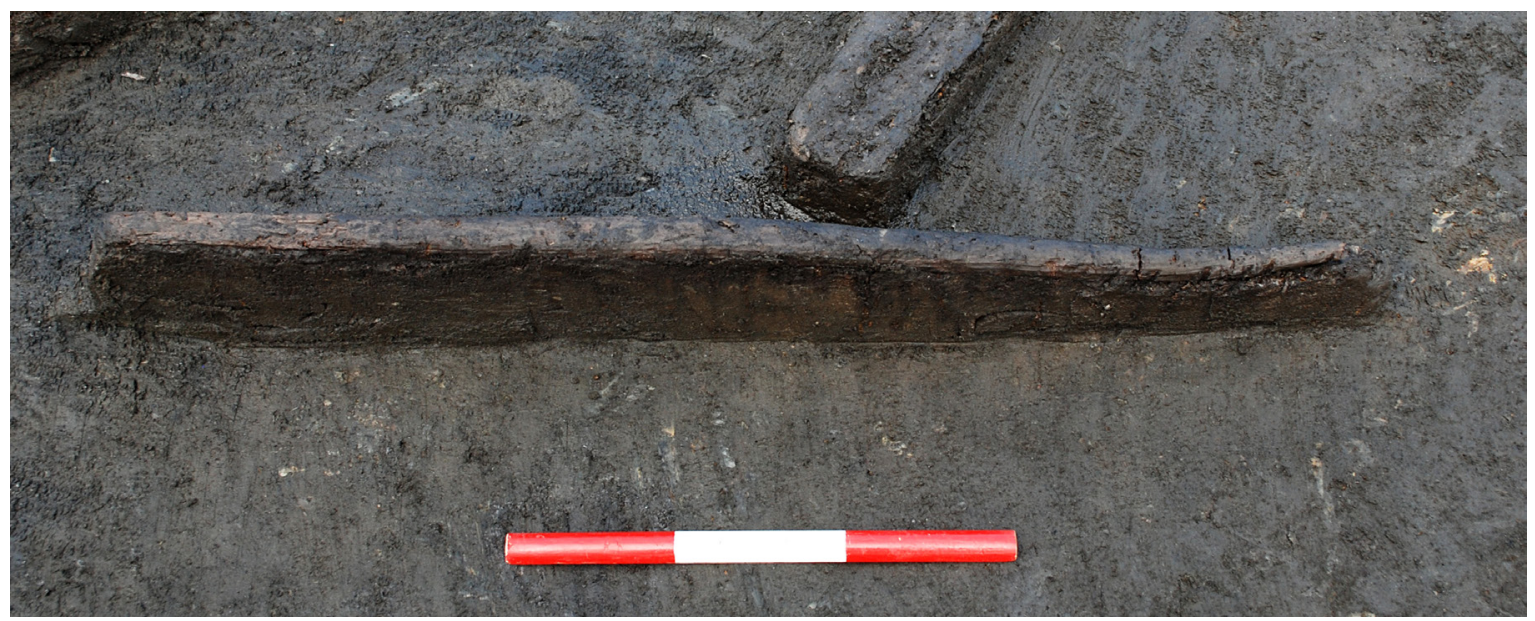

Figure 29.16: Photo of possible digging stick or haft or handle <113765> (Copyright Star Carr Project, CC BY-NC 4.0).

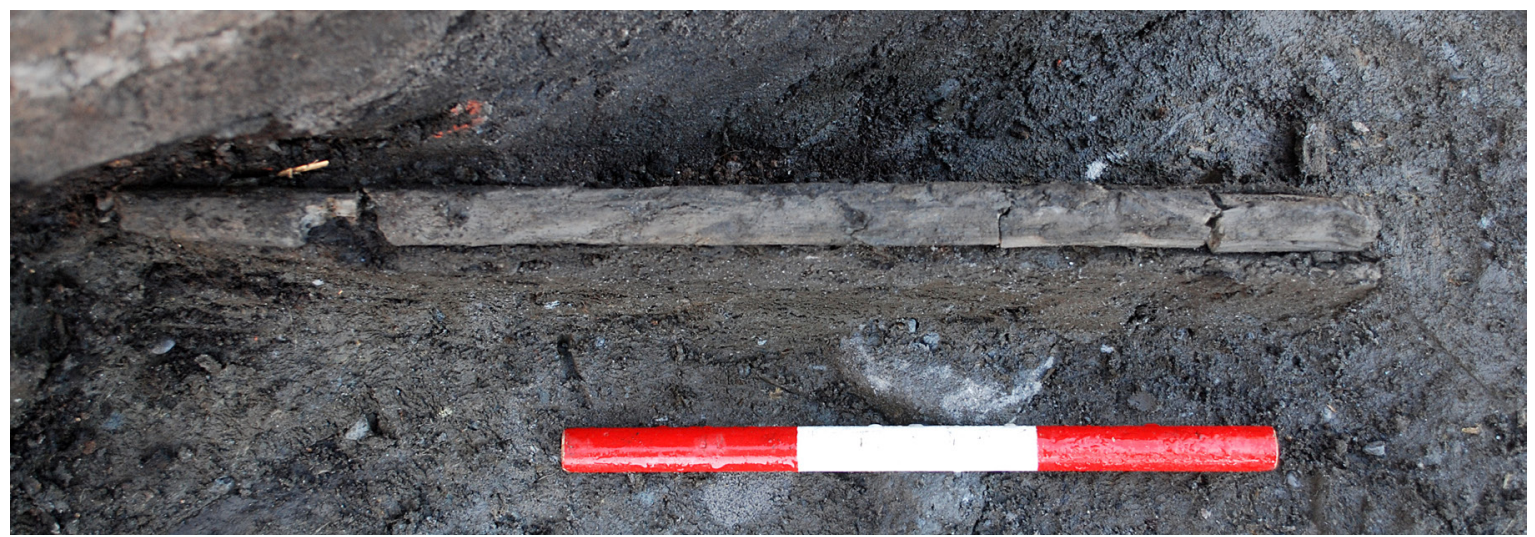

Figure 29.17: Possible dowel digging stick <116053> in situ (Copyright Star Carr Project, CC BY-NC 4.0).

$85 \mathrm{~mm}$ from the tip. They are 7 and $9 \mathrm{~mm}$ long, respectively, and approximately $2 \mathrm{~mm}$ deep at the centre. The bases of both appear flattish.

$<\mathbf{1 1 3 7 6 5}>$ (Figure $\mathbf{2 9 . 1 6}$ and 29.18b): This is radially split from a piece of willow and carved to a sub-oval dowel. It is $761 \mathrm{~mm}$ long with the widest point measuring $26 \times 11 \mathrm{~mm}$. The thick end is truncated whilst the other end tapers down to $15 \times 8 \mathrm{~mm}$ towards the point. There is very slight faceting towards the 'pencil' point, which is quite slender. There are tiny 'nicks' in the wood towards the point but it is unclear if these relate to

Figure 29.14 (page 388): Digging sticks (Copyright Chloe Watson, CC BY-NC 4.0).

Figure 29.15 (page 389): A replica digging stick was used for one hour to dig a hole (Copyright Aimée Little, CC BY-NC 4.0). 
use, taphonomy or excavation damage. This item may represent a digging stick but is also of suitable size to be a haft or handle. In terms of microwear analysis, no wear or manufacture traces were identified, but the cell structure was intact.

$<\mathbf{1 1 6 0 5 3}>$ (Figure 29.14 and 29.17): This is a dowel which is broken at one end, probably in antiquity. Some $400 \mathrm{~mm}$ survives with the section measuring $25 \times 15 \mathrm{~mm}$. One end is radially aligned, thickened and torn, possibly whilst being removed from an alder coppice stool. The tip is tangentially aligned and pointed. In terms of microwear analysis, no wear or manufacture traces were identified, but the cell structure was intact.

$<\mathbf{1 1 6 6 4 0}>$ (Figure 29.14): This is roundwood with a compressed diameter of $29 \times 20 \mathrm{~mm}$. It has broken in antiquity and $119 \mathrm{~mm}$ survives. One end is expanded, gnarled and somewhat spherical. It appears to be the natural shape of a heel end taken from a coppice stool and is included here as its appearance is strikingly similar to the handle of digging stick $<092465>$. The maximum size of this end is $59 \times 39 \mathrm{~mm}$. Species identification indicates that the wood is alder buckthorn, which is not usually coppiced, although it is a shrub that naturally produces straight stems. Although it is basically a natural shape, it has almost certainly been modified and worn.

$<\mathbf{1 1 7 1 5 2 >}$ (Figure 29.14): This is roundwood with a compressed diameter of $29 \times 18 \mathrm{~mm}$. It has broken in antiquity and $82 \mathrm{~mm}$ survives. One end is expanded, gnarled and somewhat spherical. The spherical end has been carved flat and has a chamfered edge. At its maximum it measures $71 \times 50 \mathrm{~mm}$. It is included here as its appearance is strikingly similar to the handle of digging stick $<092465\rangle$. Although it is a natural shape, it shows clear signs of modification and use.

$<\mathbf{1 1 7 1 6 5 >}$ (Figure 29.13): This is willow roundwood, some $845 \mathrm{~mm}$ long. One end terminates in a naturally expanded spherical 'handle' which may have been worked and the other end is broken, possibly in antiquity. It was also broken into two slightly dislocated refitting sections in antiquity. At its maximum the spherical end measures $55 \times 40 \mathrm{~mm}$. It tapers down to roundwood with a flattened diameter of $27 \times 15 \mathrm{~mm}$. It is included here due to its similarity of form to the complete digging stick and perhaps represents an unfinished rough-out.

\section{Hafts and handles}

Hafts or handles are difficult to identify as no hafted tools were found and there are few comparanda. The majority of hafts and handles known from the archaeological and historic record, right through to the present day, are generally heartwood dowels. This is to take advantage of the increased strength of this form over simple unconverted roundwood. Based on their size and form, four of the dowels are classified as possible hafts or handles (Table 29.9; Figure 29.18). All are radially aligned dowels. Two were recovered from Clark's area, one from the detrital wood scatter and one from later deposits located above the detrital wood scatter.

\begin{tabular}{|r|r|l|l|l|l|l|}
\hline Number & Context & Area & Type & Conversion & Description & Identification \\
\hline 110105 & 317 & $\begin{array}{l}\text { detrital wood } \\
\text { scatter }\end{array}$ & dowel & rad & $\begin{array}{l}\text { Sub-rectangular dowel, heavily } \\
\text { damaged }\end{array}$ & aspen \\
\hline 113765 & 312 & other & dowel & rad & $\begin{array}{l}\text { Pointed, sub oval dowel. Possible } \\
\text { digging stick or haft / handle }\end{array}$ & willow \\
\hline 115338 & 312 & Clark's area & dowel & rad & $\begin{array}{l}\text { Sub-oval dowel, one end pointed, } \\
\text { one end broken }\end{array}$ & alder \\
\hline 115752 & 312 & Clark's area & dowel & rad & $\begin{array}{l}\text { Sub-oval dowel, one end torn, } \\
\text { one end truncated }\end{array}$ & willow \\
\hline
\end{tabular}

Table 29.9: Material interpreted as possible hafts or handles ( $\mathrm{rad}=$ radial). 


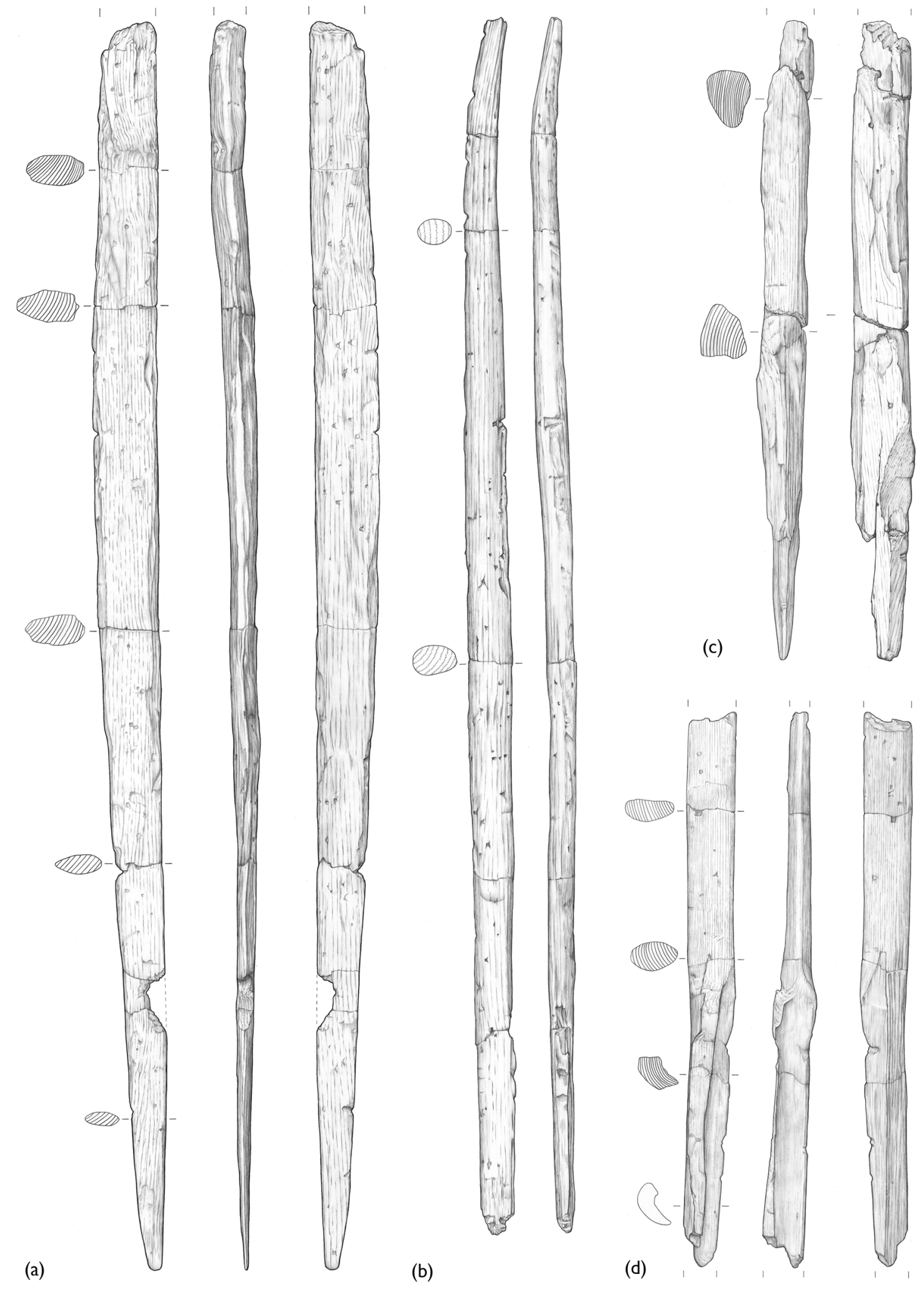

Hafts and handles $\begin{array}{llll}\text { (a) } 115338 & \text { (b) } 113765 & \text { (c) } 110105 & \text { (d) } 115752\end{array}$ 
$<\mathbf{1 1 0 1 0 5}>$ (Figure 29.18c): This is a short length of sub-rectangular dowel which could possibly be part of a haft or handle. One end extended into the baulk and so the two halves had to be excavated separately. The total length is $423 \mathrm{~mm}$ and the measurements along its length were consistently around $34 \mathrm{~mm}$ wide, with the thickness only varying between 30 and $24 \mathrm{~mm}$. The wood is straight-grained and slow-grown, with even growth rings about $1.5 \mathrm{~mm}$ wide. Analysis was difficult due to the damage where the piece broke in the section, together with other scraping and crushing. It was probably originally radially split from an aspen timber and then carved into a sub-rectangular dowel.

$<\mathbf{1 1 3 7 6 5}>$ (Figure 29.18b): This is radially split from a willow timber and carved to a sub-oval dowel. It is $761 \mathrm{~mm}$ long with the widest point measuring $26 \times 11 \mathrm{~mm}$. The thick end is truncated whilst the other end tapers down to $15 \times 8 \mathrm{~mm}$ towards the point. There is very slight faceting towards the 'pencil' point which is quite slender. There are tiny 'nicks' in the wood towards the point but it is unclear if these relate to use, taphonomy or excavation damage. This item is a suitable size to be a haft or handle but may also represent part of a digging stick.

$<\mathbf{1 1 5 3 3 8}>$ (Figures 29.18a and 29.19): This is a radially aligned sub-oval dowel with one end broken (probably in antiquity) and one end pointed and flattened. It is $755 \mathrm{~mm}$ long. The section is $23 \times 9 \mathrm{~mm}$ above the tip, thickening to $40 \times 17 \mathrm{~mm}$ before tapering to $33 \times 17 \mathrm{~mm}$ at the broken end. The dowel has been taken from near the outside of an alder log. In terms of microwear, no wear or manufacture traces were identified but the cell structure was intact.

$<\mathbf{1 1 5 7 5 2}>$ (Figure 29.18d): This is a radially aligned sub-oval dowel from willow, with an ancient tear down one side. One end was truncated by Clark's excavation and the other, torn end is an ancient break. The surviving length is $330 \mathrm{~mm}$ long and the section is $28 \times 15 \mathrm{~mm}$.

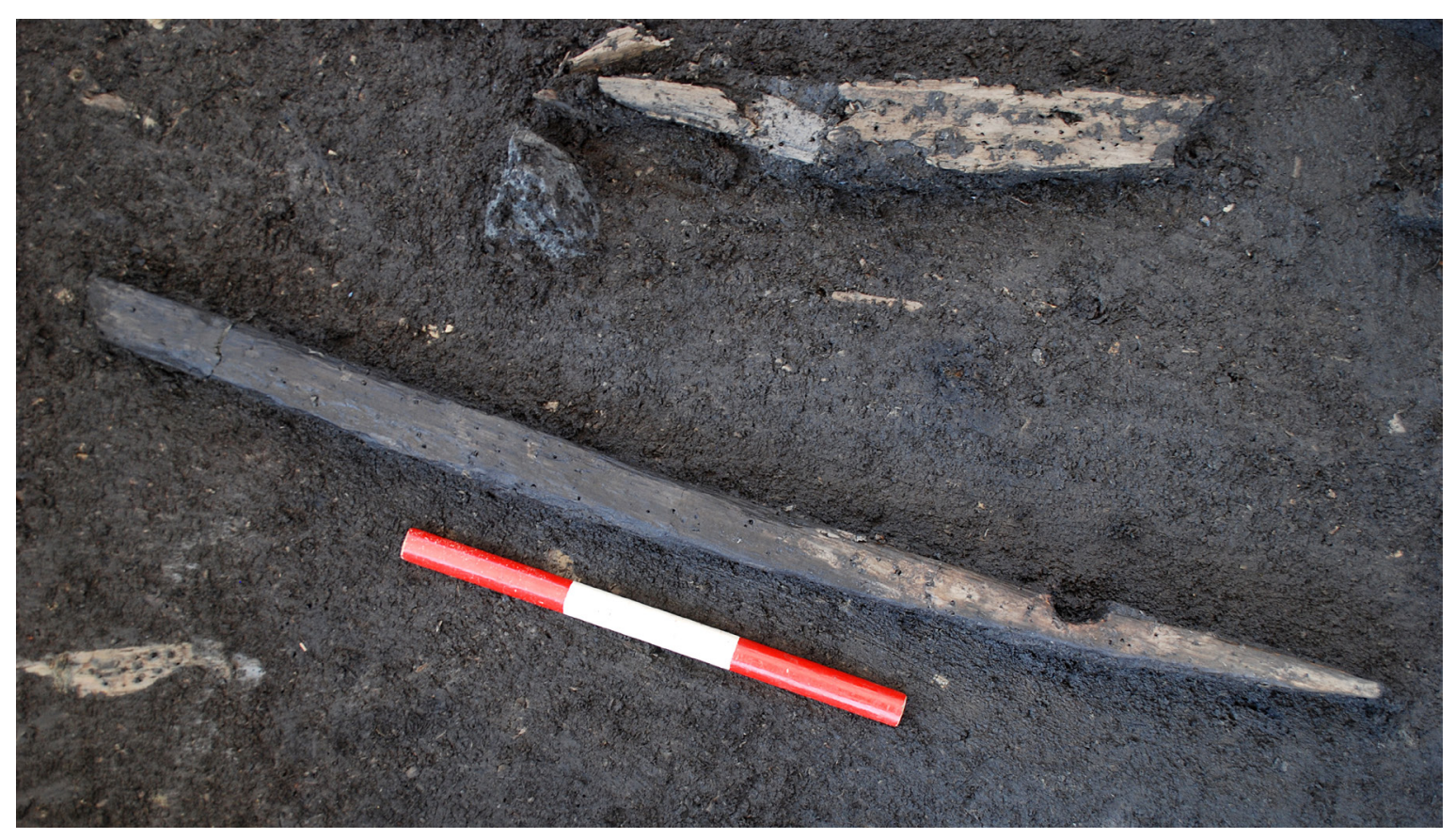

Figure 29.19: Haft or handle <115338> in situ (Copyright Star Carr Project, CC BY-NC 4.0).

Figure 29.18 (page 392): Hafts and handles (Copyright Chloe Watson, CC BY-NC 4.0). 


\section{Other dowels}

There are six dowels of unknown function (Table 29.10; Figure 29.20), with two of each recovered from the detrital wood scatter, Clark's area and other.

$<\mathbf{1 1 0 5 4 4}>$ (Figure 29.20b): This is a rough aspen dowel with both ends broken. The surviving length is 265 $\mathrm{mm}$ and the width and thickness vary along its length from $25-21 \mathrm{~mm}$ and from $21-17 \mathrm{~mm}$. This item appears unfinished. No original function is suggested for this item.

$<\mathbf{1 1 3 2 5 0}>$ (Figure 29.20d): This is a sub-rectangular dowel with at least two faces that appear well-finished. One face was badly damaged during excavation. Where the two well-finished faces meet, the join is rounded and also well-finished. It is $126 \mathrm{~mm}$ long and the section measures $12 \times 10 \mathrm{~mm}$. It was originally a radial quarter split, probably taken from a piece of willow roundwood. No original function is suggested for this item.

$<\mathbf{1 1 3 2 8 7}>$ (Figure 29.20e): This is a curved radially split rough dowel, with one end pointed and the other broken. Both the upper surface and the point were damaged during excavation. It is $103 \mathrm{~mm} \mathrm{long,} 11 \mathrm{~mm}$ wide and $5 \mathrm{~mm}$ thick. There is some gentle faceting and grooves on the surface. It is unclear if these represent deliberate working or taphonomic processes. The piece is a quarter split, taken from a small piece of willow roundwood, which only just misses the pith. It is curved and was shaped from two sides, although it is hard to tell how much of the curvature is original and how much post-depositional. Although it is of unknown function, its form leads to the tentative suggestion that it may have been used to pierce some kind of soft material, or perhaps used as a needle-like device.

The entire surface of $<113287>$ was analysed with low and high power magnification. This object displays three depressions along one edge (L2, L3, L4). One of these (L2) appears to have been cut intentionally as the cut goes against the grain. The other two depressions (L3 \& L4) have no clear cut mark; instead they display a more textured 'mashed up' surface. L3 has possible medullary rays visible; this may be working or wear which has led to a 'bottoming out'. The tip has been formed by working in the same direction (towards the point) from both edges.

$<\mathbf{1 1 3 7 6 8}>$ (Figure 29.20c): This is a radially aligned dowel taken from a piece of willow roundwood. It has a slight curve and a worn or utilised point. It is $229 \mathrm{~mm}$ long and $9 \times 5 \mathrm{~mm}$ in section. Although one end is degraded and there was some damage during excavation, it is possible to see that it has been thinned down to a point by the removal of a narrow parallel sided strip from one side. The wood is noticeably fine and dense compared to other items in the assemblage. Like $<113287>$ this is also of unknown function, though it too may have been used to pierce some kind of soft material or used as a needle-like device.

\begin{tabular}{|c|c|c|c|c|c|c|}
\hline Number & Context & Area & Conversion & Description & Identification & Function \\
\hline 110544 & 320 & $\begin{array}{l}\text { detrital wood } \\
\text { scatter }\end{array}$ & $\mathrm{rad} / \tan$ & Rough, unfinished dowel & aspen & \\
\hline 113250 & 317 & $\begin{array}{l}\text { detrital wood } \\
\text { scatter }\end{array}$ & $\operatorname{rad} 1 / 4$ & $\begin{array}{l}\text { Sub-rectangular dowel with one } \\
\text { rounded corner }\end{array}$ & willow & \\
\hline 113287 & 312 & Clark's area & $\operatorname{rad} 1 / 4$ & $\begin{array}{l}\text { Rough dowel with pointed, } \\
\text { possibly utilised, end }\end{array}$ & willow & ?piercer \\
\hline 113768 & 317 & other & $\mathrm{rad}$ & Dowel with worn or utilised end & willow & ?piercer \\
\hline 113778 & 312 & other & $\mathrm{rad}$ & $\begin{array}{l}\text { Slender, sub-rectangular item with } \\
\text { pointed end }\end{array}$ & alder & \\
\hline 116655 & 312 & Clark's area & $\mathrm{rad}$ & Sub-oval with trimmed end & aspen & \\
\hline
\end{tabular}

Table 29.10: Material interpreted as other dowels.

Figure 29.20 (page 395): Other dowels (Copyright Chloe Watson, CC BY-NC 4.0). 

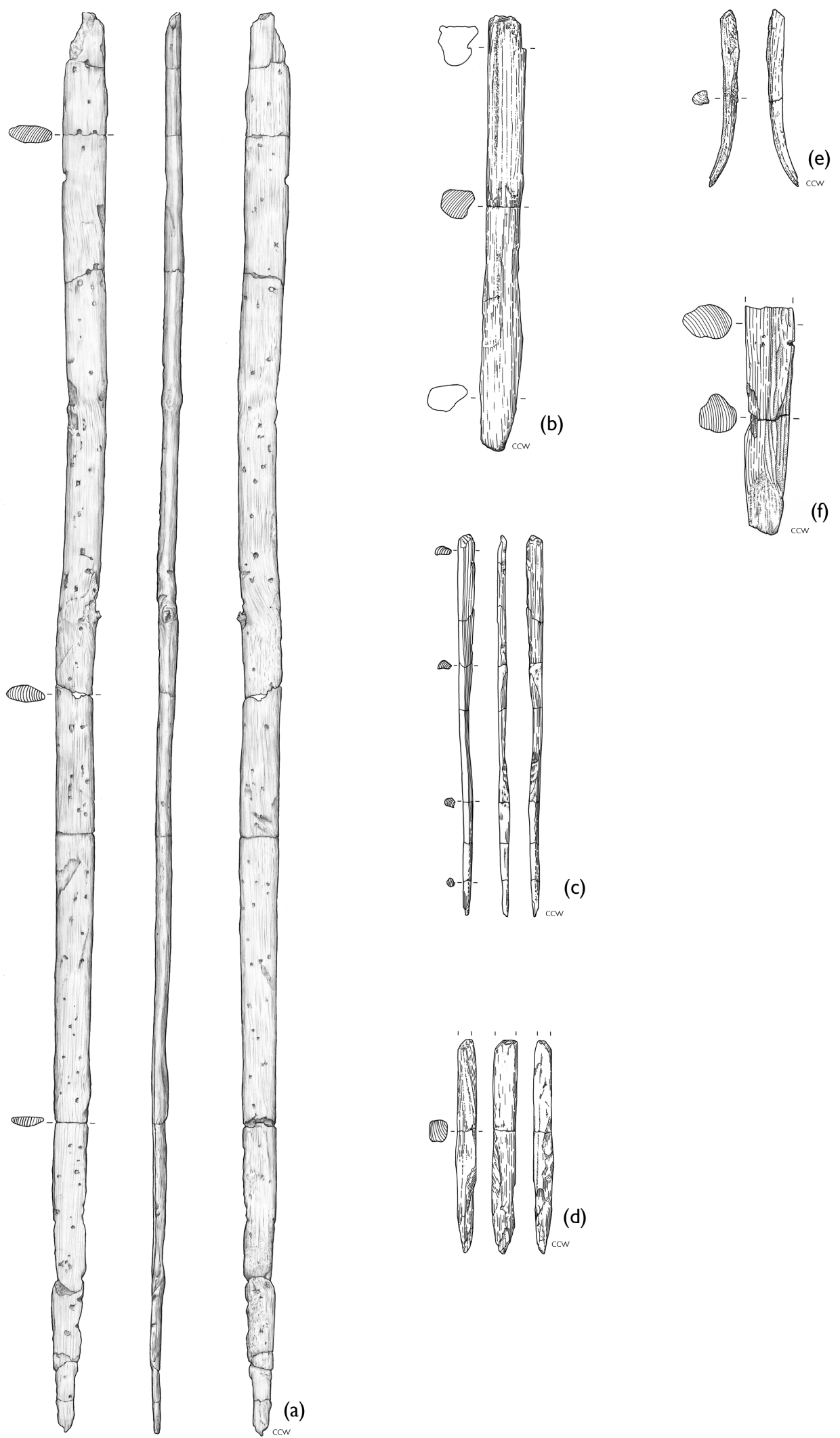

(b)
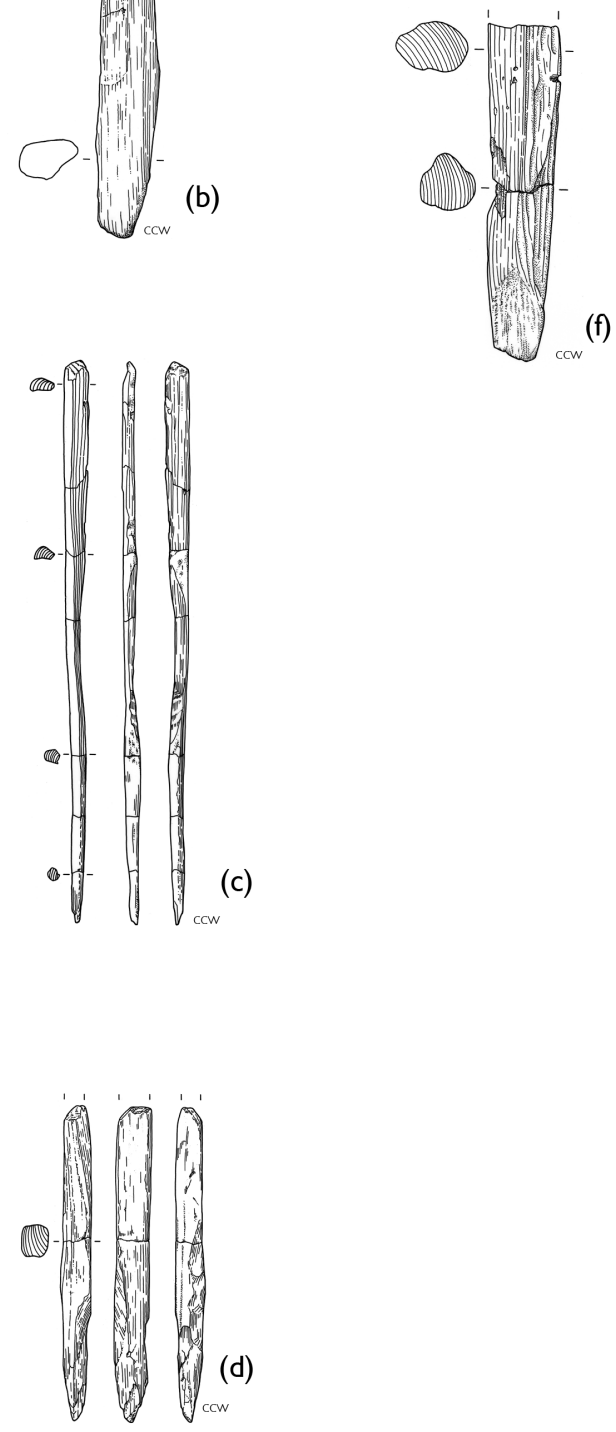

Dowels $0 . \ldots 50 \mathrm{~mm}$

$\begin{array}{llllll}\text { (a) } 113778 & \text { (b) } 110544 & \text { (c) } 1 / 3768 & \text { (d) III3250 (e) III3287 } & \text { (f) II6655 }\end{array}$ 
This was analysed in its entirety with low and high-power magnification. No manufacture or wear traces were identified. The cell structure was still intact. Some very bright PDSM (post-depositional surface modification spots) were noted. The very end of the tip had been broken in antiquity, possibly through use.

$<\mathbf{1 1 3 7 7 8}>$ (Figure 29.20a and 29.21): This is a slender, sub-rectangular, radially split dowel of alder with one end badly degraded and the other end pointed and possibly utilised. There is excavation damage along its length. The dowel measures $855 \mathrm{~mm}$ long and the section is $25 \times 10 \mathrm{~mm}$. No original function is suggested for this item. No wear or manufacture traces were identified from microwear analysis but the cell structure was still intact.

$<\mathbf{1 1 6 6 5 5}>$ (Figure 29.20f): This is a radially aligned, sub-oval dowel of aspen. One end is broken and the other end has a clear, concave tool facet where it has been trimmed with a single chop. The surviving length is 137 $\mathrm{mm}$ and the section measures $19 \times 28 \mathrm{~mm}$. No original function is suggested for this item.

\section{Pegs and wedges}

A wedge of willow, $<116520>$, was identified during the excavations. It was recovered from reed peat (312) in Clark's area (Table 29.11). Another piece, also willow, was identified as a possible peg or wedge $<103149>$ and was recovered from reed peat (312) in the detrital wood scatter (Figure 29.22).

$<\mathbf{1 0 3 1 4 9 >}$ (Figure 29.22): This is the buckled tip of a peg or wedge measuring $148 \times 22 \times 18 \mathrm{~mm}$. It is split across the grain and buckled at one end through use.

$<\mathbf{1 1 6 5 2 0}>$ (Figure 29.22): This is a piece of woodworking debris which has been tangentially split out of a larger timber. It is $164 \mathrm{~mm}$ long with a triangular cross section and the split fades to a wedge shape. The thicker end measures $40 \times 29 \mathrm{~mm}$ and has been chopped almost flat with a cut across the grain. There are slight signs of 'bruising' on the surface of this end, implying that the piece has been hammered. The thin end of the wedge is

\begin{tabular}{|r|r|l|l|l|l|l|}
\hline Number & Context & Area & Type & Conversion & Description & Identification \\
\hline 103149 & 312 & detrital wood scatter & utilised debris & cross grain & Debris with buckled tip & willow \\
\hline 116520 & 312 & Clark's area & utilised debris & tangential & Wedge with bruising to top & willow \\
\hline
\end{tabular}

Table 29.11: Material interpreted as pegs and wedges.

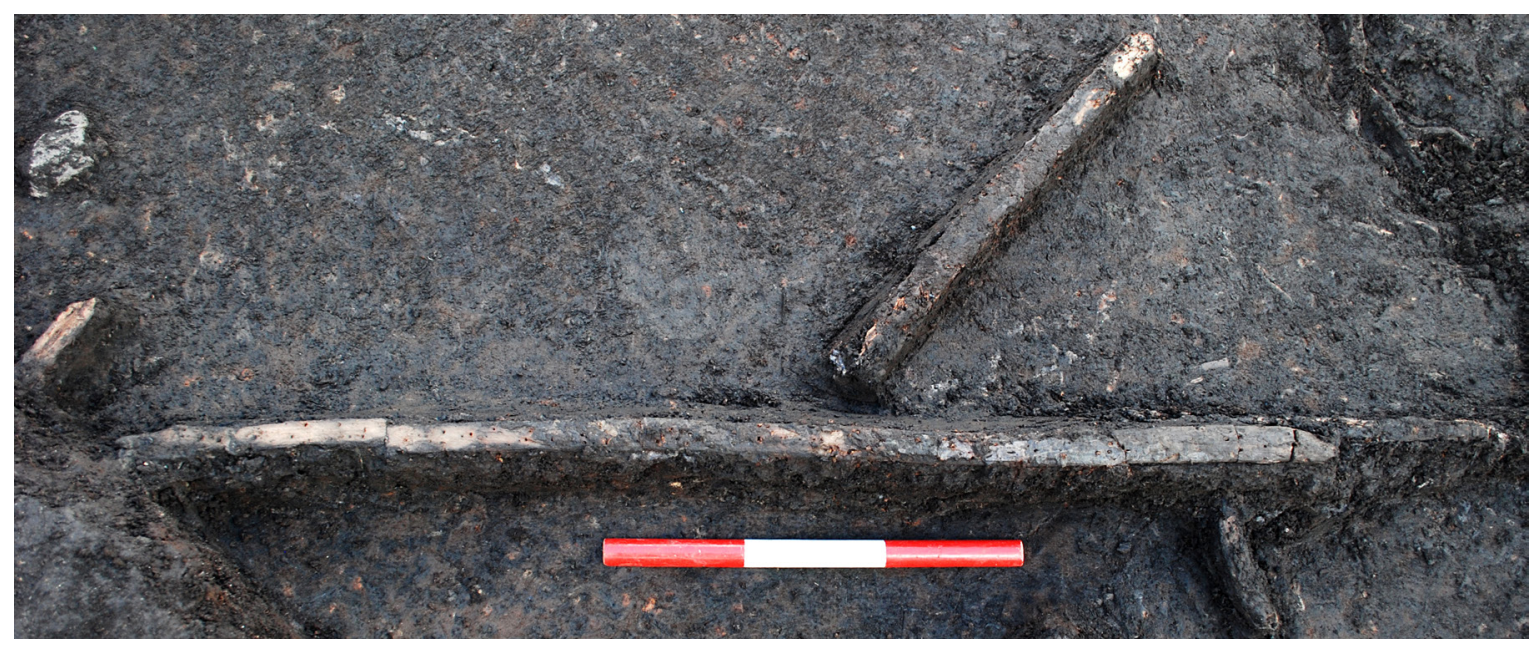

Figure 29.21: Dowel <113778> in situ (Copyright Star Carr Project, CC BY-NC 4.0). 


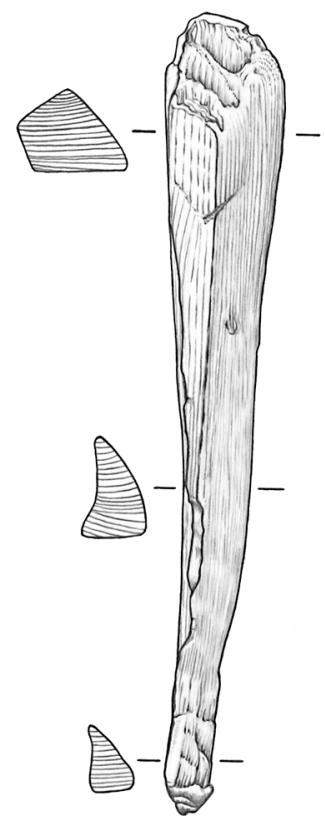

103149
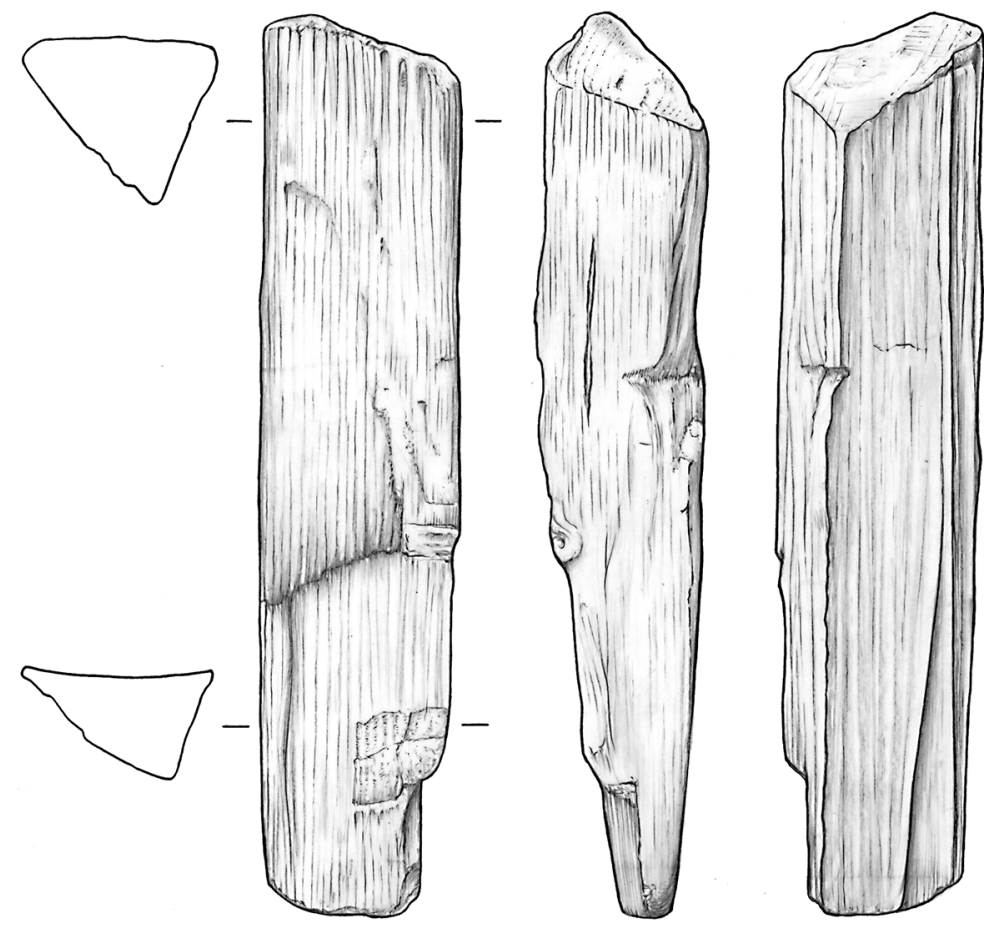

116520

0 $50 \mathrm{~mm}$

Figure 29.22: Pegs and wedges (Copyright Chloe Watson, CC BY-NC 4.0).

\begin{tabular}{|r|r|l|l|l|}
\hline Number & Context & Area & Description & Identification \\
\hline 109586 & 317 & detrital wood scatter & $\begin{array}{l}\text { Light faceting along length, one end rounded, one square, } \\
\text { small spherical hole }\end{array}$ & aspen \\
\hline 115952 & 312 & Clark's area & Item with hole, worn face and broken end & willow \\
\hline
\end{tabular}

Table 29.12: Material interpreted as roundwood with holes.

$29 \mathrm{~mm}$ wide and $2 \mathrm{~mm}$ thick. The piece is slightly buckled along most of its length, including the thin end where the grain is distinctly distorted. Given the item's shape and the bruising to the top, it seems highly likely that this item has been used as a wedge to split wood.

\section{Roundwood with holes}

Only two pieces of wood with deliberate, anthropogenic holes were encountered during the excavations. Both are roundwood and were recovered from the detrital wood scatter and Clark's area (Table 29.12; Figure 29.23).

<109586> (Figure 29.23): This is aspen roundwood measuring $172 \mathrm{~mm}$ long with a compressed diameter of $12 / 20 \mathrm{~mm}$. It has been crushed in the middle during excavation. There is slight faceting on the ends and along its length. One end is rounded and the other square. There is a small spherical hole that does not pass all the way through the object, on what was the underside, towards one end. No original function is suggested for this item. No wear or manufacture traces were identified from microwear analysis but the cell structure was intact. 

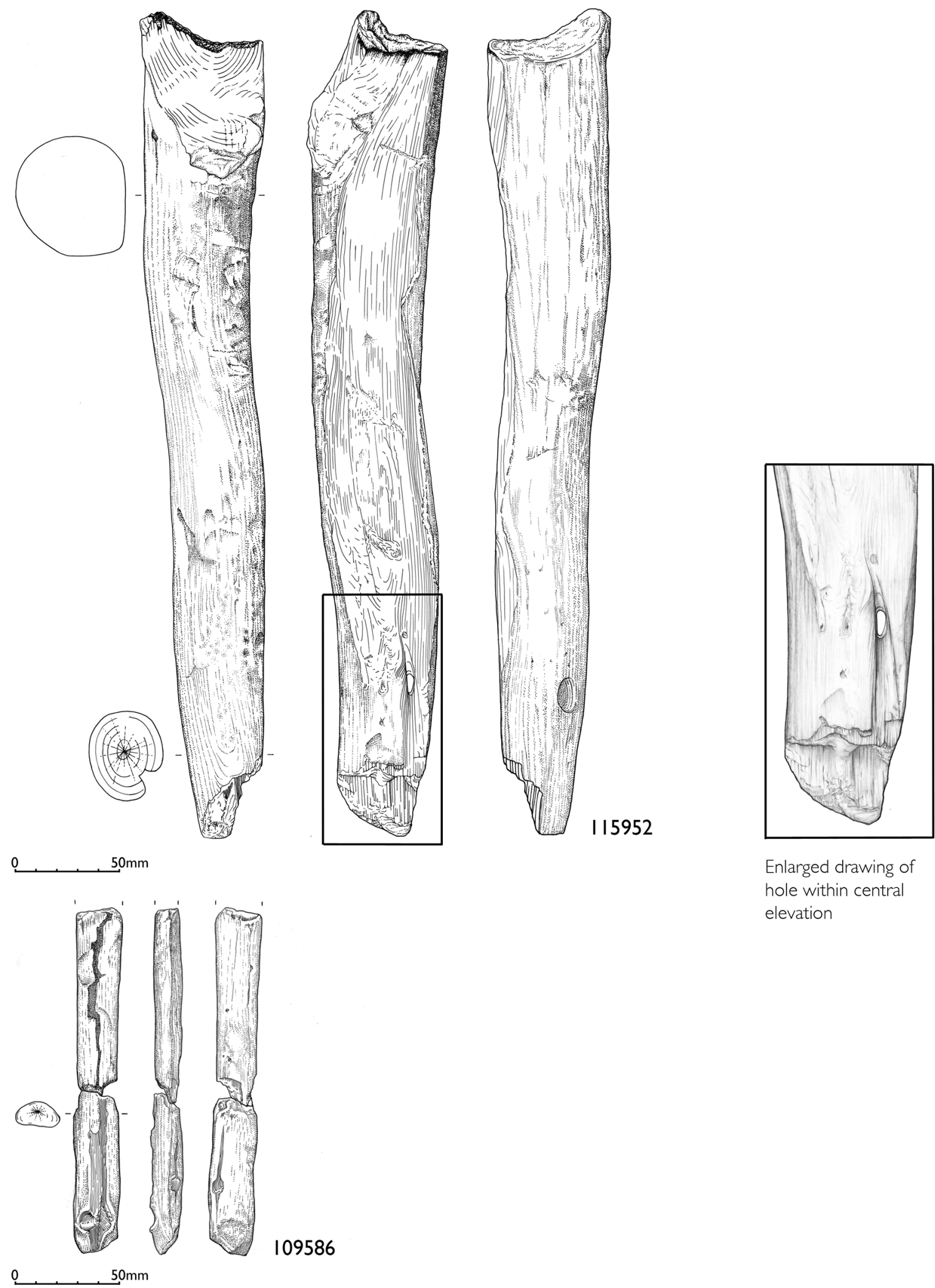

Enlarged drawing of hole within central elevation 


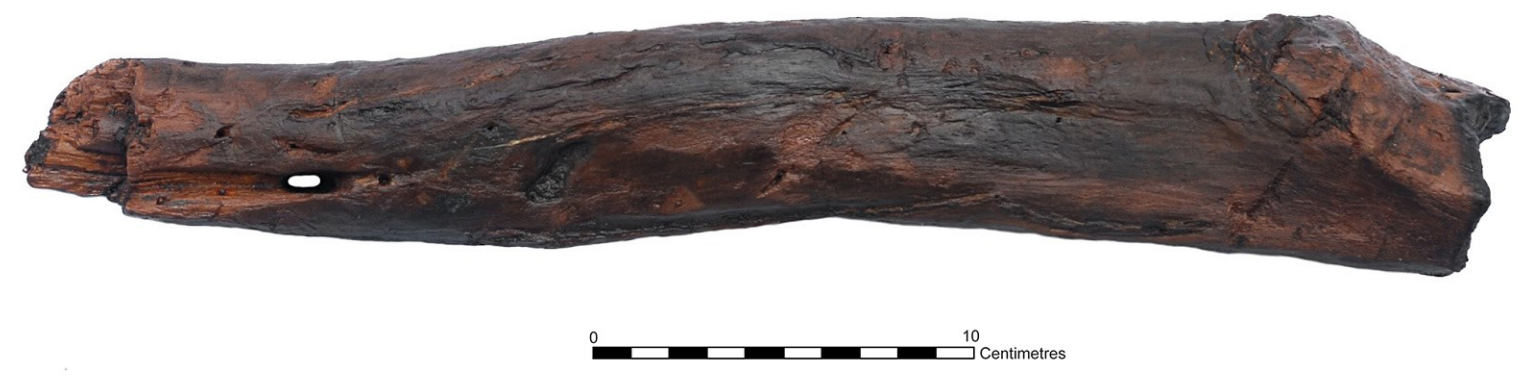

Figure 29.24: Roundwood with hole <115952> (Copyright Michael Bamforth, CC BY-NC 4.0).

\begin{tabular}{|c|r|l|l|l|l|l|}
\hline Number & Context & Area & Type & Conversion & Description & Identification \\
\hline 098878 & 317 & $\begin{array}{l}\text { western } \\
\text { platform }\end{array}$ & utilised debris & $\begin{array}{l}\text { rad } 1 / 4 / \text { tan } \\
\text { outer }\end{array}$ & $\begin{array}{l}\text { Side branch that has been } \\
\text { torn from a tree }\end{array}$ & willow \\
\hline 107784 & 317 & $\begin{array}{l}\text { detrital wood } \\
\text { scatter }\end{array}$ & $\begin{array}{l}\text { utilised } \\
\text { roundwood }\end{array}$ & none & $\begin{array}{l}\text { Trimmed at base and } \\
\text { charred at top }\end{array}$ & willow \\
\hline 110020 & 312 & $\begin{array}{l}\text { western } \\
\text { platform }\end{array}$ & utilised debris & rad & Split and trimmed to point & aspen \\
\hline 116654 & 312 & Clark's area & $\begin{array}{l}\text { utilised } \\
\text { roundwood }\end{array}$ & none & Possibly trimmed to point & aspen \\
\hline
\end{tabular}

Table 29.13: Material interpreted as stakes ( $\mathrm{rad}=$ radial, $\tan =$ tangential).

$<\mathbf{1 1 5 9 5 2}>$ (Figures 29.23 and 29.24): This is heavily shaped and partially charred willow roundwood with a hole in one end. It is one of the few pieces which could have been jointed. A joint is simply a means of articulation with another component to make a structure or more complex artefact. This piece is $398 \mathrm{~mm}$ long with the section measuring $62 \times 59 \mathrm{~mm}$ maximum and $43 \times 37 \mathrm{~mm}$ minimum. It is naturally curved, suggesting it originated as a coppice stem. One end is trimmed and lightly charred. The other was broken in antiquity and has a hole $10 \times 4.5 \mathrm{~mm}$ which passes through the grain at an angle, emerging onto a surface which is flattened and appears worn. On this side the hole measures $12 \times 4 \mathrm{~mm}$. The wood is torn from the hole to the broken end and a parallel-sided piece is missing. This damage suggests that the hole was drilled or cut from the upper side, tearing this piece and pushing it away from the surface. There is no sign of the classic 'hour-glass' shape which indicates drilling from two sides and the wood is not well enough preserved to show internal working or wear. Given the hole and the wear to one face, it is tentatively suggested that this item may have formed one half of a wooden frame.

\section{Stakes}

The rarity of vertically set stakes at Star Carr has led to their categorisation as artefacts. Five vertically set pieces, all interpreted as stakes, were recorded from around the site (Table 29.13; Figure 29.25). The tops of two of the stakes had totally decayed. Of the five stakes, three are roundwood and two are utilised debris. One was recovered from the detrital wood scatter, two from the western platform and two from Clark's area.

Figure 29.23 (page 398): Roundwood with holes (Copyright Chloe Watson, CC BY-NC 4.0). 


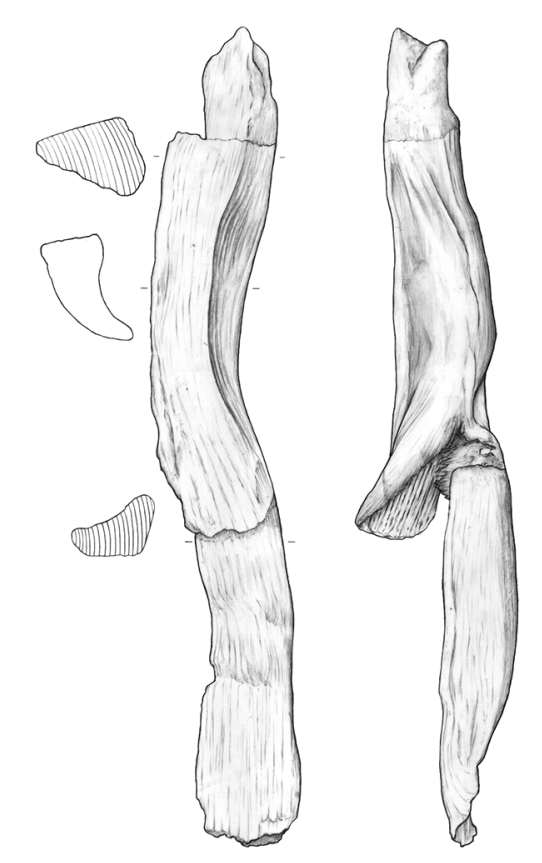

(a)

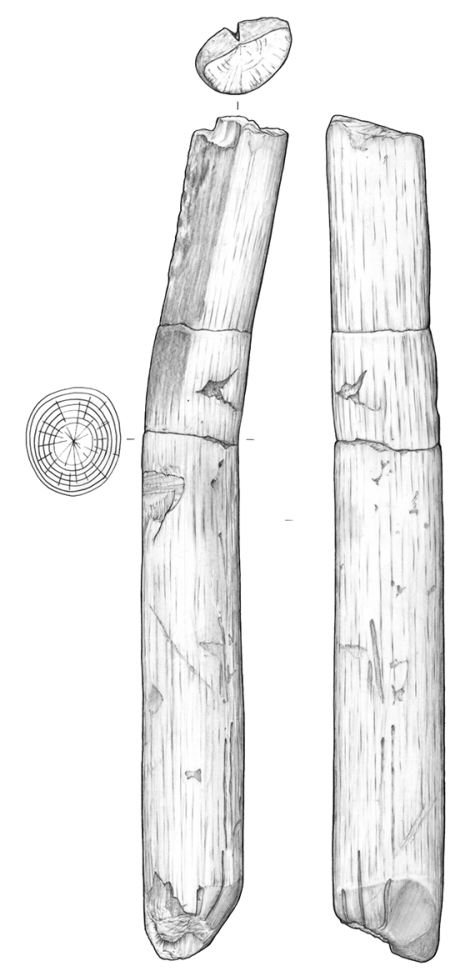

(c)

(d)

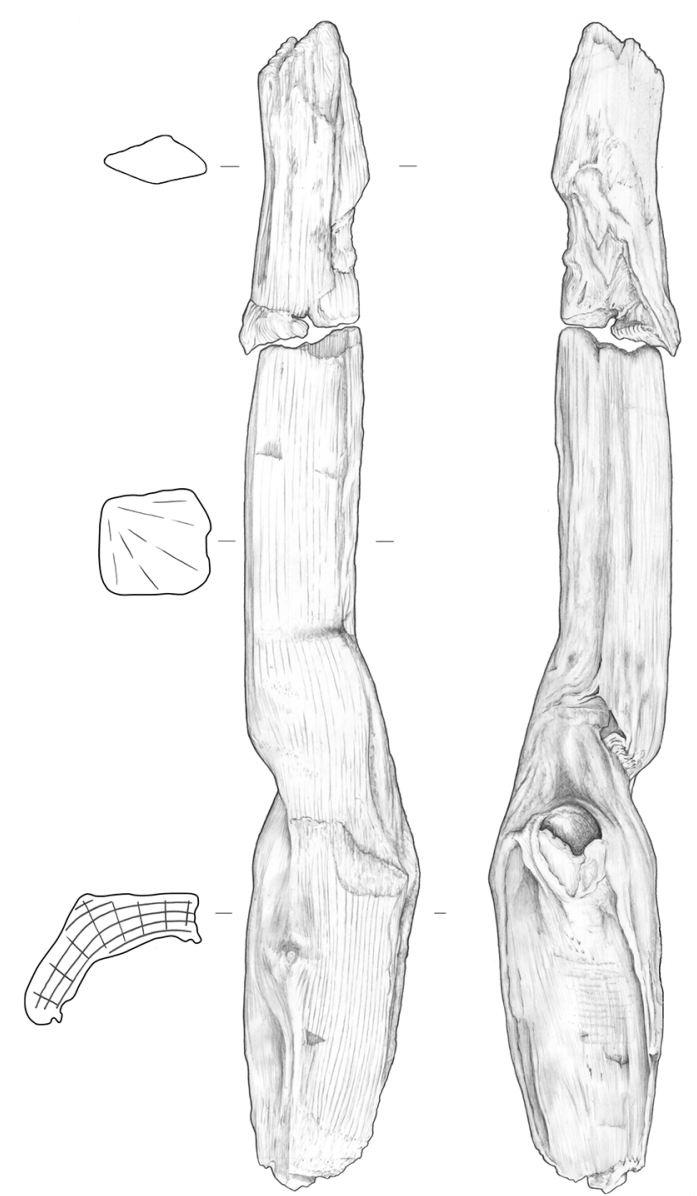

(b)

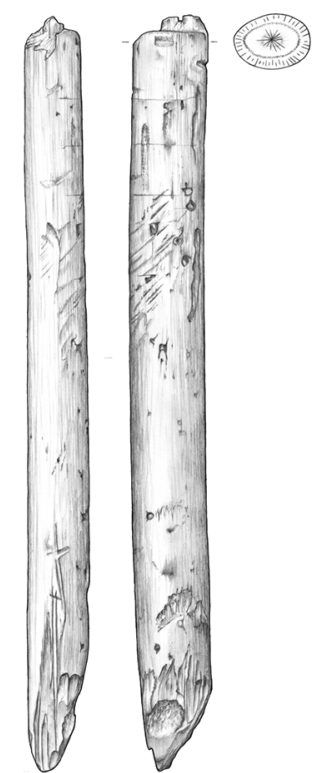

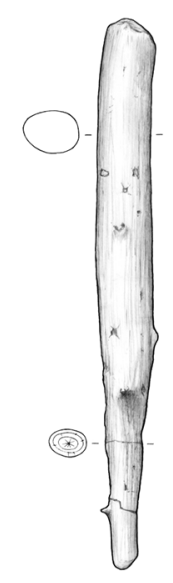

(e)

$\begin{array}{lllll}\text { (a) } 110020 & \text { (b) } 98878 & \text { (c) } 107784 & \text { (d) } 116678 & \text { (e) } 116654\end{array}$ 
$<\mathbf{9 8 8 7 8}>$ (Figure 29.25b): This is a piece of modified and utilised debris $470 \mathrm{~mm}$ long. The top section is a radially quarter split side branch of willow that measures $35 \times 40 \mathrm{~mm}$. The side branch has been torn from the tree and the tear carries through to form the point. At this point it measures $21 \times 51 \mathrm{~mm}$. The top is damaged, possibly by hammering and the tip was damaged when it hit a stone.

$<\mathbf{1 0 7 7 8 4}>$ (Figure 29.25c): This is willow roundwood which is worked at both ends, indicating that it is complete with a total length of $325 \mathrm{~mm}$ and maximum diameter of $45 \mathrm{~mm}$. The tip is trimmed bluntly from several directions. The top end is charred but it features a sharp 'step', which may be a horizontal chop.

$<\mathbf{1 1 0 0 2 0}>$ (Figure 29.25a): This is a piece of radially split aspen timber debris found set vertically. It is $313 \mathrm{~mm}$ long with a maximum breadth of $52 \mathrm{~mm}$ and width of $31 \mathrm{~mm}$. The tip is trimmed in one direction, possibly utilising a split surface which fades towards the end. It has been damaged by vertical compression so that it has broken in two. The top end has deteriorated.

$<\mathbf{1 1 6 6 5 4}>$ (Figure 29.25e): This is a short length of aspen roundwood $185 \mathrm{~mm}$ long. The diameter is slightly distorted at $16 / 19 \mathrm{~mm}$. One end is pointed and possibly shows light faceting. The other end is degraded.

$<\mathbf{1 1 6 6 7 8}>$ (Figure 29.25d): This is another piece of roundwood which appears to have both ends intact, showing that it was $284 \mathrm{~mm}$ long. It is a straight piece of willow roundwood, with no side branches and a slight curve at one end, which suggests it could have been a coppice stem. The top looks as if it may originally have been chopped and torn but the tear has been truncated close to the end. There is slight faceting where the tip has been trimmed. There are also small diagonal striations near the top, which could be from taphonomic processes, wear or use, but which look almost as if something had been wrapped tightly around it.

\section{Vessels and containers}

Two pieces, $<115316>$ and $<115317>$, possessed the characteristics of a carved vessel or container (Figure 29.26 and 29.27). It was not clear at first whether they represented two different vessels or whether they were two parts of the same vessel which had become separated in the ground: they were found $2 \mathrm{~m}$ apart in reed peat (312) in Clark's area. However, they are now thought to be parts of the same artefact, a platter modified from a naturally shaped piece of willow.

Unfortunately, the pieces had been damaged in antiquity and then further damaged by roots and during excavation. The end of the 'dish' <115317> was broken in antiquity. The end of the handle, a dowel worked down from a radial quarter split, is also broken, probably in antiquity. It is difficult to measure accurately because of the damage and because part of it is missing. The total length is approximately $500 \mathrm{~mm}$ and it is $235 \mathrm{~mm}$ across at the widest point. The thickness of the wood varies but is generally around $25 \mathrm{~mm}$. The 'dish' is approximately $50 \mathrm{~mm}$ deep and there is possible charring on the handle, which is $40 \mathrm{~mm}$ wide.

Although it is definitely carved and modified, it is probably based on a natural shape, which has been carved to exaggerate the existing form. Such natural curvature can be found around a knot, where the increasing circumference of a tree grows over a side branch, or some natural damage. The branch may already be dead, but if not, it simply continues growing, but at a different rate to the trunk. Tension wood forms on the upper side, and reaction wood on the lower. This process would produce the distinctive lenticular shape seen in the vessel and the bulge which is the 'bowl'. If the side branch was dead when the process began, it would form a classic 'knot' which would be a weakness. There is no sign of a knot in this piece. If the side branch continued to grow, even if only for a while, it would be less weak and easier to shape. The growth of trees could be manipulated to produce wood of useful shapes (see Figure 29.28).

Figure 29.25 (page 400): Stakes (Copyright Chloe Watson, CC BY-NC 4.0). 


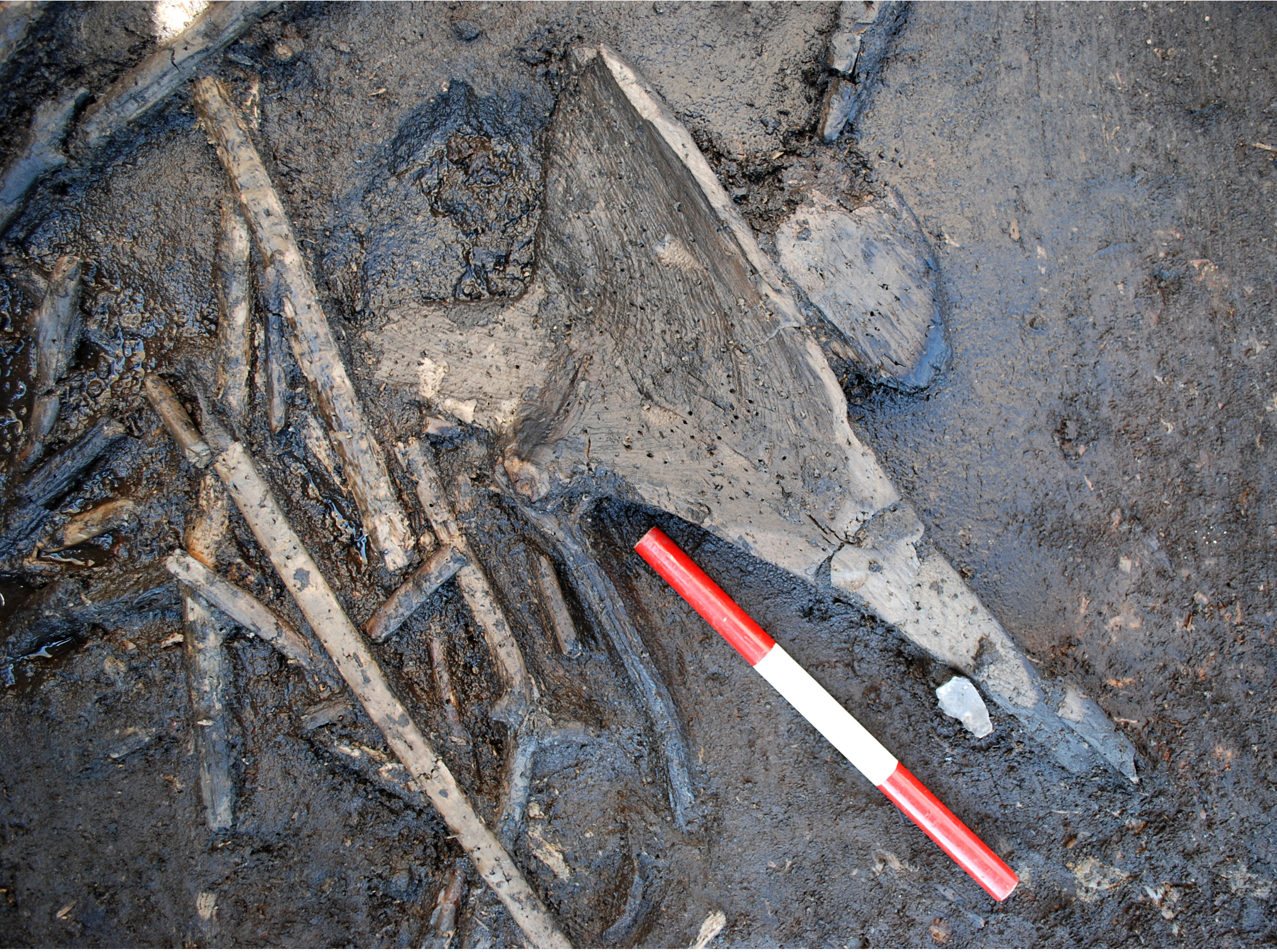

Figure 29.26: Platter $<115317>$ in situ (note that the piece of wood next to the platter was a piece of debris that was not part of the platter) (Copyright Star Carr Project, CC BY-NC 4.0).

\section{Withies}

Only one withy <94048> was found, but it had been carefully made from two twisted and plied coppice stems of willow (Figure 29.29). It was recovered from reed peat (312) in the brushwood. It is formed out of two strands of small-diameter roundwood and one of the stems still had the heel of a coppice attached. Both pieces have slightly compressed diameters: $15 / 5 \mathrm{~mm}$ and 10/5 $\mathrm{mm}$. They are respectively $222 \mathrm{~mm}$ and $291 \mathrm{~mm}$ long. Both stems have been twisted in an anticlockwise direction. They then cross each other in a way which suggests that they may subsequently have been plied in a clockwise direction. However, the twisting of the individual stems to increase flexibility weakened the fibres and added to the level of degradation, making it very frail when excavated. It was recorded and illustrated in the ground (by Hayley Saul) and did not survive lifting.

This technique of twisting stems in one direction (in this case an ' $S$ ' twist) before plying them together in the opposite ('Z') direction has been recorded elsewhere, but much later in prehistory (Brennand and Taylor 2003). The presence of the coppice heel here may also be of significance, as it is needed to hold the stems securely during twisting: the simplest way to do this is to stand on the enlarged end (Brennand and Taylor $2003,30)$. This is an extremely early example of a withy made using the same technique that was later employed for making rope.

Figure 29.27 (page 403): Platter <115316-7> (Copyright Chloe Watson, CC BY-NC 4.0). 

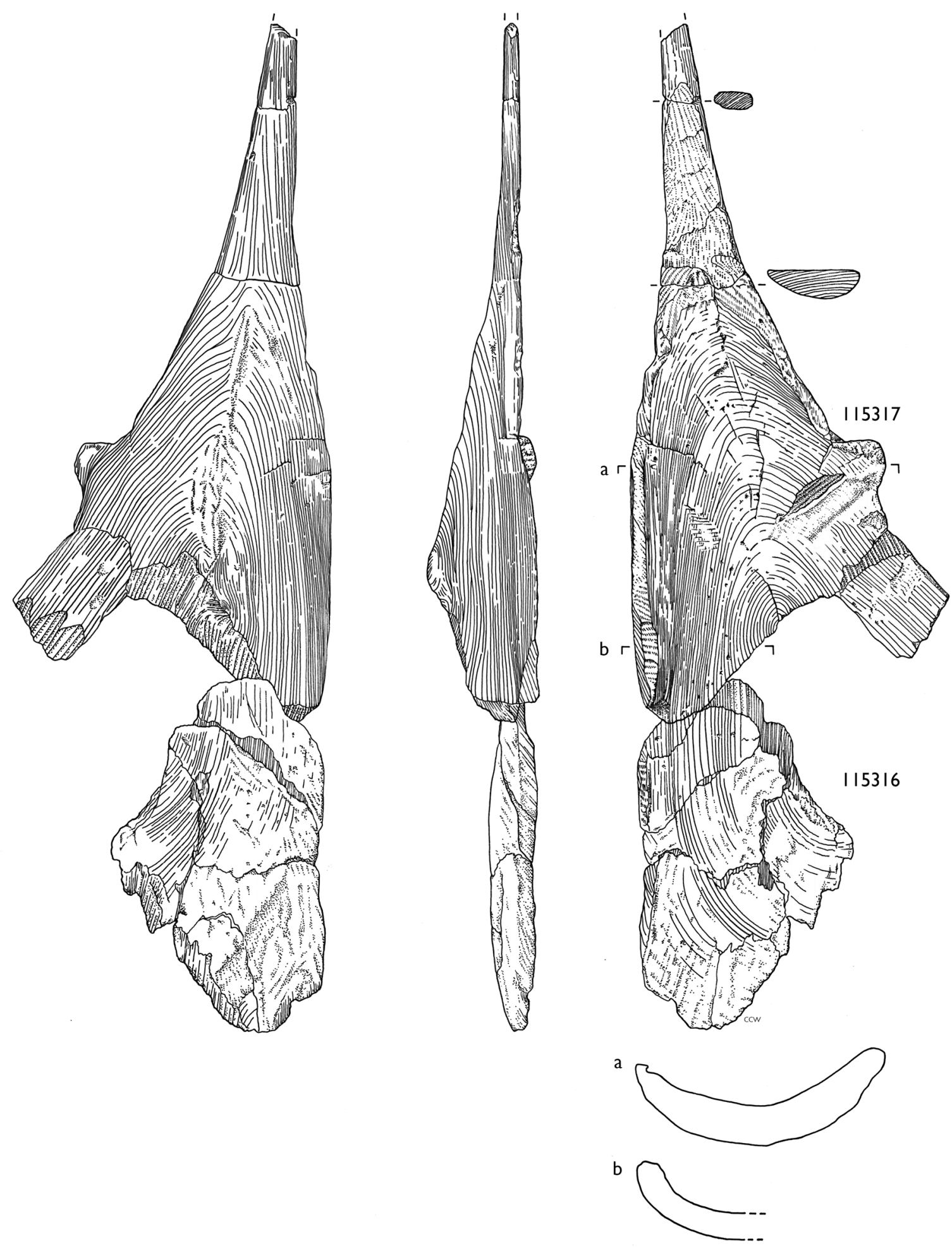


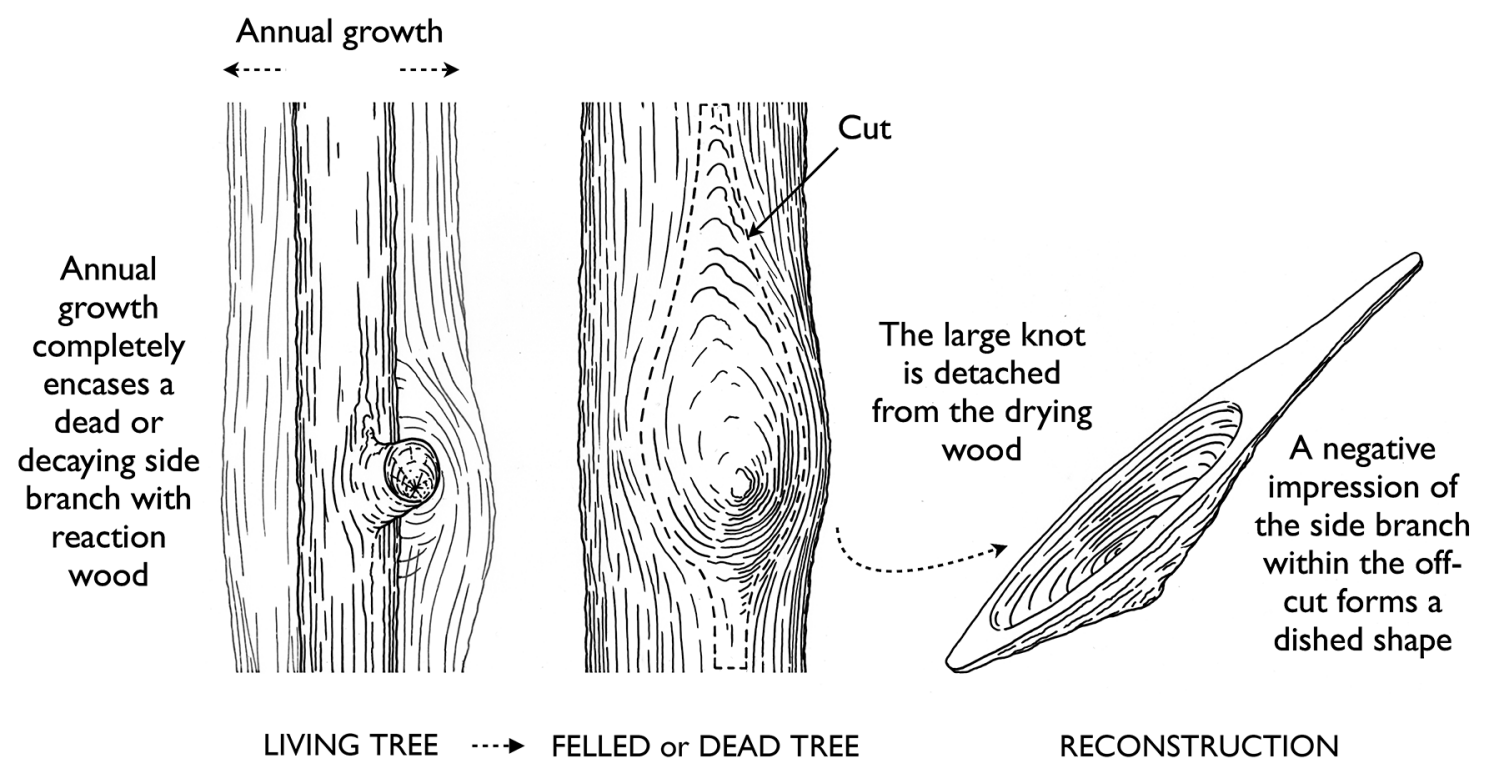

Figure 29.28: Origins of platter $<115316-7>$ (Copyright Chloe Watson, CC BY-NC 4.0).

\section{Examination of Clark's artefacts}

In addition, the paddle and carbonised wood associated with the antler mattock head were examined by MT at the Museum of Archaeology and Ethnology at Downing Street in Cambridge.

The 'mattock handle' (Accession no. 1953.68.4) is a heavily carbonised piece of roundwood and although the wood has opened up along the medullary rays it has survived reasonably well. This effect may have been caused by carbonisation or by drying out through time; the effects of both are roughly the same. Splitting along the medullary ray exaggerates the radial structure of the wood, making it easier to identify as simple, unmodified roundwood with a diameter of $12 \mathrm{~mm}$ and length of $204 \mathrm{~mm}$ (Figure 29.30).

A replica of one of Clark's elk antler mattocks, complete with roundwood haft, was produced by DP in order to test the efficacy of this item as a woodworking tool. It was noted that it functioned efficiently as a woodworking adze even with the relatively weak roundwood haft in place (see Figure 29.30).

However, it should be noted that there are problems with assuming that the piece of roundwood found in Clark's mattock is the original handle. Although roundwood might appear to be the most obvious material for hafts and handles, some of the properties associated with dowels make these more desirable. Certainly it appears that by the Bronze Age, roundwood poles are never used as hafts for items such as spear shafts and only specific species are selected. The reasons for this are functional and the same criteria would have applied in the Mesolithic. Good handles and hafts for tools and weapons will affect efficiency and ease of use. A roundwood pole has bark, sapwood, heartwood and pith. These four components all have different properties. Bark is designed to protect the cambium, which is directly below it, and which is the part of the tree that lays down new wood cells. The cambium and newly created wood (sapwood) is designed to carry sap (nutrients) around the tree. In most species it is soft, flexible and not very durable. The heartwood contains no living cells, is harder, less flexible and more durable than the sapwood. The pith is at the very centre of the tree trunk or branch. It is the point from which the tree begins to grow, with the first growth ring laid concentrically around it. However, a dowel, because it is carved down from a section of a trunk or branch need not, and usually does not, have the same four components. Dowels are usually carved entirely from heartwood, and occasionally sapwood, without bark or pith present.

Figure 29.29 (page 405): Withy <94048> (Illustration by Chloe Watson, after Hayley Saul. Copyright Chloe Watson, CC BY-NC 4.0). 


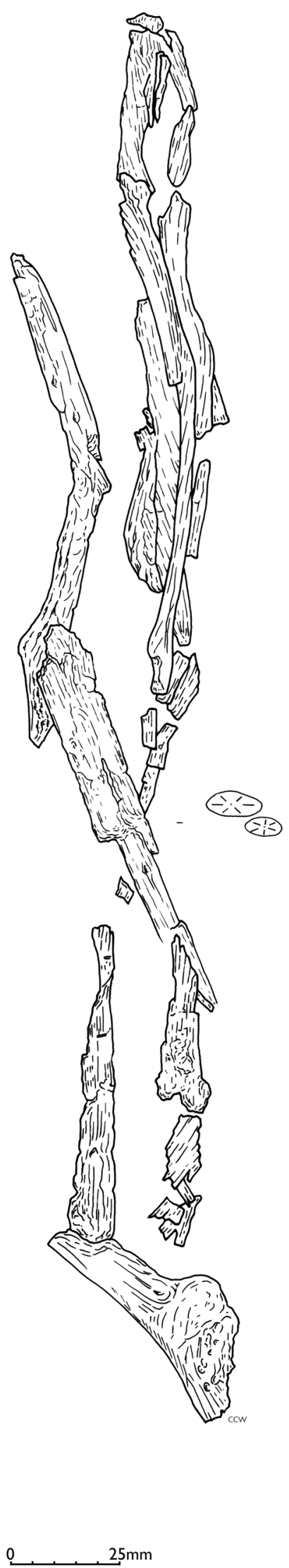



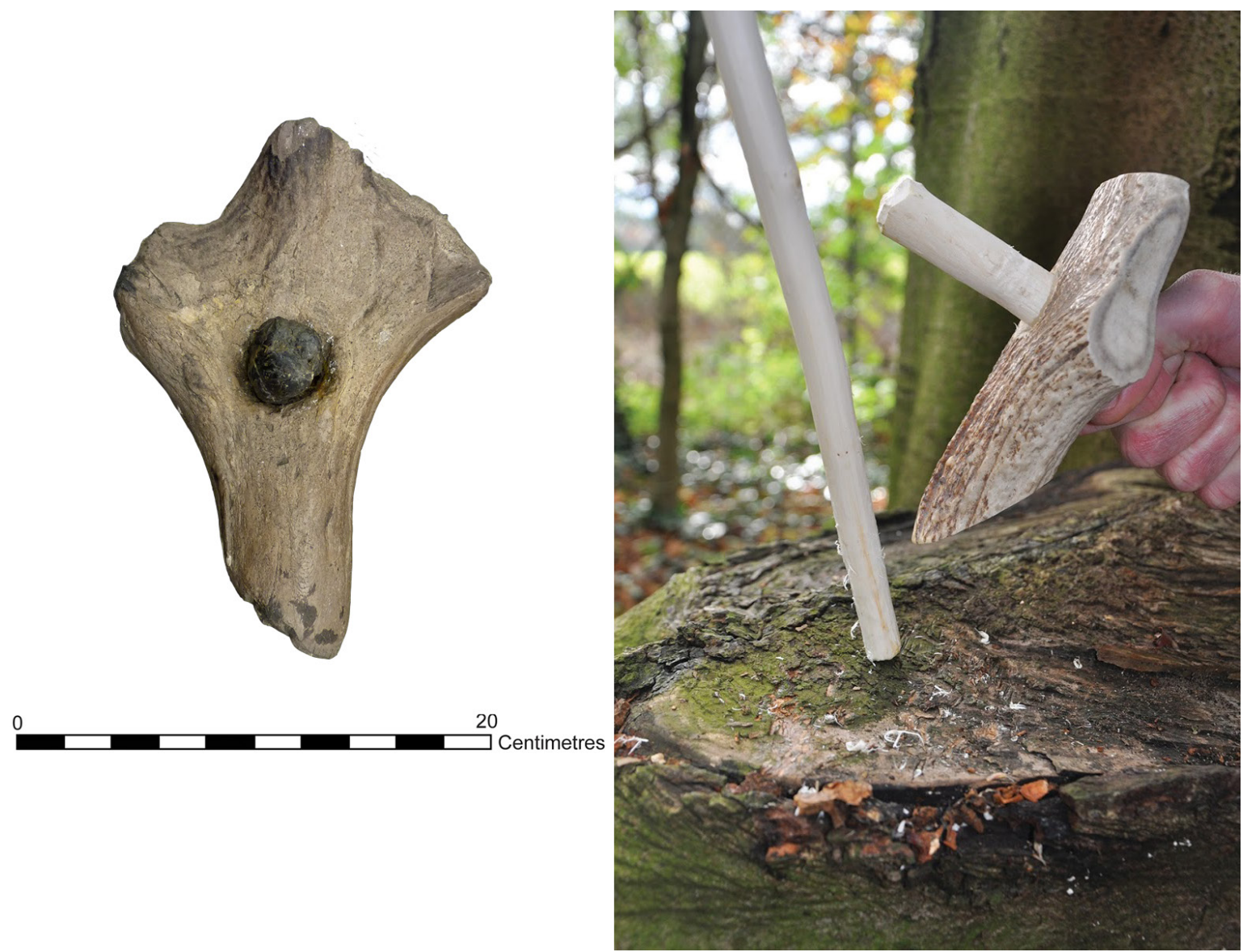

Figure 29.30: (left) Clark's mattock with charred roundwood; (right) a replica elk mattock with a roundwood haft is used to trim a piece of roundwood (Left photograph copyright Nicky Milner, CC BY-NC 4.0, reproduced by the permission of the University of Cambridge Museum of Archaeology \& Anthropology. Accession no. 1953.68.4. Right photograph copyright Aimée Little, CC BY-NC 4.0).

If roundwood is to be used as a shaft or spear it will need considerable preparation. First of all it is quite difficult to find totally straight poles, of any size, growing naturally. Even when a species such as willow is coppiced there still tends to be a curve at the bottom end of the stem where it attaches to the tree. The bark would not normally be left on roundwood which is to be utilised. It is often rough and may come off unevenly as the wood dries. The outer surface of roundwood may also have small snags (such as nodes) on the surface which would need to be smoothed. At certain times of the year, the sapwood may be wet and sticky and liable to fungal or insect attack. Although it will be very flexible when fresh, it may quickly become brittle as it dries. When a dowel is fashioned, the removal of the bark and sapwood removes these complications. The surface can then be smoothed and the wood will dry evenly throughout, making it less likely to crack. The behaviour of the material will be more predictable. A dowel may be less flexible than roundwood but when cut from a young pole will still have considerable flexibility and is likely to become brittle less rapidly. It will also retain its shock-absorbing qualities, which are important for the hafts and handles of impact tools, such as axes.

There is one scenario in which a roundwood haft may be a superior choice: an antler mattock head is extremely light and portable, and if carried unhafted, a suitable stick could be rapidly sourced and shaped with a flint flake to provide a temporary haft. However, the main reason for suggesting that this is not a handle is that the wood is carbonized but the elk antler mattock is not. This suggests that the wood was not in place when it was charred and it seems very unlikely that a severely weakened and unstable piece of charred wood would have been used as a haft. It is more likely that it was in the hole in the mattock-head for some other 


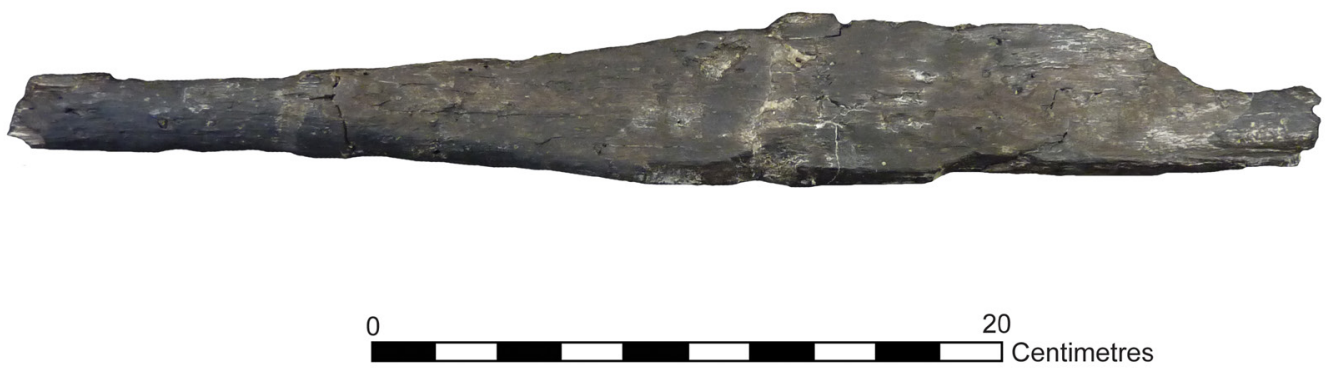

Figure 29.31: Photograph of the paddle (Copyright Nicky Milner, CC BY-NC 4.0, reproduced by the permission of the University of Cambridge Museum of Archaeology \& Anthropology. Accession no. 1995.446).

purpose, or by accident. The oval dowel $<110105>$ described above has a more likely form for the handle of a mattock to take, measuring $34 \times 29 \mathrm{~mm}$. Unfortunately, not enough of the length survives to be sure.

The paddle (Accession no. 1995.446) is in very good condition given its age and the length of time it has been in storage. The detail is not now as sharp as it is in the published drawing and photograph, but it is quite clear that the paddle was carved from a tangentially split plank (Figure 29.31). The paddle was identified by Donald Walker as birch (Clark 1954, figure 77, plate xxi). There are traces of a flange surviving along one edge of the paddle blade. Careful examination shows that this is not post-depositional distortion as the curve of the blade crosses the grain of the wood. Its dimensions are L. $422 \times 180 \times 30 \mathrm{~mm}$. Although it has a slender blade, it may have been used as a paddle, as similar examples are known from around the world. However, there are also examples of paddle-shaped objects known from later British Prehistory that are interpreted as tools for processing plant or animal fibres (Earwood 1993).

\section{Discussion}

\section{Tree species and technology}

Several different tree species have been used to produce wooden artefacts at Star Carr. The most frequent is willow, with moderate aspen, alder and occasional birch, alder buckthorn and elder (Figure 29.32). The wood from each of these trees has different characteristics. Even the wood of poplar and willow, which are often indistinguishable microscopically, do not share the same characteristics when worked or used. The majority of these species have been identified in the wider wood assemblage, the exception to this being alder, alder buckthorn and elder.

Willow seems to be the favoured wood for working into artefacts at Star Carr (Figure 29.32). Although it shares many of the properties of aspen, it has the advantage of coppicing well and regrowth is rapid. This means that it is possible to generate large amounts of small- to medium-sized pieces of wood of straight grain and good quality. Like aspen, it burns well if completely dry and is nearly smokeless. However, once the wood is dry, it rapidly becomes brittle and snaps easily (Edlin 1973, chapter xvi). The flexibility of the wood when fresh would be a useful property in a tool like a digging stick, but this flexibility would soon be lost.

Aspen trees do not coppice well, as they do not always sucker reliably; however, they do respond quite well to pollarding. The stems from pollarded aspen are not usually as long, straight and even as they are with other trees, such as willow. The fact that it does not coppice reliably probably explains why aspen was generally used in the form of large, unmodified trunks in the Star Carr platform. It is not a good fuel wood and only 

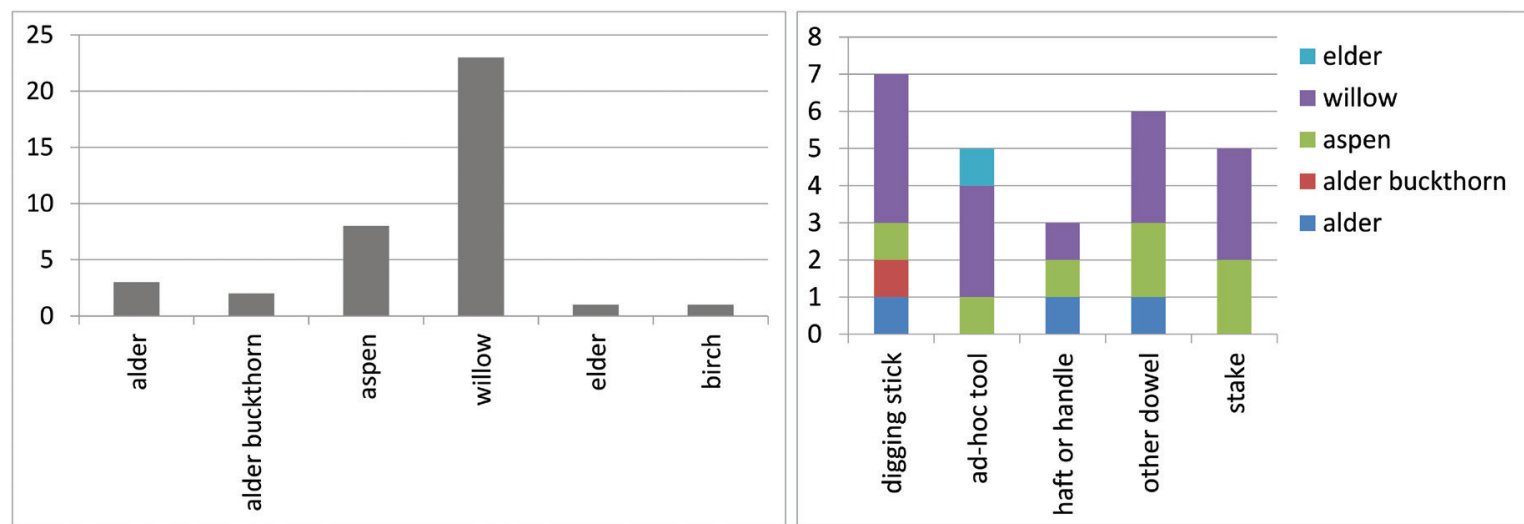

Figure 29.32: (left) Frequency of tree species used to produce wooden artefacts; (right) frequency of wood types used for the main categories of tools (Copyright Star Carr Project, CC BY-NC 4.0).

burns when it is well dried, possibly after a year or more. The wood is very soft and not durable outside, but is surprisingly resistant to wear and splitting. Large trees, which often develop a pronounced curve when growing in windy places, have been used for the timber frame in medieval cruck buildings, such as barns (Brunskill 1985, 28-9). This is an example of exploiting natural shapes and forms in woodworking: the curve of the trunk is very strong. As long as it remains dry, aspen wood will resist rot. A heart-shaped paddle found in Denmark and dated to the early Ertebølle period (in the mid-5th millenium cal BC) was identified as aspen (Myrhøj and Willemoes 1997, 164).

Birch is generally an ornamental tree in modern Britain but it was very important in the past and indeed still is in Scandinavia and Russia. Birch wood occurs in a number of contexts at Star Carr, generally as roundwood but notably the paddle from Clark's excavations is the only wooden artefact made from birch. Birch cannot be coppiced as it does not sucker. It rots quickly when wet but is very strong if kept dry and it is an excellent fuel wood and yields good quality charcoal. In a prehistoric context its most important asset is perhaps its bark, which is waterproof. It is readily removed in strips or pieces, is easily worked and can also be sewn. It is rich in resin, which means that it burns with a clear flame. Recently in Scandinavia the wood has been burnt to produce smoke for smoking fish, and beer can be brewed from its sap (Edlin 1973, chapter xvi). At Star Carr it does not appear to have been used extensively for wooden artefacts, but it does occur frequently in the form of birch bark rolls (Chapter 30). Indeed, some species of birch trees produce bark rolls as part of the natural shedding process. Bark can easily be detached from the tree without killing it, especially in the spring and early summer months, because of the heavy flow of sap. However, the tree may be weakened, sometimes fatally, if the sap continues to flow strongly after the bark has been removed. It is important that sufficient bark is left on the tree to support future growth. Where a tree continues to grow after the removal of a substantial amount of bark it will always carry scars.

Virtually every part of the elder has been exploited for food, drink, dyes and medicines but the wood has seldom been utilised either now or in the past (Usher 1974, 521). When the shrub is young it produces long, straight stems which can be very pithy. The later wood is harder but is seldom produced in pieces of a usable size or shape. The ad-hoc tool here is made from roundwood which probably represents a couple of years of growth, so it would still have been quite flexible.

Alder buckthorn also naturally produces long, straight stems. It has traditionally been used for walking sticks (www.forestry.gov.uk) and so is probably also well suited for making into digging sticks.

Alder is not related to alder buckthorn, although they look very similar. Alder can grow into a large tree and produce substantial timbers. It also regenerates well when coppiced. The wood is soft and easily worked and it is not particularly durable unless it is kept permanently wet (Edlin 1973, chapter xvi).

The artefacts themselves are generally relatively light and slender. With the exception of $<115952>$ there is no evidence for jointing or multiple pieces of wood being joined together. Dowel technology is a central aspect of the artefact assemblage, with a clear preference for radially aligned objects, the exception being bow $<113300>$. 
Alongside the well-planned, executed and finished items sits a group of ad-hoc tools. These are conveniently shaped and proportioned pieces of roundwood and debris that were to hand when a task needed to be performed, and have been used as tools.

The artefacts show an excellent understanding of wood in terms of selection of suitable raw material and its physical properties when used in both converted and unconverted forms. Raw material was carefully selected for the production of artefacts to ensure that the items can be 'brought out' of the raw material and into their finished form. For instance, the complete digging stick $<92465>$ was notable for the use of a natural feature in the shaping of the knob or handle. It was made by cutting a stem from a coppice, but cutting it in such a way that a chunk of the stool was still attached. This chunk, which would have been roughly the right shape to fit into the hand, was then shaped, slightly flattened and smoothed to make the finished handle. The stem had most of the wood split off its length, until it could be shaped into a dowel for the shaft. The stool wood of the handle is slightly gnarled by the coppice-cutting (and subsequent regeneration), which would make it naturally resistant to splitting or breaking. The join between the stool wood and the shaft, previously the join between the stool and stem, is also strong because, when growing, it would flex and absorb the energy of the wind. This stronger wood at the join between the stool wood and stem is used on several pieces: $\langle 116640\rangle$, $<117152>$ and $<117165>$. The similarity is so great that it seems likely these pieces are derived from broken digging sticks.

The artefact which is most remarkable for the use of a natural shape/growth pattern is the carved 'platter' which survived in two pieces: $<115316>$ and $<115317>$. This vessel utilises the natural shape of a knot and its surrounding wood. 'Knots' in wood are formed where a trunk grows faster than a side branch until it completely encases it. If the side branch is long dead and/or decaying when it becomes encased in the living wood, it will not be integral with the wood surrounding it. It may be loose or even disintegrating. Where the remnant of the side branch is sound, the wood may grow round it so that it is securely fixed; this is known as a 'tight knot' (Corkhill 1979, 289-290). Wood grows eccentrically around side-branches and not just because it has to accommodate the form of the branch. Other factors that influence and distort wood growth include the weight of the side branch (gravity) and the way it flexes in windy conditions. The wood thus formed is called 'reaction wood'. In hardwood trees (dicotyledons) this is the wood laid down above the branch, where it is known as 'tension wood'. In tension wood, the growth rings are further apart than normal; this leads to an eccentric growth pattern in which the pith is closer to the lower side (Jane 1970, figure 108). Tension wood may be harder and denser than normal wood, with a more compact structure and more fibres, although the latter are only visible under magnification. It also has a different pattern of drying from normal wood, shrinking much more longitudinally (Jane 1970, 210-222). This would mean that if there was a large knot formed (or forming) in a tree which had been felled or had died, it would be relatively easy to detach, once the dead wood started drying out. The hardness of the reaction wood might make it difficult to work, but in the case of the platter formed from $<115316>$ and $<115317>$, very little extra shaping was necessary. The reaction wood has naturally formed a dished shape. The growth rings are highly visible, which could be due to wear. The earlier wood laid down in growth rings is softer than that laid down later, making it more susceptible to erosion (Jane 1970, figure 139).

The woodworking practices of the Bindibu people of Central Western Australia illustrate the importance of understanding the natural properties of the raw material (Thompson 1964). These people cut parallel-sided tangential planks from standing Mulga trees (a species of acacia) using groove-and-splitting techniques. This, as reported in experiments along similar lines elsewhere in this volume (Chapter 28), is difficult and time consuming. For the Bindibu this was the longest and most skilful part of making a spear thrower. The planks were cut in this particular way because the natural curve of the sapwood formed the basic shape of the artefact (Thompson 1964). The tangential planks produced by this method are not dissimilar to those recorded from the wooden structures and also from which Clark's paddle was manufactured. Another striking example from the Bindibu people is the description of how they excavated long, straight shrub roots, when there were no standing saplings with wood straight enough for making spears.

The wooden artefacts were recovered from five of the spatial analytical groups: brushwood, detrital wood scatter, Clark's area, western platform and other (Figure 29.33). However, it is important to note that although the brushwood has the earliest start date, the wooden artefacts were all recovered from the upper portion, stratigraphically above the western platform. In most areas dowels and utilised roundwood are used most often, though in the western platform only utilised debris has been found in the form of two stakes (Figure 29.34). 


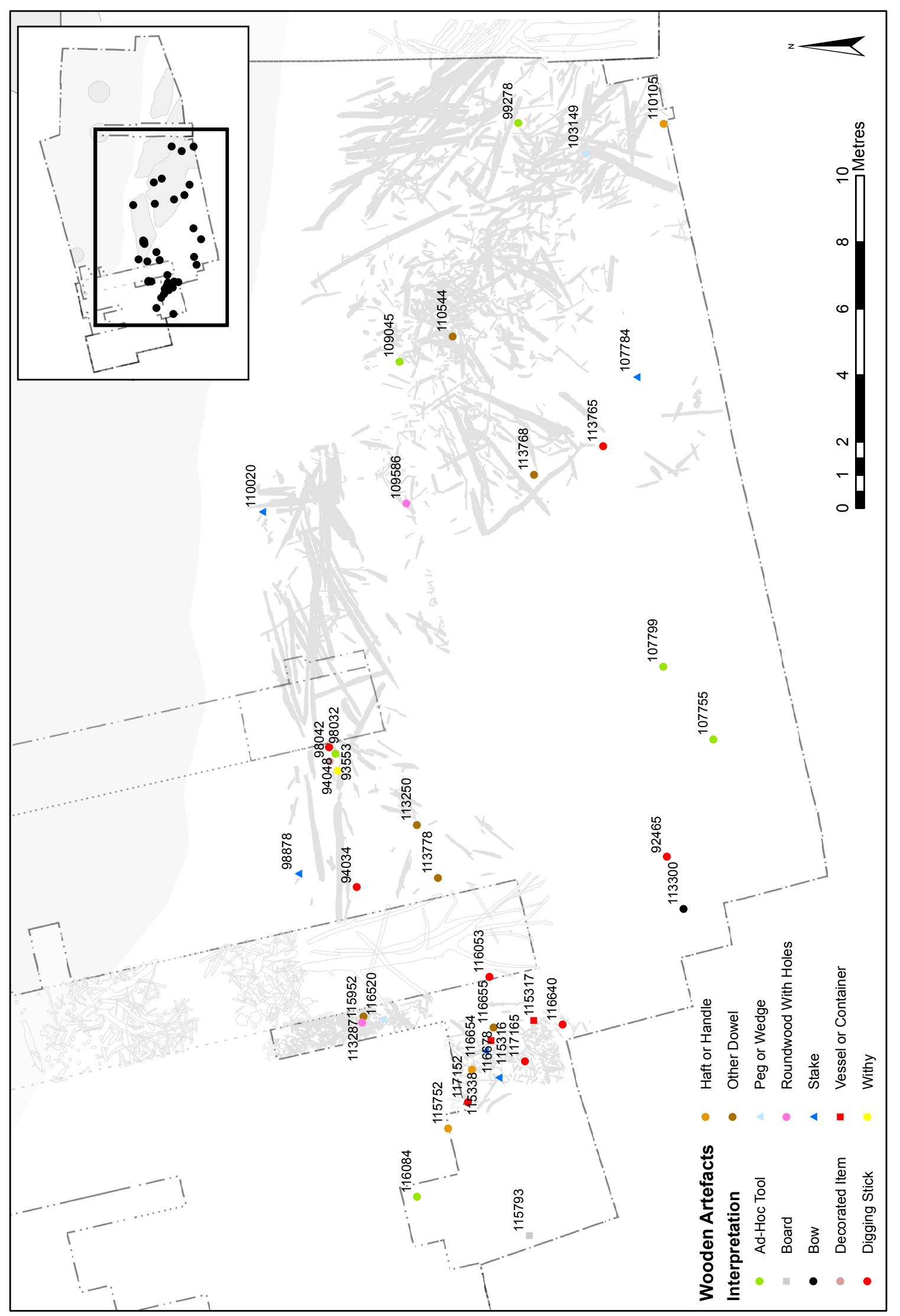

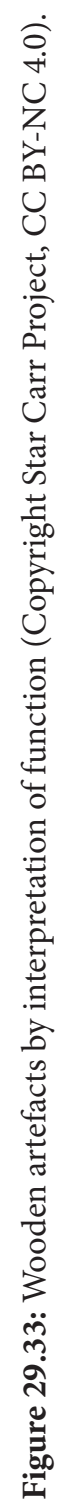




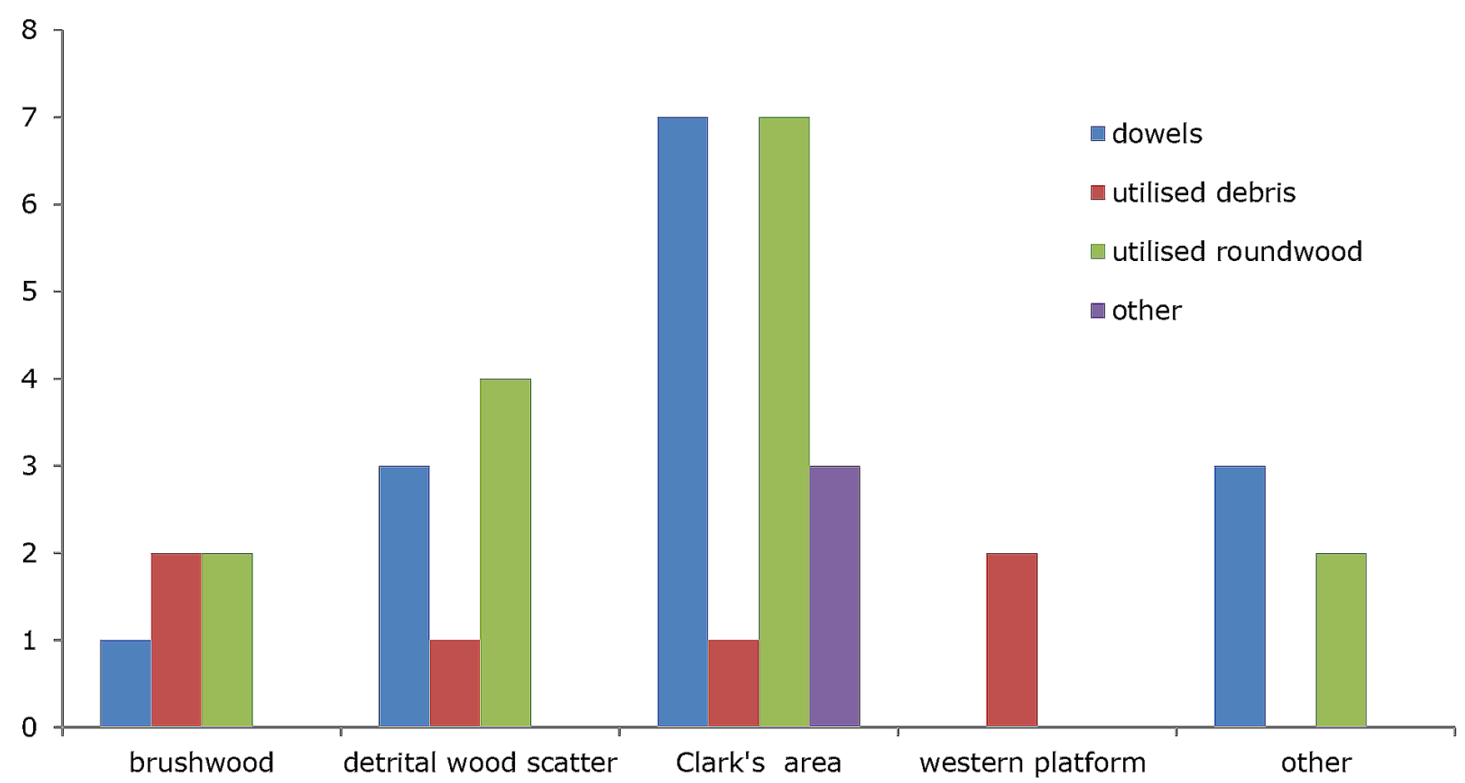

Figure 29.34: Technological groupings by area (Copyright Star Carr Project, CC BY-NC 4.0).

\begin{tabular}{|c|c|c|c|c|c|c|}
\hline & Brushwood & $\begin{array}{l}\text { Detrital wood } \\
\text { scatter }\end{array}$ & Clark's area & $\begin{array}{l}\text { Western } \\
\text { platform }\end{array}$ & Other & Total \\
\hline Ad-hoc tool & 1 & 2 & 1 & & 2 & 6 \\
\hline Board & & & 1 & & & 1 \\
\hline Bow & & & 1 & & & 1 \\
\hline Decorated item & 1 & & & & & 1 \\
\hline Digging stick & 2 & & 5 & & & 7 \\
\hline $\begin{array}{l}\text { Digging stick / haft or } \\
\text { handle }\end{array}$ & & & & & 1 & 1 \\
\hline Haft or handle & & 1 & 2 & & & 3 \\
\hline Other dowels & & 2 & 2 & & 2 & 6 \\
\hline Peg & & 1 & & & & 1 \\
\hline Roundwood with holes & & 1 & 1 & & & 2 \\
\hline Stake & & 1 & 2 & 2 & & 5 \\
\hline Vessel or container & & & 2 & & & 2 \\
\hline Wedge & & & 1 & & & 1 \\
\hline Withy & 1 & & & & & 1 \\
\hline Total & 5 & 8 & 18 & 2 & 5 & 38 \\
\hline
\end{tabular}

Table 29.14: Function by area.

Apart from these items, the platforms are not associated with any other artefacts. In addition, it is only Clark's area which includes the category of 'other'.

There is no clear patterning to the distribution of certain artefact types, such as digging sticks, which appear to occur in a number of areas (Figure 29.33, Table 29.14). A single item, utilised roundwood spindle/toggle, is the only wooden artefact recovered from the latest waterlogged deposit encountered, wood peat (310) in 
'other'. However, by far the greatest frequency and diversity of wooden artefacts were recovered from Clark's area (Table 29.14), a situation mirrored by the osseous artefact assemblage (Chapter 24).

As has been discussed elsewhere in this volume (Chapter 22), the wood at Star Carr has been subjected to a variety of taphonomic processes including shrinkage, compression and movement of the surrounding matrix caused by changing groundwater levels as well as desiccation and mechanical damage from roots. During the many campaigns and seasons of fieldwork, several items have been truncated by previous trenches. Furthermore, due to the extremely fragile nature of the material, some artefacts were damaged during excavation. There is also an unusually high level of ancient damage recorded from the artefact assemblage.

The combination of these factors means that only 10 artefacts are complete: digging stick $<92465\rangle$, ad-hoc tool $<93553>$, decorated woodchip $<98042>$, stake $<98878>$, peg/wedge $<103149>$, stake $<107784>$, roundwood with hole $\langle 109586>$, bow $\langle 113300>$, wedge $<116520\rangle$ and stake $<116678>$. Waterlogged stakes are generally degraded at the top, where they pass through the preservation horizon for waterlogged wood, so it is surprising that three of the five encountered have their tops intact.

A further 18 artefacts are incomplete due to truncation, modern damage or degradation: digging stick $<94034\rangle$, withy $\langle 94048\rangle$, digging stick $\langle 98032\rangle$, ad-hoc tool $\langle 99278\rangle$, ad-hoc tool $\langle 107755\rangle$, ad-hoc tool $\langle 107799\rangle$, ad-hoc tool $\langle 109045\rangle$, stake $\langle 110020\rangle$, haft or handle $\langle 110105\rangle$, dowel $\langle 110544\rangle$, dowel $<113250>$, dowel $<113287>$, digging stick/haft or handle $<113765>$, dowel $<113768>$, dowel $<113778>$, ad-hoc tool $<116084>$, stake $<116654>$ and dowel $<116655>$.

The other 10 artefacts are incomplete due to ancient damage: vessel/container $<115316-7>$, haft or handle $<115338>$, haft or handle $<115752>$, board $<115793>$, roundwood with hole $<115952>$, digging stick $<116053>$, digging stick $<116640>$, digging stick $<117152>$, digging stick $<117165>$. Half of the eight possible digging sticks were broken in antiquity, as were two of the three possible hafts or handles. This is an unusually high percentage, perhaps suggesting that for the most part, these items were discarded because they had broken through use or perhaps had been deliberately broken to decommission the objects.

The 10 artefacts which have been broken in antiquity make up a much higher prevalence (26\%) than for the waterlogged wood assemblage as a whole (1.8\%). Interestingly, these items are all located in Clark's area (Figure 29.35) which is similar to the patterning of barbed points broken in antiquity which also occur mainly in Clark's area (Chapter 25). There are also two interesting cases of ancient damage: digging stick $<117165>$ was broken in two pieces in antiquity, which were close to each other in the ground; the vessel/container $<115316-7>$ was also broken into two pieces, hinting perhaps at trample or of possible structured deposition.

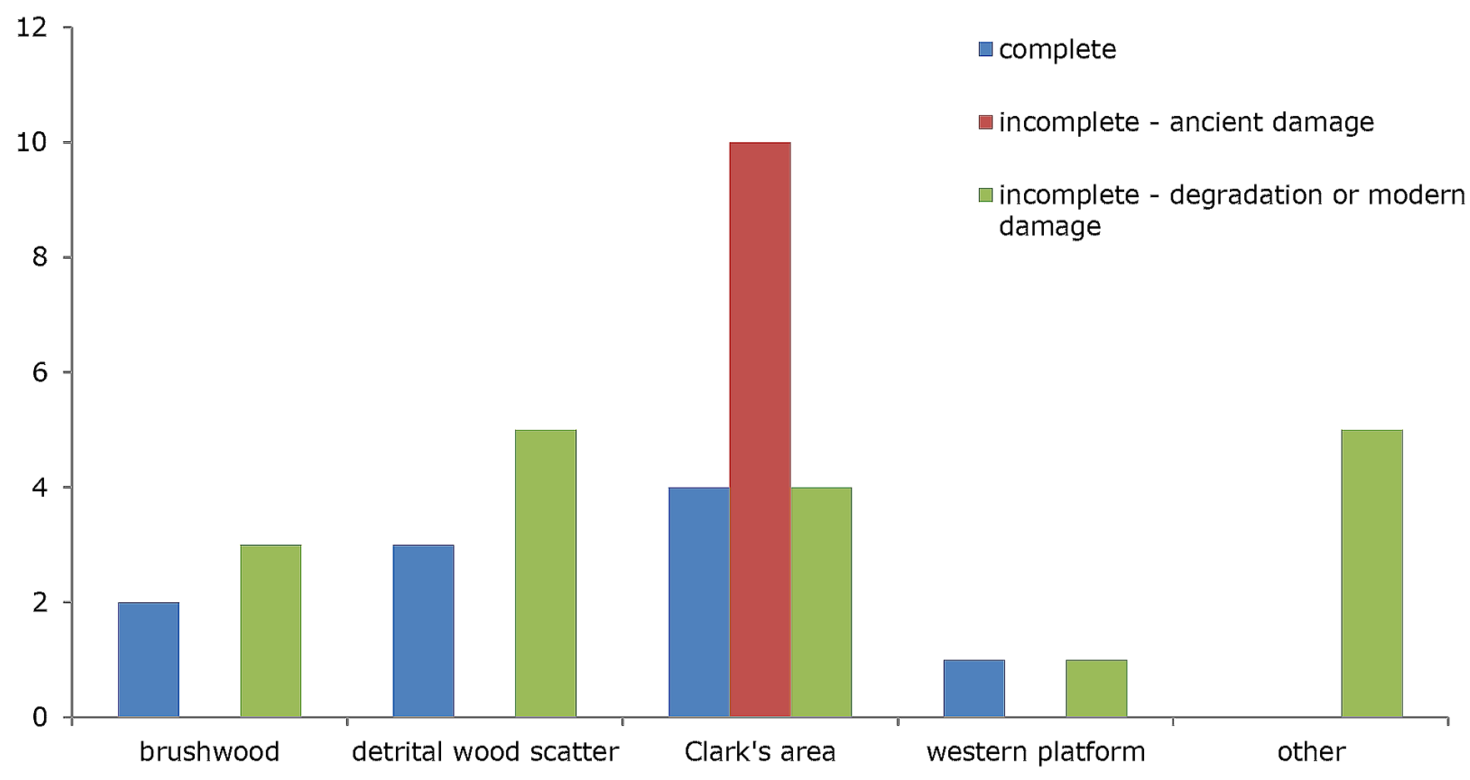

Figure 29.35: Damage to artefacts by area (Copyright Star Carr Project, CC BY-NC 4.0). 


\section{European wooden artefacts}

\section{Introduction}

The Shigir Idol is the most outstanding Mesolithic wooden artefact, found under $4 \mathrm{~m}$ of peat in 1894 at Shigir (in the Urals, Russian Federation). It is a tall figurine which currently stands at $2.8 \mathrm{~m}$ high, though it may have been even taller as it was found in pieces (Figure 29.36). The piece was constructed from a single piece of larch (Larix sp.) which was 159 years old and dates to the 8th millennium cal BC. In total, seven faces as well as numerous symbols, straight and wavy lines have been identified on the piece (Chairkina et al. 2001; Lillie et al. 2005; Savchenko et al. 2015).

The presence of other, numerous wooden artefacts and traces of their manufacture from Northern European Mesolithic sites, in particular Southern Scandinavia, demonstrates the importance of wood as a resource during this period (Brunning 2007). Although the majority of sites in Northern Europe are dated to the later Mesolithic (see Klooß 2015), there are several Early Mesolithic sites that have yielded spectacular assemblages such as Friesack IV in Germany. In comparison, the UK evidence is remarkably scant for the entire Mesolithic period. This is partly due to preservation but also the substantially lower number of excavations conducted on submerged and wetland sites. This section is not intended to act as a gazetteer (see Klooß 2015

for a comprehensive overview of wooden artefacts in Northern Europe); instead, we consider a number of sites which provide good examples of wooden artefacts and in particular focus on bows, digging sticks, hafts/ handles, paddles and stakes, to provide comparisons for the artefacts found at Star Carr.

Mesolithic worked wood in Britain is restricted to around a dozen sites (Brunning 2007; Taylor 2011). Of these, several Late Mesolithic sites at Goldcliff East in the Severn Estuary, dated to the 6th millennium cal BC, have more than doubled the number of UK Mesolithic wooden artefacts in recent years (Brunning 2007, 125). However, in general, the assemblages from Goldcliff East were poorly preserved; many pieces were highly fragmented, eroded and/or showed signs of decay, and several had been compressed within the burial environment. These data suggested that some of the wood in the assemblage, particularly from Site J, had been deposited by water action, perhaps along the strandline, although its location in relation to the bone and lithics indicated that it had not moved very far (Brunning 2007, 130). Overall, a total of 38 pieces of worked wood were identified (Bell 2007, 81). These included modified and/or utilised roundwood (possibly the remains of a fish structure), woodchips, probable stakes, small tools, a Y-shaped tool, a charred drum-shaped wooden object (which may represent a bead), a V-shaped tool, a pointed tool tip or pin, a pronged object and several artefacts of unknown function (Bell 2007; Brunning 2007).

Bouldnor Cliff is another Late Mesolithic site that has been excavated in the last decade. It is situated in the Solent and is a submerged site also dating to the 6th millennium cal BC (Smith et al. 2015). The wood was in a good condition although compression had occurred. Here, several pieces appear to have been artificially modified in some way and show definite signs of working; however, others were not as clear (Taylor 2011, 85). The assemblage, albeit small, comprised two pieces that had been trimmed at one end and from two directions, four pieces that retained all or part of the heel, two pieces that had both ends modified, three pieces of roundwood that had been split and modified in various ways, three pieces that had been split in half, one chip that had been removed from a piece of roundwood, one piece of roundwood that had been split and squared, and four further pieces that had also been trimmed or modified using the chop and tear technique (Taylor 2011, 86). In addition, one larger timber that was identified as oak (Quercus sp.) had been tangentially split. On this piece, charring was evident on one end and along one side, and it could have been hewn. Although this technique was used for boat building in later prehistory such as the Bronze Age, the evidence at Bouldnor Cliff is inconclusive (Taylor 2011, 89).

In Northern Europe, the situation is notably different. Excavations on submerged and wetland locations have yielded far more wooden artefacts, many of which have become well-known due to their craftsmanship and in some cases decoration; for instance the decorated paddles from the Late Mesolithic Ertebølle sites of Hjarnø (Skriver and Borup 2012) and Tybrind Vig (Andersen 2011). The range of artefacts is also greater and includes bows and arrows, digging sticks, dugout canoes, paddles and spears, to name but a few. In general the majority are dated to the Late Mesolithic Ertebølle culture, whilst only a handful of Early Mesolithic sites are represented. In addition, focus has primarily been on the artefacts themselves and not necessarily the utilised debris or roundwood. 


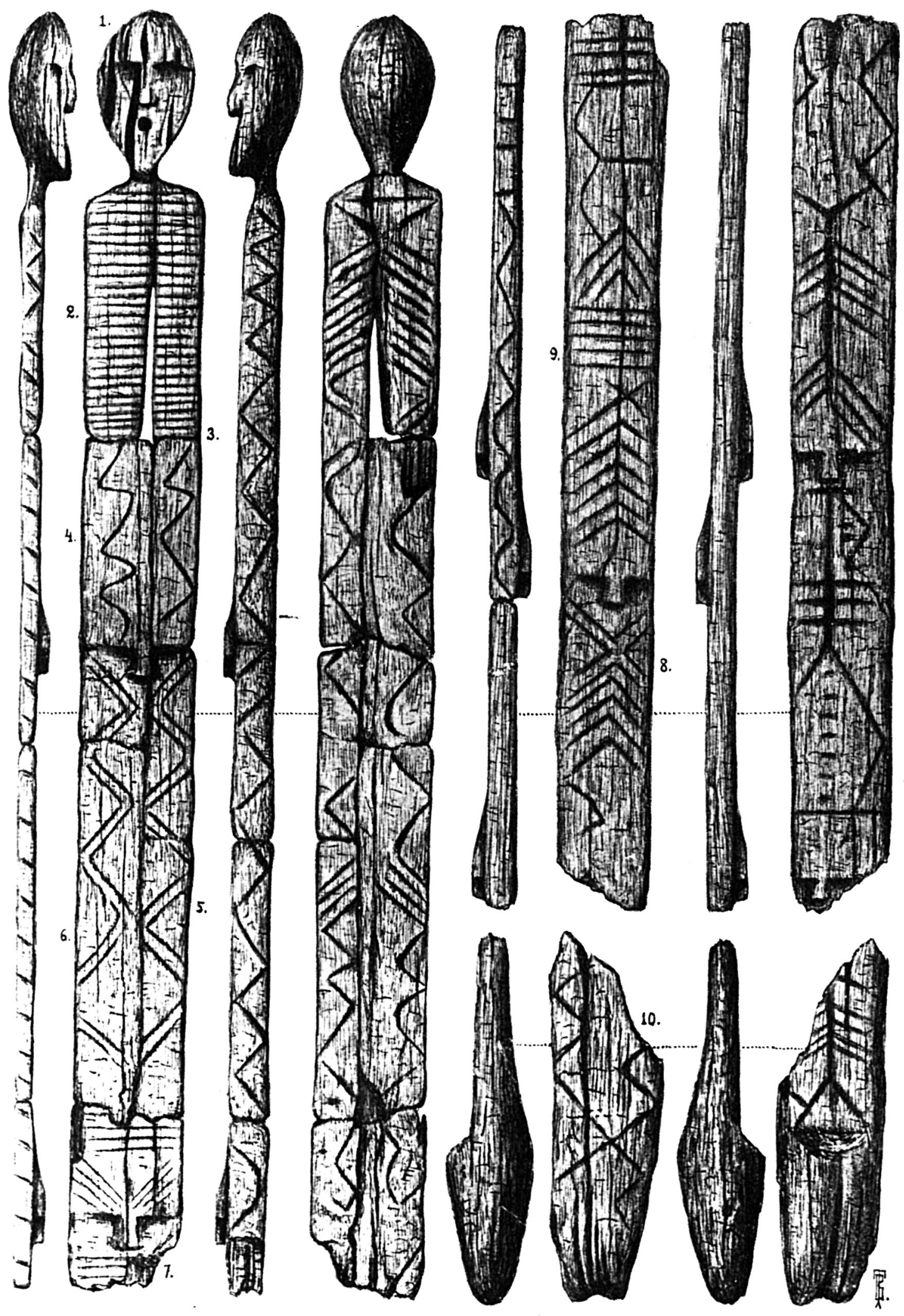

Figure 29.36: The Shigir idol (courtesy of Svetlana Savchenko and Mikhail Zhilin; original drawing by Vladimir Tolmachev: adapted from Milner et al. 2013c). 
One of the most important Early Mesolithic wooden assemblages is that from Friesack IV (see Chapter 12). Here, 134 artefacts made from bark and/or wood were recovered but again these were generally fragmented and in varying states of preservation, meaning that little can be said regarding function (Gramsch 1992, 2016; Gramsch and Kloss 1989). The wooden implements that were recovered include fragments of spears and arrows, a probable bow, blunted arrows (thought to be for bird hunting or the recovery of undamaged pelts), two possible digging sticks (one of which had a 'fire-hardened semi-circular end'), fragments of paddles, fragments of possibly more than one dugout canoe, sticks, poles, planks and slats (of unknown function) and worked fragments, two small boards with opposing notches for winding bast cord, one net float made of birch bark, as well as hafts and shafts (Gramsch and Kloss 1989, 322; Gramsch 1992, 2016). In addition, a carefully worked, pointed-end trough was found like the Australian aboriginal 'koolamon' with a handle that was made from twisted rods, thought to have been used as a basket or carrying net (Gramsch and Kloss 1989, 322).

A later Mesolithic site that has yielded important wooden artefacts is Vis I in Russia. Dated to the 6th millennium BC, a total of 39 pieces of wood with manufacturing traces were found (Burov 1989). Noteworthy artefacts include sledge runners, skis, bows, arrows, spears, throwing-sticks, hoops of landing-nets or fish traps, a wooden disk, an oar, an arched scraper, a series of stakes, a fragment of a fishing basket or mat, a net made from sedge fibres, a pine bark float and a birch bark vessel (Burov 1989). Similarly, Veretye I in Russia has produced a range of artefacts, including rectangular or round wooden boards with handles or holes; on one of these, fish scales were identified and so they may have been used for fish processing (Oshibkina 2007).

\section{Bows}

Potentially the oldest known bow from Northern Europe, c. 18,000 years old, is a fragment of pine (Pinus sp.), which was recovered from the French site of Mannheim-Vogelstang (Rosendahl et al. 2006). However, this is generally thought to be unconvincing. Two fragments of potential bows were also recovered from the German site of Stellmoor. They were made from pine and accompanied by more than 100 fragments of arrows (Bokelmann 1991; Rust 1943). Unfortunately the assemblage was destroyed by bombing during the Second World War, meaning that the only data available is derived from the original publication (Rust 1943). Whilst the arrows appear to be unequivocal in terms of form, the bows are generally considered to be unconvincing.

Prior to the discovery of the bow from Star Carr, the oldest, irrefutable example from Northern Europe were recovered from Holmegård in Denmark. In total, the remains of five bows were recovered, dated to the younger Maglemose culture (Becker 1945). At least two of the bows were constructed from elm (Ulmus sp.) and measured $1540 \mathrm{~mm}$ and $900 \mathrm{~mm}$ respectively (Becker 1945). A slightly younger example was recovered from Ulkestrup Lyng (Andresen et al. 1981). Here, one side of an elm bow had been charred prior to deposition, the pointed end is flat and there is no evidence of a notch (Andresen et al. 1981). However, an examination of the literature has demonstrated that at least one possible pine bow was recovered at Friesack IV from a middle Preboreal context (Gramsch and Kloss 1989, 322). The example was incomplete measuring c. $300 \mathrm{~mm}$ in length (Gramsch pers. comm. 2016).

From Russia, the Early Boreal site of Veretye I has produced bows with indentations for affixing the string (Oshibkina 2007). Similarly, at least six bows (potentially eight) are known from the site of Vis I. These examples were smaller when compared with numerous other Mesolithic examples and were interpreted as being used for boring antler and bone or for making fire (Burov 1989).

\section{Digging sticks}

Until the recent discoveries at Star Carr, the oldest known digging stick in Northern Europe was said to have been recovered from the Ertebølle site of Lindholm I in Nyborg Fjord, Denmark, dating to the 5th millenium cal BC (Figure 29.37) (Fischer and Pedersen 1997). The piece measures $1170 \mathrm{~mm}$ in length and $35 \mathrm{~mm}$ in diameter and is sharpened to a point (Fischer and Pedersen 1997; Troels-Smith and Fischer 1992). 


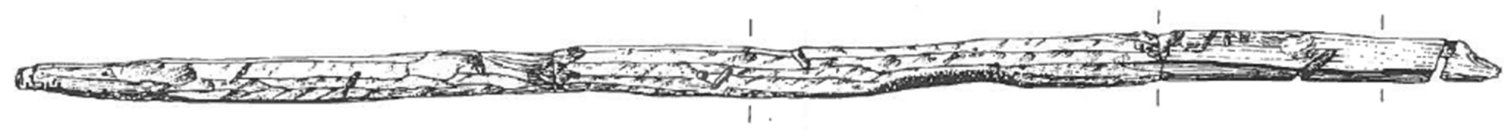

Figure 29.37: Illustration of the Lindholm I digging stick (Illustration by Eva och. Reproduced with permission of Slots- og Kulturstyrelsen).

At least two examples of digging sticks were recovered from the Early Mesolithic site at Friesack IV, Germany. Both were made of ash (Fraxinus excelsior). One measures $470 \mathrm{~mm}$ in length and has a rounded cut at one end which was subsequently charred. It was recovered from a layer which has been dated to the Early Boreal (Gramsch 1992; pers. comm. 2016).

Several Middle and Late Mesolithic sites in Southern Scandinavia have also yielded digging sticks: Smakkerup Huse (Price and Gebauer 2005), Tybrind Vig (Andersen 2013), Rüde LA 2 (Hartz pers. comm. 2015); Ringkloster (Andersen 1998); and Tågerup (Karsten and Knarrström 2003). These have been made from a variety of wood species including hazel, oak, ash and dogwood.

The only Mesolithic site in the UK that has yielded a potential digging stick is Site J at Goldcliff East in the Severn Estuary, dating to the 5th millenium cal BC (Bell 2007). Described as a 'carefully worked curved pointed stick' (Bell 2007, 81), the specimen measured $1160 \mathrm{~m}$ in length, and $45 \mathrm{~mm} \times 30 \mathrm{~mm}$ at its widest point and was interpreted as either a digging stick or a spear-like object. It is constructed from oak roundwood, one end is broken and several side branches have been removed. Cut marks are present on several sides, and it is pointed, though the stick also has a slight bend in it (Brunning 2007, 125).

\section{Hafts and handles}

Although numerous examples of hafts and handles are known from the Middle Mesolithic Kongemose and Late Mesolithic Ertebølle cultures of Southern Scandinavia (Klooß 2015), specimens dating to the Early Mesolithic are extremely rare. However, a haft with a handle made from pine was recovered from Wp 1 at Duvensee (Bokelmann 1971, 14, figure 8), and at least one socket (for an elk antler axe) made from hazel (Corylus sp.) was recovered from Hohen Viecheln (Schuldt 1961, Tables 141 and 142). In addition, at least six axe shafts and handles are known from Friesack IV (Gramsch 2016). During the Preboreal and Boreal occupational phases at the site hazel was used, whereas hazel or hornbeam (Carpinus betulus) was utilised in the Atlantic period. In all instances they were either made from trunks or branches (Gramsch 2016, 42).

\section{Paddles}

Numerous paddles dating to the Mesolithic are known in Northern Europe (Klooß 2015). At Friesack IV at least two paddles were recovered (Gramsch and Kloss 1989; Gramsch 1992). One of these was made from rowan (Sorbus aucuparia) and dates to the younger Preboreal, whereas the second specimen has not been identified to species and is dated to the early Boreal (Gramsch 1987a; 1987b; 1992; Gramsch and Kloss 1989). From the Duvensee peat bog a pine paddle was recovered (Holst 2007; Hartz and Lübke 1999; 2000; Jenke 2009; 2011; Schwantes et al. 1925). It derived from the gyttia layers next to Wp 2 and has recently been dated to the mid-8th millenium cal BC; the Boreal phase of the Early Mesolithic Maglemose culture. A paddle made from willow was also found within the later Maglemose site of Holmegård I in Denmark (Broholm 1924).

An almost complete hazel (Corylus sp.) paddle is known from Ulkestrup Lyng (Andresen et al. 1981). It had been compressed due to the overlying peat and unfortunately was damaged during excavation, but it was possible to note that the handle measures $900 \times 20.5 \times 20.5 \mathrm{~mm}$ and was virtually circular, and the blade measures $300 \times 120 \times 13 \mathrm{~mm}$ (Figure 29.37). The annual rings demonstrate that it had been constructed from a single piece of wood: it is assumed that core axes had not been used in the manufacture as they would have left traces; instead antler axes and wooden wedges are suggested (Andresen et al. 1981). 


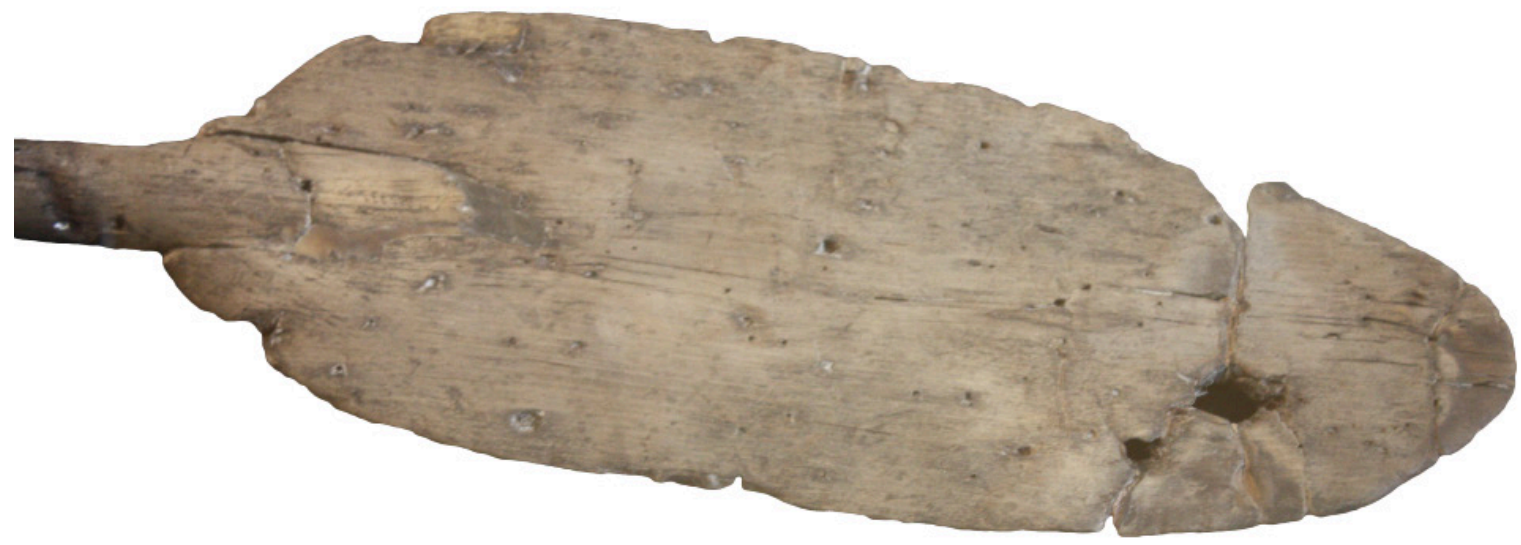

Figure 29.38: The hazel paddle blade from Hut I at Ulkestrup Lyng, Denmark (Copyright Harry Robson, CC BY-NC 4.0).

\section{Stakes}

At Ulkestrup Lyng several vertical posts relating to the two huts at the site were recovered (Andresen et al. 1981). Nearly all of these are hazel branches, about $50 \mathrm{~mm}$ thick, all of which terminate close to the wooden floor (Andresen et al. 1981, 87). As the paddle was found in the same location as some of the posts, it has been suggested that these must have been mooring posts for a boat; however, unfortunately, no boat was found (Andresen et al. 1981, 89). In addition, several stakes were identified on the Danish, Maglemosian site of Lavringe Mose. These were found either vertically or at a slight angle and have been interpreted as the remnants of a structure (Sørensen 1987, 54).

From the UK, a possible stake made from alder roundwood was identified in the wood assemblage from Site J, Goldcliff East in the Severn Estuary. The piece was $28 \mathrm{~mm}$ in diameter and both ends had been broken. It showed signs of buckling in several places, which suggested that it had been driven into a hard substrate when green (Brunning 2007). Four further stakes were also identified, although they were categorised as either probable, possible or rather doubtful (Brunning 2007). A further dubious example was recovered from under $4 \mathrm{~m}$ of peat at Lordenshaw hillfort in Northumberland (Brunning 2007).

\section{Conclusions}

There is no assertion that all the objects considered herein are 'artefacts'. However, based on their conversion, context or possible evidence for utilisation they are all potential artefacts. It is hoped that the analytical approach used within this chapter has, where possible, provided interpretations for the function of as many of the objects as feasible. It is felt that the approach of considering all items by their technological conversion before attempting to infer use has proved robust. In addition, the microwear analysis has provided data in some cases, though this technique on waterlogged wood provides a challenging workflow and the condition of the material has, in many cases, impeded the collection of microwear data. Unfortunately, organic residue analysis did not provide any conclusive results. The experimental work showed that as long as suitable raw material could be sourced, an experienced woodworker could, with a small tool kit, produce wooden artefacts similar to those excavated at the site both quickly and efficiently. Many of the artefacts are well finished and show a concern for aesthetic in addition to function.

The potential uses of the wooden artefacts very much mirror the evidence for activities being carried out at the site gleaned from other types of artefacts. The bow provides evidence for hunting and the digging sticks for gathering. The wooden wedges for splitting wood and perhaps antler and the spindle/bobbin for processing plant fibres. The possible hafts or handles may have originally hafted the flint tranchet axes, barbed points or elk antler mattocks. Within the ad-hoc tool assemblage are items that may have been used as burnishers, 
piercers or perhaps needles. The greatest frequency and diversity of wooden artefacts were recovered from Clark's area, a distribution that is mirrored by the bone and antler artefact assemblage. In contrast, the three platforms produced no wooden artefacts, with the exception of two wooden stakes from the western platform; this again mirrors the bone and antler artefact distribution, both material types being relatively scarce amongst the platforms.

No intact hafted items were encountered, despite the recovery of several dowels that are a suitable size to be hafts or handles and microwear evidence showing that both flint tools and barbed points were hafted with wood. When considering the size of the barbed point assemblage, this strongly suggests deliberate de-hafting of artefacts prior to deposition in the lake.

There is a higher prevalence of ancient breakage among the artefact assemblage, particularly amongst the dowels than recorded from the wider wood assemblage. These broken items are all clustered within Clark's area and similarly, this is an area from which barbed points that have broken in antiquity have been discovered. It is unclear whether these items have broken during use or have been deliberately broken to decommission them before being deposited in the shallow water at the edge of the lake. The 'platter' $<115316-7>$ and broken digging stick $<117165>$ both provide tantalising glimpses of possible deliberate breakage and subsequent deposition. The broken halves of the digging stick were next to each other (raising the possibility that they may in fact have been broken by trampling) whilst the two pieces of the platter were recovered several metres apart. The close association of the two complete, unbroken artefacts, bow $<113300>$ and digging stick <92465> (Figure 29.12), also hint at structured deposition, representing a hunting tool and a gathering tool, lying tip to tip with one another. 